\author{
UNIVERSIDADE DE SÃO PAULO \\ INSTITUTO DE QUÍMICA DE SÃO CARLOS
}

Adriel Martins Lima

\title{
ENCAPSULAÇÃO DE FOTOSSENSIBILIZADORES EM NANOPARTÍCULAS LIPÍDICAS SÓLIDAS PARA MAXIMIZAÇÃO DA EFICIÊNCIA FOTODINÂMICA E FOTOTOXICIDADE
}




\section{UNIVERSIDADE DE SÃO PAULO \\ INSTITUTO DE QUÍMICA DE SÃO CARLOS}

Adriel Martins Lima

\section{Encapsulação de fotossensibilizadores em nanopartículas lipídicas sólidas para maximização da eficiência fotodinâmica e fototoxicidade}

Dissertação apresentada ao Instituto de Química de São Carlos, da Universidade de São Paulo para obtenção do título de Mestre em Química Analítica e Inorgânica

\section{Exemplar revisado}

O exemplar original encontra-se em acervo reservado na Biblioteca do IQSC-USP

Orientadora: Profa. Dra. Janice Rodrigues Perussi

São Carlos

2013 


\section{AGRADECIMENTOS}

Gostaria de agradecer primeiramente a Deus acima de tudo, pois sem ele não somos nada.

Aos meus pais Zenair e Euripedessem eles eu não seria ninguém, se hoje estou aqui é graças a eles que sempre me deram muito amor, carinho e ótimos conselhos.

Ao meu irmão Carlos pelas varias brigas e desentendimentos na infância, que só serviram para fortalecer mais esses laços fraternais que une a gente.

À minha namorada Leruama que sempre ficou ao meu lado me "aguentando" nos momentos difíceis (e sinceramente eu sou muito chato quando estou estressado), por todo amor e carinho que sempre me deu, pela paciência que teve comigo muitas vezes e por todo o apoio que me deu até hoje. Obrigadomeu Amor.

À profa. Dra. Janice Rodrigues Perussi pela paciência que teve comigo durante o período de desenvolvimento deste trabalho, pelos vários conselhos dados tanto na área acadêmica como na vida pessoal, tenho certeza que cresci muito sob sua orientação.

Aos professores da banca avaliadora(Dr. Andrei Leitão e Dra. Tania Beatriz Creczynski Pasa)que se dispuseram a vir contribuir para melhoria deste trabalho.

À profa. Dra. Tania Beatriz Creczynski Pasa e a Ms. Carine Dal Pizzolpela total ajuda no preparo do sistema das nanopartículas lipídicas sólidas e pela disposição com que me receberam em seu laboratório na UFSC.

Ao prof. Dr. Hidetake Imasato pelas dicas que me forneceu e pela ajuda na parte instrumental da pesquisa.

Não poderia me esquecer de agradecer aos meus amigos de "cervejada", pois esses momentos com toda certeza me ajudaram a vencer os momentos difíceis que passei. 
A todos os meus companheiros de laboratório Lucas, Milene, Yara, Wanessa entre outros que passaram pelo laboratório, pela ajuda e pelo tempo que passamos juntos nesses dois anos.

À "Dona Joyce" por todas as conversas que tivemos, algumas cientificas mais a maioria só besteira mesmo, porém que sempre me ajudou muito a superar todos os obstáculos.

À "Dona Cráudia" uma grande amiga que fiz, que me ensinou muito dentro do laboratório e tantas risadas que demos juntos das besteiras ditas dentro e fora do laboratório.

Não posso esquecer de agradecer a "Titia Tania Tominaga" que me ajudou muito quando comecei, me ensinado e tendo muita paciência pra isso.

À todos os meus amigos do IQSC (que não são poucos) pelos momentos alegres que me proporcionaram nos corredores, na hora do café e em diversos outros lugares.

À FAPESP pela auxilio financeiro concedido ao laboratório para a execução deste trabalho.Ao CNPq pela concessão da bolsa de estudos.

Àtodos os professores e funcionários do Instituto de Química de São Carlos que contribuíram para minha formação.

Atodos da secretária da Pós-Graduação em especial à Silvia, Andréia e Gustavo que sempre estiveram dispostos a ajudar e me "aguentaram" por esse tempo.

Enfim, a todos que de alguma forma contribuíram para a realização deste trabalho. 
Aos meus queridos pais Zenair e Euripedes que são minha fonte de inspiração, são meu porto seguro, um só muito obrigado seria pouco por tudo que vocês fizeram e fazem por mim, por isso vou passar a vida toda agradecendo. 


\section{RESUMO}

A Terapia Fotodinâmica (TFD) é uma técnica para tratamento de câncer que usa um fotossensibilizador (FS) na presença de luz e oxigênio molecular gerando espécies altamente reativas de oxigênio que levam as células tumorais à morte. Porém a hidrofobicidade de alguns FSs podem induzir a agregação em sistemas biológicos, com redução da sua atividade fotodinâmica. A incorporação de FSs em sistemas nanocarreadores pode ser uma alternativa para superar este problema. $\mathrm{O}$ objetivo deste trabalho foi preparar e caracterizar dois FSs hidrofóbicos (Hipericina e Tetra-carboxiftalocianinade zinco) encapsulados em nanopartículas lipídicas sólidas (NLS) para um potencial uso em terapia fotodinâmica. Os FSs incorporados em nanopartículas lipídicas sólidas foram preparados utilizando a técnica de ultrasonicação e a caracterização físico-química foi realizada. O tamanho médio das nanopartículas de hipericina e tetra-carboxiftalocianinade zinco foram de 153 e 245 $\mathrm{nm}$ respectivamente, índice de polidispersão de 0,28 para Hy-NLS e 0,29 para FtZnT-NLS. Uma das vantagens dos sistemas de encapsulação utilizando NLS é o alto valor de eficiência de encapsulação (EE\%) e neste estudo foram obtidos valores de eficiência de encapsulação superior a $80 \%$ para a Hy-NLS e FtZnT-NLS. De modo a obter a eficiência fotodinâmica da Hy e FtZnT antes e depois do encapsulamento em NLS, as constantes de velocidade de foto-decomposição utilizando dois agentes captadores de ${ }^{1} \mathrm{O}_{2}$ (1,3 Difenilisobenzofurano e ácido úrico) foram determinadas. As constantes de velocidade de foto-decomposição tiveram aumento significativo após o encapsulamento que ocorreu provavelmente devido a um aumento no tempo de vida do estado triplete causado pelo aumento da solubilidade. Hy-NLS e FtZnT-NLS apresentaram um aumento acima de 30\% e 60\% respectivamente na acumulação intracelular e uma melhoria na fototoxicidade correlacionado com o aumento da acumulação intracelular. Todas essas vantagens sugerem que hipericina e a tetra-carboxiftalocianinade zincoencapsuladas em nanopartículas lipídicas sólidas tem potencial para serem utilizadas em terapia fotodinâmica.

Palavras-chave: Nanopartículas biocompatíveis, nanopartículas lipídicas sólidas, terapia fotodinâmica, fotossensibilizadores, nanocarregadores, hipericina, tetracarboxiftalocianinade zinco, células tumorais. 


\begin{abstract}
Photodynamic therapy (PDT) is a technique for treating cancer using a photosensitizer (PS) in the presence of light and molecular oxygen generating highly reactive oxygen species that lead to tumor cell death. The hydrophobicity of some photosensitizers can induce aggregation in biological systems, reducing its photodynamic activity. The incorporation of PSs in nanocarriers can be an alternative to overcome this problem. The aim of this work was to prepare and characterize two hydrophobic photosensitizers (Hypericin and Zinc tetra-carboxylicphthalocyanine) encapsulated in solid lipid nanoparticles (SLN) for potential use in photodynamic therapy. The PSs incorporated into solid lipid nanoparticles were prepared using the ultrasonication technique, and physico-chemical characterization was performed. The average size of the nanoparticles with hypericin and zinc tetracarboxylicphthalocyanine was 153 and $245 \mathrm{~nm}$ respectively, the polydispersivity index of 0.28 to Hy-SLN and 0.29 to FtZnT-SLN. One of the advantages of encapsulation systems using SLN is the high value of encapsulation efficiency (EE $\%)$. In this study were obtained values of encapsulation efficiency greater than $80 \%$ for the Hy-SLN and FtZnT-SLN. In order to obtain the photodynamic efficiency of Hy and FtZnT before and after encapsulation in SLN, rate constants using photodecomposition of two scavengers of ${ }^{1} \mathrm{O}_{2}$ agents (1,3-Diphenylisobenzofuran and uric acid) were determined. The rate constants of photo-decomposition had significant increase after encapsulation which occurred probably due to an increase in the lifetime of the triplet state caused by the increased solubility. Hy-SLN and FtZnT-SLN showed an increase above $30 \%$ and $60 \%$ respectively in the intracellular accumulation and an improvement in phototoxicity correlated with increased intracellular accumulation. So, all these advantages suggest that hypericin and zinc tetra-carboxylicphthalocyanine encapsulated in solid lipid nanoparticles have potential to be used in photodynamic therapy.
\end{abstract}

Keywords: Biocompatible nanoparticles, solid lipid nanoparticles, photodynamic therapy, photosensitizers, nanocarrier, hypericin, zinc tetra-carboxylicphthalocyanine, cancer cells. 


\section{ÍNDICE DE FIGURAS}

Figura 1: Diagrama de Jablonski - ilustração gráfica dos mecanismos fotoquímicos e fotofísicos em TFD (adaptado de Lakowicz, 1999).

Figura 2: Mecanismos de ação da TFD nos tumores adaptado de (Castano, Mroz et al., 2006)

Figura 3: Classificação dos fotossensibilizadores adaptado de (O'connor, Gallagher et al., 2009) 25

Figura 4: a) Estrutura da Hipericina e b) espectro de absorção ótica da Hipericina em etanol.

Figura 5: Estrutura molecular da ftalocianina de zinco (II) (FtZn) 36

Figura 6: a) Estrutura molecular e b) espectro de absorção molecular da tetracarboxiftalocianina de zinco em DMSO

Figura 7: Fontes de luz utilizadas: a) LED com emissão em $630 \pm 10 \mathrm{~nm}$ e b) LED com emissão em $590 \pm 10 \mathrm{~nm}$.

Figura 8: Microscopia eletrônica de transmissão das nanopartículas (barras $=0,2$ $\mu \mathrm{m})$. a) NLS e b) Hy-NLS.

Figura 9: Espectro de absorção de $5,0 \mu \mathrm{g} \mathrm{mL}^{-1}$ de a) Hy e b) Hy-NLS em tampão fosfato $\mathrm{pH} 7,0$.

Figura 10: Espectro de absorção de 4,0 $\mu \mathrm{g} \mathrm{mL}^{-1}$ de a) Hy e b) Hy-NLS em etanol antes e depois da irradiação com LED $590 \pm 10 \mathrm{~nm}, \mathrm{I}=10 \mathrm{~mW} \mathrm{~cm} \mathrm{cor}^{-2}$ por vários intervalos de tempos de irradiação $(0,5,10,15,20,25,30,35$ e 40 minutos). .51

Figura 11: Porcentagem de Hy e Hy-NLS remanescentes após a irradiação com LED $590 \pm 10 \mathrm{~nm}, \mathrm{I}=10 \mathrm{~mW} \mathrm{~cm}{ }^{-2}$ por vários intervalos de tempos de irradiação $(0$, $10,20,30$ and 40 minutes) em solução $0,1 \%$ de etanol

Figura 12: Intensidade de fluorescência da Hy em função de sua concentração em tampão fosfato $\mathrm{pH} 7,0+0,001 \%$ de Tween 20 em várias concentrações $(\mathrm{a} 1$ e b1 $=$ $5,0 \times 10^{-7} \mathrm{~mol} \mathrm{~L}^{-1}$; a2 e b2=7,5 $\times 10^{-7} \mathrm{~mol} \mathrm{~L}^{-1}$; a3 e b3 $=1,0 \times 10^{-6} \mathrm{~mol} \mathrm{~L}^{-1}$ ) de a) Hy e b) Hy-NLS. 53

Figura 13: Reação do DPBF com oxigênio singlete levando a formação do endoperóxido (Matheson, 1979; Spiller, Kliesch et al., 1998). 
Figura 14: Espectro de absorção de $1,85 \times 10^{-4} \mathrm{~mol} \mathrm{~L}^{-1}$ de DPBF em tampão fosfato $\mathrm{pH} 7,0+0,001 \%$ Tween 20 .

Figura 15: Espectros de absorção de $1,85 \times 10^{-4} \mathrm{~mol} \mathrm{L-1}$ de DPBF na presença de

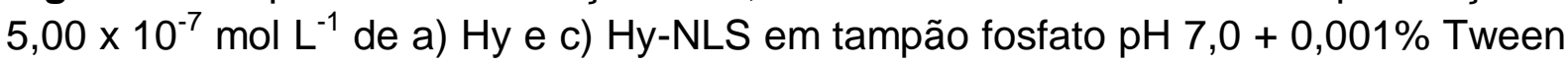
20. Constantes de velocidade de decomposição do DPBF para b) Hy e d) Hy-NLS.55

Figura 16: Espectros de absorção de $1,85 \times 10^{-4} \mathrm{~mol} \mathrm{~L}^{-1}$ de DPBF na presença de

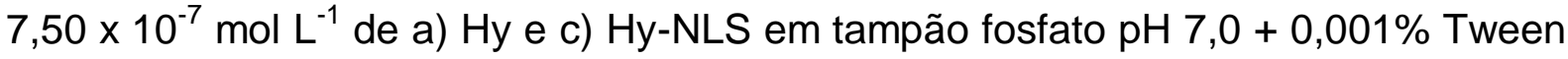
20. Constantes de velocidade de decomposição do DPBF para b) Hy e d) Hy-NLS.56

Figura 17: Espectros de absorção de $1,85 \times 10^{-4} \mathrm{~mol} \mathrm{~L}^{-1}$ de DPBF na presença de $1,00 \times 10^{-6} \mathrm{~mol} \mathrm{~L}^{-1}$ de a) Hy e c) Hy-NLS em tampão fosfato $\mathrm{pH} 7,0+0,001 \%$ Tween 20. Constantes de velocidade de decomposição do DPBF para b) Hy e d) Hy-NLS.57

Figura 18: Espectro de absorção de $6,00 \times 10^{-5} \mathrm{~mol} \mathrm{~L}^{-1}$ de $\mathrm{AU}$ em tampão fosfato pH 7,0 + 0,001\% Tween 20

Figura 19: Espectros de absorção de $6,00 \times 10^{-5} \mathrm{~mol} \mathrm{~L}^{-1}$ de AU na presença de 5,00 $\times 10^{-7} \mathrm{~mol} \mathrm{~L}^{-1}$ de a) Hy e c) Hy-NLS em tampão fosfato $\mathrm{pH} \mathrm{7,0+0,001 \%} \mathrm{Tween} 20$. Constantes de velocidade de decomposição do AU para b) Hy e d) Hy-NLS.

Figura 20: Espectros de absorção de $6,00 \times 10^{-5} \mathrm{~mol} \mathrm{~L}^{-1}$ de AU na presença de 7,50 $\times 10^{-7} \mathrm{~mol} \mathrm{~L}^{-1}$ de a) Hy e c) Hy-NLS em tampão fosfato $\mathrm{pH} 7,0+0,001 \%$ Tween 20 . Constantes de velocidade de decomposição do AU para b) Hy e d) Hy-NLS.

Figura 21: Espectros de absorção de $6,00 \times 10^{-5} \mathrm{~mol} \mathrm{~L}^{-1}$ de AU na presença de 1,00 $\times 10^{-6} \mathrm{~mol} \mathrm{~L}^{-1}$ de a) Hy e c) Hy-NLS em tampão fosfato $\mathrm{pH} \mathrm{7,0}+0,001 \%$ Tween 20 depois. Constantes de velocidade de decomposição do AU para b) Hy e d) Hy-NLS.

Figura 22: Curva padrão da absorbância em $750 \mathrm{~nm}$ em função da concentração de BSA ( $\mathrm{mg} \mathrm{mL}^{-1}$ ). As médias de absorbância foram obtidas de dois ensaios realizados em triplicata.

Figura 23: a) Espectro de emissão variando a concentração da Hy em etanol com excitação em $545 \mathrm{~nm}$ e emissão em 560 - $800 \mathrm{~nm}$. b) Curva analítica para a Hy obtida a partir das intensidades de fluorescência em $597 \mathrm{~nm}(\mathrm{n}=3)$.

Figura 24: Acumulação intracelular de Hy e Hy-NLS nos tempos de incubação de 30 minutos, 1 hora e 2 horas nas células a) HEp-2 e b) B16-F10. Os valores são as médias \pm desvio padrão $(n=3)$. ${ }^{*}$ As diferenças foram significativas $(p<0,05)$. .64 
Figura 25: $O$ efeito da dose de luz sobre a viabilidade de célula HEp-2 e B16-F10. Os valores são as médias \pm desvio padrão $(n=18)$ o resultado não foi significativamente diferente (teste t de Student, $p>0,05$ ).

Figura 26: Viabilidade celular após 2 horas de incubação com diferentes concentrações de Hy, Hy-NLS e NLS no escuro para a) HEp-2 e b) B16-F10. Os valores são as médias \pm desvio padrão $(n=18)$ a resultado não foi significativamente diferente (teste t de Student, $p>0,05$ ).

Figura 27: $O$ efeito fototóxicos de diferentes concentrações de Hy, Hy-NLS e NLS sobre duas linhagens celulares sob irradiação com LED $590 \pm 10 \mathrm{~nm}$, intensidade de luz de $10 \mathrm{~mW} \mathrm{~cm}^{-2}$ e tempo de incubação de 2 horas. a) e c) para as células HEp-2 nas doses de luz de 6 e $12 \mathrm{~J} \mathrm{~cm}^{-2}$ e b) e d) para as células B16-F10 nas doses de luz de 6 e $12 \mathrm{~J} \mathrm{~cm}^{-2}$. Os valores são as médias \pm desvio padrão $(\mathrm{n}=18)$, * resultados significativamente diferentes (teste $t$ de Student, $p<0,05$ ).

Figura 28: Espectros de absorção de $3,70 \times 10^{-5} \mathrm{~mol} \mathrm{~L}^{-1}$ de DPBF na presença de 2,65 $\times 10^{-7} \mathrm{~mol} \mathrm{~L}^{-1}$ de a) FtZnT e c) FtZnT-NLS em tampão fosfato $\mathrm{pH}$ 7,0 depois de diferentes tempos de irradiação com LED vermelho $630 \pm 10 \mathrm{~nm}$. Constantes de velocidade de decomposição do DPBF para b) FtZnT e d) FtZnT-NLS. 73

Figura 29: Espectros de absorção de $5,95 \times 10^{-5} \mathrm{~mol} \mathrm{~L}^{-1}$ de AU na presença de 6,65 $X 10^{-7} \mathrm{~mol} \mathrm{~L}^{-1}$ de a) FtZnT e c) FtZnT-NLS em tampão fosfato $\mathrm{pH} 7,0$ depois de diferentes tempos de irradiação com LED vermelho $630 \pm 10 \mathrm{~nm}$. Constantes de velocidade de decomposição do AU para b) FtZnT e d) FtZnT-NLS. .75

Figura 30: a) Espectro de emissão variando a concentração da FtZnT em DMSO com excitação em $620 \mathrm{~nm}$ e emissão em 630 - $800 \mathrm{~nm}$. b) Curva analítica para a FtZnT obtida a partir das intensidades de fluorescência em $697 \mathrm{~nm}$. Experimentos foram realizados em triplicata $(n=3)$. .77

Figura 31: Acumulação intracelular de FtZnT e FtZnT-NLS nos tempos de incubação de 12, 18 e 24 horas nas células a) HEp-2 e b) B16-F10. Os valores são as médias \pm desvio padrão $(n=3)$. As diferenças são consideradas estatisticamente significantes quando * $\mathrm{p}<0,05$ (teste $t$ de Student) ...........................................77

Figura 32: $O$ efeito da dose de luz sobre a viabilidade celular HEp-2 e B16-F10. Os valores são as médias \pm desvio padrão $(n=18)$ a resultado não foi significativamente diferente (teste t de Student, $p>0,05) \ldots \ldots \ldots \ldots \ldots \ldots \ldots \ldots \ldots \ldots \ldots \ldots \ldots . . . . .79$

Figura 33: Viabilidade celular após 18 horas de incubação com diferentes concentrações de FtZnT, FtZnT-NLS e NLS no escuro para HEp-2 $(a, b)$ e para B16-F10 (c, d). Os valores são as médias \pm desvio padrão $(n=18)$ o resultado não foi significativamente diferente (teste t de Student, $p>0,05$ ). 
Figura 34: $O$ efeito fototóxico nas células HEp-2 de diferentes concentrações de FtZnT e FtZnT-NLS, 18 horas de incubação e utilizando três doses de luz diferentes sob irradiação com LED $630 \pm 10 \mathrm{~nm}$ com. Para a FtZnT e doses de luz de a) 50, c) 100 , e) $150 \mathrm{~J} \mathrm{~cm}^{-2}$ e para FtZnT-NLS b) 50 , d) 100 , f) $150 \mathrm{~J} \mathrm{~cm}^{-2}$. Os valores são as médias \pm desvio padrão $(n=18)$ a resultado foi significativamente diferente (teste $t$ de Student, $p<0,05)$.

Figura 35: $O$ efeito fototóxico nas células B16-F10 de diferentes concentrações de FtZnT e FtZnT-NLS, 18 horas de incubação e utilizando três doses de luz diferentes sob irradiação com LED $630 \pm 10 \mathrm{~nm}$ com. Para a FtZnT e doses de luz de a) 50, c) 100 , e) $150 \mathrm{~J} \mathrm{~cm}^{-2}$ e para FtZnT-NLS b) 50 , d) 100 , f) $150 \mathrm{~J} \mathrm{~cm}^{-2}$. Os valores são as médias \pm desvio padrão $(n=18)$ a resultado foi significativamente diferente (teste $t$ de Student, $p<0,05$ ). .83 


\section{ÍNDICE DE TABELAS}

Tabela 1: Características dos NLS: tamanho médio, índice Polidispersão (IP), potencial Zeta (PZ) e Eficiência de Encapsulação das Hy-NLS (média \pm desvio padrão, $n=3$ ).

Tabela 2: Constantes de velocidade de decomposição do DPBF para a $\mathrm{Hy}$ e $\mathrm{Hy}$ NLS variando a concentração de FS. Os valores são as médias \pm desvio padrão ( $n=$ 3 ), os valores referentes à Hy-NLS foram significativamente maior do que a Hy livre $(p<0,05)$.

Tabela 3: Constantes de velocidade de decomposição do ácido úrico para a Hy e Hy-NLS variando a concentração de FS. Os valores são as médias \pm desvio padrão $(n=3)$, os valores referentes à Hy-NLS foram significativamente maior do que a $\mathrm{Hy}$ livre $(p<0,05)$.

Tabela 4: Acumulação intracelular de Hy e Hy-NLS nos tempos de incubação de 0,5 horas, 1,0 horas e 2,0 horas nas células HEp-2 e B16-F10. Os valores são as médias \pm desvio padrão $(n=3)$. As diferenças foram significativas $(p<0,05)$.

Tabela 5: A concentração média inibitória $\left(\mathrm{IC}_{50}\right)$ de Hy e Hy-NLS nas células tumorais HEp-2 e B16-F10 na presença de luz $\left(6\right.$ e $12 \mathrm{~J} \mathrm{~cm}^{-2}$ ) com LED $590 \pm 10$ $\mathrm{nm}$, intensidade de luz de $10 \mathrm{~mW} \mathrm{\textrm {cm } ^ { - 2 }}$ e tempo de incubação de 2 horas. Os valores são as médias \pm desvio padrão $(n=18)$. As diferenças são consideradas estatisticamente significantes quando $p<0,05$ (teste t de Student).

Tabela 6: Características dos NLS: tamanho médio, índice Polidispersão, potencial zeta e eficiência de encapsulação das FtZnT-NLS (média \pm desvio padrão, $n=3$ ).. 71

Tabela 7: Constantes de velocidade de fotodecomposição do DPBF para a FtZnT e FtZnT-NLS. Os valores são as médias \pm desvio padrão $(n=3)$, os valores referentes à FtZnT-NLS foram significativamente maior do que a FtZnT livre (teste t de Student, $p<0,05)$.

Tabela 8: Constantes de velocidade de decomposição do ácido úrico para a FtZnT e FtZnT-NLS. Os valores são as médias \pm desvio padrão $(n=3)$, os valores referentes à FtZnT-NLS foram significativamente maior do que a FtZnT livre (teste t de Student, $p<0,05)$. .76

Tabela 9: Acumulação intracelular de FtZnT e FtZnT-NLS nos tempos de incubação de 12 horas, 18 horas e 24 horas nas células HEp-2 e B16-F10. Os valores são as médias \pm desvio padrão $(n=3)$. As diferenças são consideradas estatisticamente significantes quando $p<0,05$ (teste $t$ de Student). 
Tabela 10: A concentração média inibitória $\left(\mathrm{IC}_{50}\right)$ de FtZnT e FtZnT-NLS das células tumorais HEp-2 e B16-F10 na presença de luz LED $630 \pm 10$ nm com três doses de luz diferente e 18 horas de incubação. Os valores são as médias \pm desvio padrão ( $\mathrm{n}$ $=18$ ). As diferenças são consideradas estatisticamente significantes quando $p<$ 0,05 (teste $t$ de Student). 


\section{LISTA DE ABREVIATURAS}

FS - Fotossensibilizador

FSs - Fotossensibilizadores

TFD - Terapia Fotodinâmica

EROs - Espécies reativas de oxigênio

$\mathrm{Hp}$ - Hematoporfirina

$\mathrm{HpD}$ - Derivado de Hematoporfirinas

NLS - Nanopartículas lipídicas sólidas

EE \% - Eficiência de encapsulação

PZ - Potencial zeta

IP - Índice de polidispersão

MET - Microscopia eletrônica de Transmissão

Hy - Hipericina

FtZn - Ftalocianina de zinco

FtZnT - Tetra-carboxiftalocianina de zinco

Hy-NLS - Hipericina incorporada em nanopartículas lipídicas sólidas

FtZnT-NLS - Tetra-carboxiftalocianina de zinco incorporada em nanopartículas lipídicas sólidas

DBPF - 1,3-Difenilisobenzofurano

LED - light-emitting diode (Diodo emissor de Luz)

AU - Ácido úrico 


\section{Sumário}

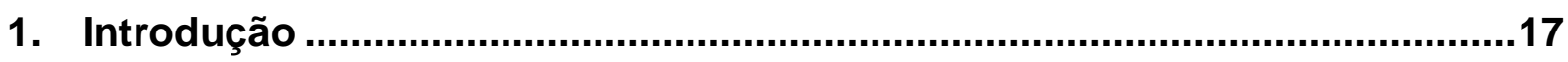

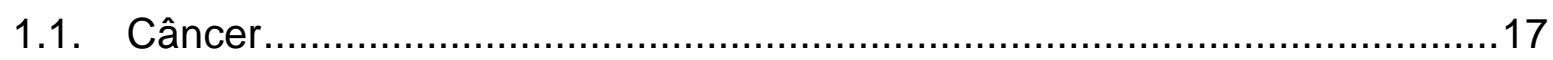

1.2. Tratamentos convencionais para o câncer ..............................................18

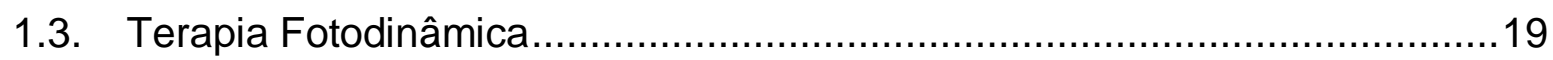

1.4. Mecanismo de reações da TFD - Processos Fotoquímicos …....................20

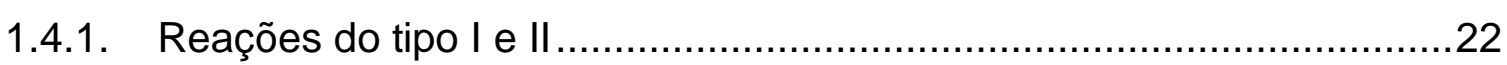

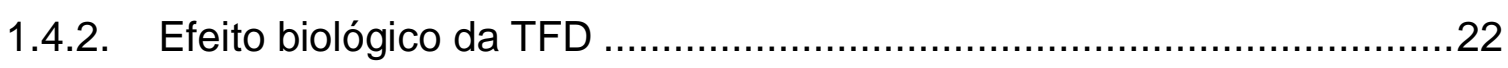

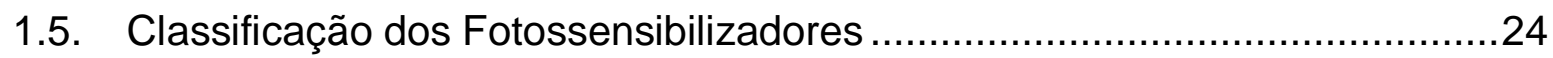

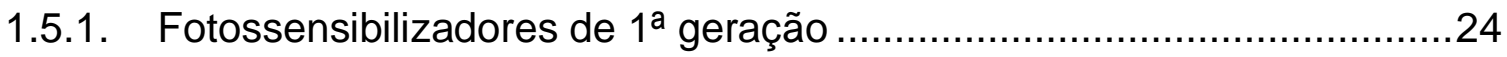

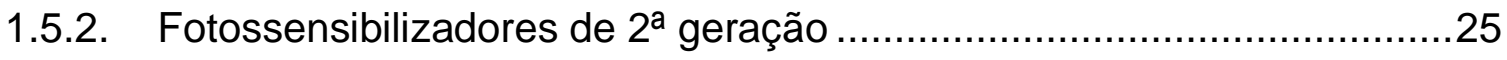

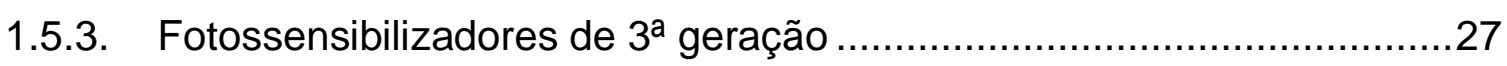

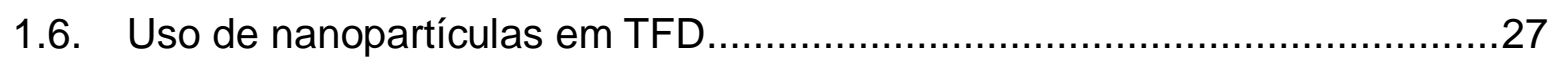

1.6.1. Tipos de Interação entre as nanopartículas e os FS ...........................28

1.7. Nanopartículas Lipídicas Sólidas (NLS) ..............................................30

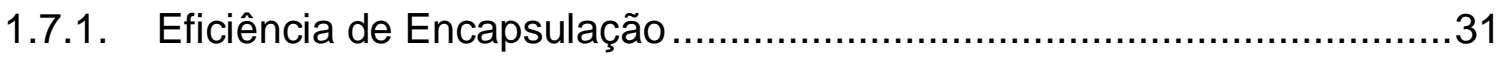

1.7.2. Tamanho da partícula e potencial zeta …...............................................32

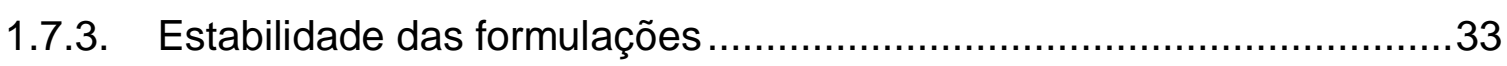

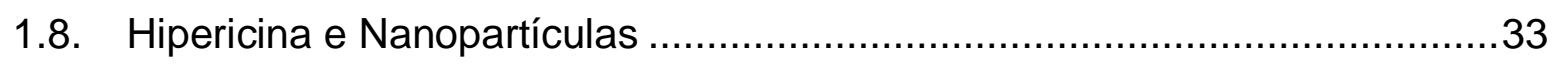

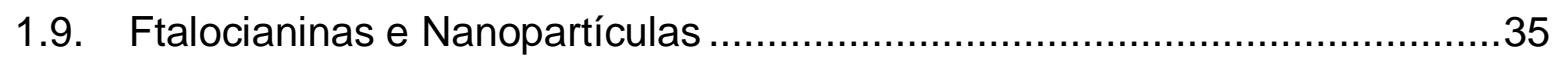

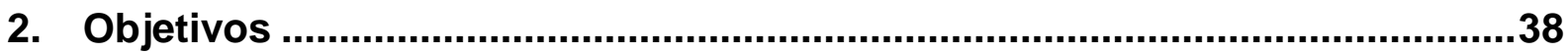

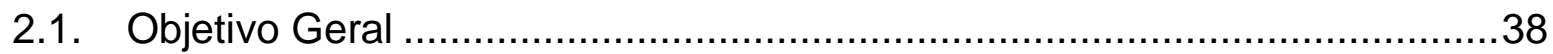

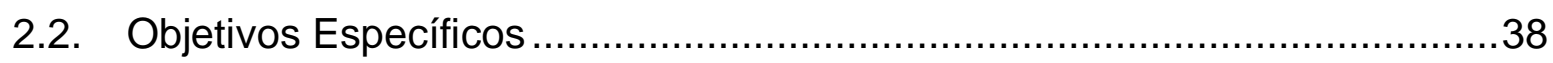

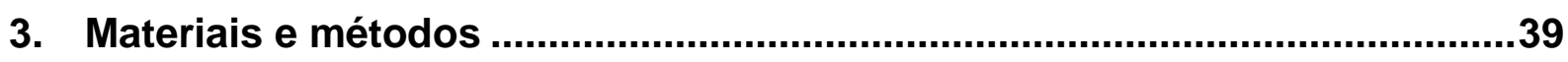

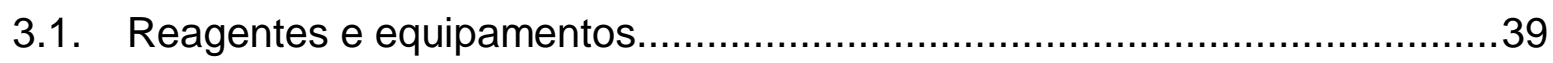

3.2. Preparo das Nanopartículas Lipídicas Sólidas (NLS) com Hy e FtZnT ........40

3.2.1. Caracterização das nanopartículas lipídicas sólidas ..............................40

3.2.2. Determinação do teor e eficiência de encapsulação da Hy e FtZnT .......41

3.3. Fotodegradação da Hy e Hy-NLS ..................................................... 41

3.4. Dependência entre fluorescência e concentração da Hy e Hy-NLS..............42

3.5. Atividade fotodinâmica da Hy e Hy-NLS ............................................... 42

3.5.1. Constante de velocidade de foto-decomposição do DPBF $\left(\mathrm{k}_{\mathrm{DPBF}}\right)$........42

3.5.2. Constante de velocidade de fotodecomposição do ácido úrico $\left(\mathrm{k}_{\mathrm{AU}}\right) \ldots . . .43$ 
3.6. Cultura celular .43

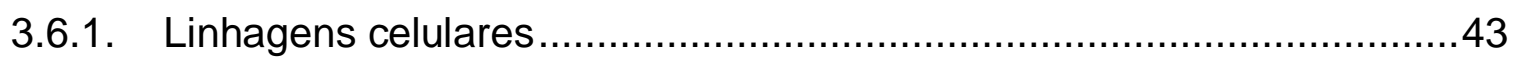

3.6.2. Congelamento e descongelamento das células .................................43

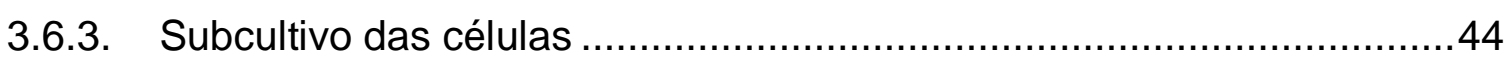

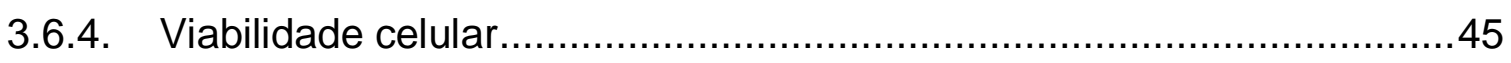

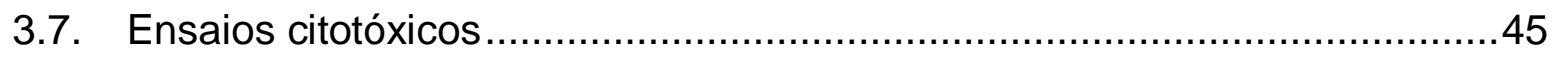

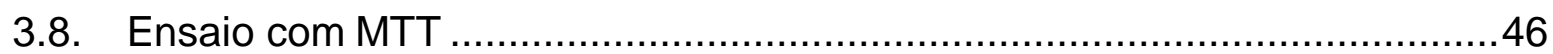

3.9. Acumulação intracelular dos FSs livres e incorporados em NLS ...............46

3.10. Cálculo da média amostral e do desvio padrão e análise estatística dos

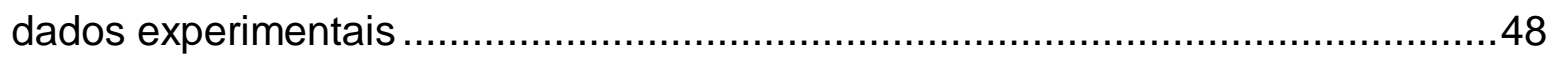

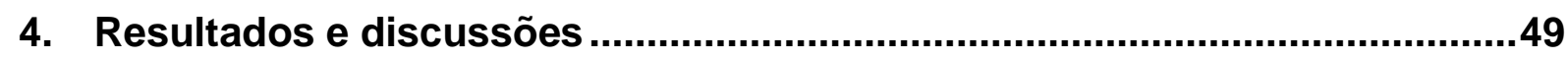

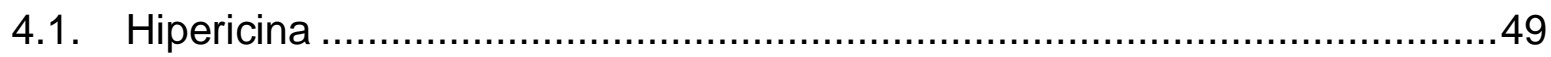

4.1.1. Preparação e caracterização das Nanopartículas lipídicas sólidas (NLS)

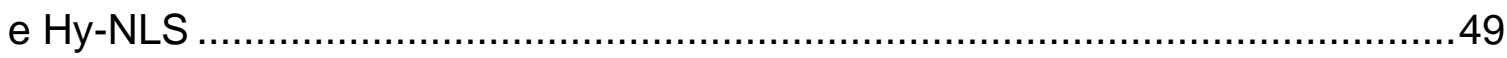

4.1.2. Fotodegradação da Hy e Hy-NLS ................................................... 51

4.1.3. Dependência entre fluorescência e concentração da Hy e Hy-NLS ......52

4.1.4. Atividade Fotodinâmica da Hy e Hy-NLS...........................................53

> Constante de velocidade de fotodecomposição do DPBF ( $\left.\mathrm{k}_{\mathrm{DPBF}}\right)$................53

> Constante de velocidade de fotodecomposição do Ácido Úrico $\left(\mathrm{k}_{\mathrm{AU}}\right)$...........58

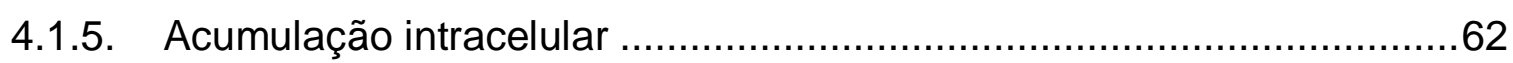

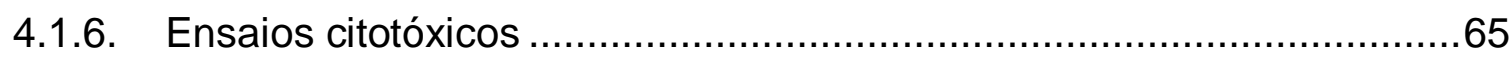

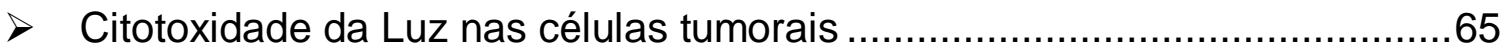

> Citotoxidade da Hy livre, NLS e Hy-NLS nas células HEp-2 e B16-F10 sem a

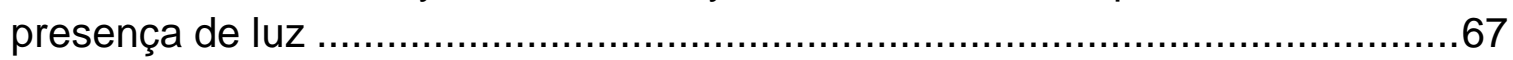

> Efeito da dose de irradiação na fototoxicidade da Hy, NLS e Hy-NLS nas

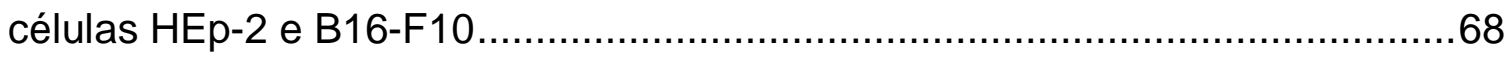

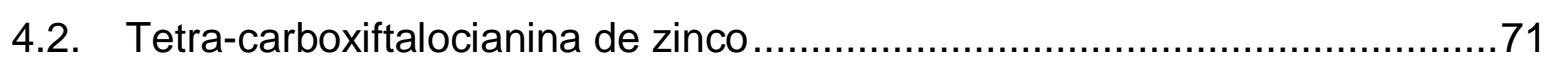

4.2.1. Preparação e caracterização das Nanopartículas lipídicas sólidas (NLS)

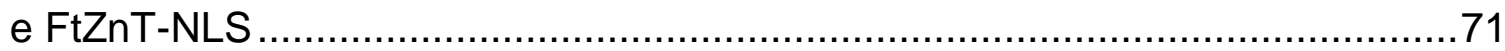

4.2.2. Atividade Fotodinâmica da FtZnT e FtZnT-NLS .................................72

> Constante de velocidade de fotodecomposição do DPBF ...........................72

> Constante de velocidade de fotodecomposição do AU .................................74

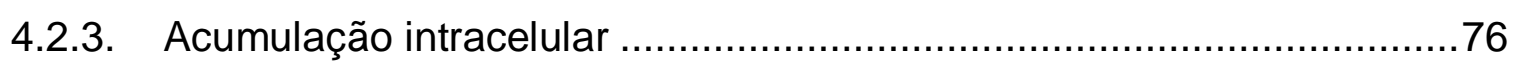

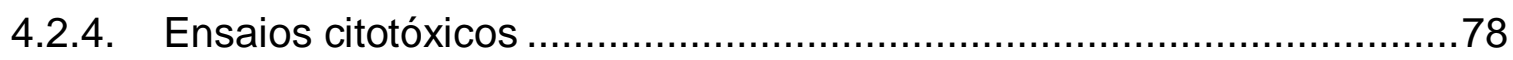

$>$ Citotoxidade da Luz nas células tumorais ................................................ 
> Citotoxidade da FtZnT livre, NLS e FtZnT-NLS nas células HEp-2 e B16-F10

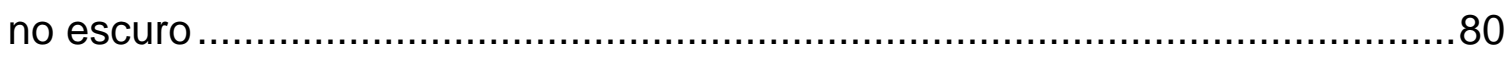

> Efeito da dose de irradiação na fototoxicidade da FtZnT, NLS e FtZnT-NLS

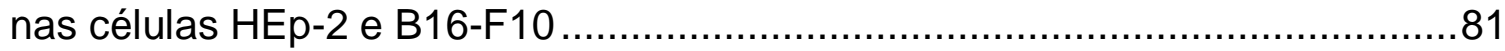

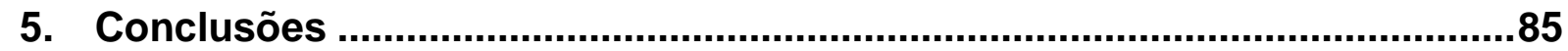

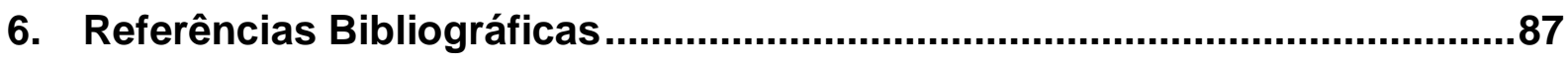




\section{Introdução}

\subsection{Câncer}

O câncer é uma das doenças que mais causam temor na sociedade por ter se tornado um estigma de mortalidade e dor. $O$ câncer é uma das principais causas de morte em todo o mundo e considerado como um grande problema de saúde pública. As maiores taxas de incidência de câncer são encontradas nos países desenvolvidos (Estados Unidos, Itália, Austrália, Alemanha, Canadá e França). Nos países em desenvolvimento, as taxas mais elevadas encontram-se nos países africanos e no leste asiático (www.inca.gov.br). Segundo a Organização Mundial de Saúde (OMS) os maiores índices de óbito ocorreram nos casos de câncer de pulmão, estômago, fígado, cólon e mama. O câncer de pulmão é o mais comum de todos os tumores malignos e permanece como uma doença altamente letal.

O câncer, também denominado neoplasia maligna e tumor maligno, é uma doença caracterizada pela multiplicação e propagação descontroladas de formas anormais das próprias células corporais (Rang et al., 2004). Metástase é o nome dado quando uma ou mais células tumorais deixam seu local de origem, atravessam as barreiras teciduais, vasos sanguíneos e linfáticos, atingindo a corrente circulatória e se desenvolvem em outro lugar onde continuam a se proliferar. Dividindo-se rapidamente, estas células tendem a ser muito agressivas e incontroláveis, determinando a formação de tumores (acúmulo de células cancerosas) ou neoplasias malignas (Vermeulen, Van Bockstaele et al., 2003). Por outro lado, um tumor benigno significa simplesmente uma massa localizada de células que se multiplica vagarosamente e se assemelha ao seu tecido original, raramente constituindo risco de vida. Existem muitas causas para o câncer, podendo ser classificadas em externas e internas ao organismo, estando ambas relacionadas entre si. As causas externas podem ser encontradas no meio ambiente e corresponde a maioria dos casos (cerca de 80\%). Entende-se por ambiente, o meio em geral (água, terra e ar), o ambiente ocupacional (quando insalubre), o ambiente social e cultural (estilo e hábitos de vida) e o ambiente de consumo (alimentos, medicamentos). As mudanças provocadas no meio ambiente pelo próprio homem, os hábitos e estilos de vida adotados pelas pessoas podem determinar os diferentes tipos de câncer. As causas internas estão relacionadas em sua totalidade à capacidade do organismo de se defender das agressões externas (Franco, 1994). 


\subsection{Tratamentos convencionais para o câncer}

O tratamento clássico do câncer envolve diversas terapias como a quimioterapia, radioterapia e procedimentos cirúrgicos. Os objetivos da quimioterapia e da radioterapia são impedir a proliferação celular e promover a destruição das células tumorais, que são mais susceptíveis à morte por possuírem uma maior velocidade de crescimento do que as células sadias (Brown, Brown et al., 1999). A cirurgia, por sua vez, é utilizada para a retirada mecânica de tecidos neoplásicos localizados. A quimioterapia, como o próprio nome já diz, baseia-se na utilização de compostos químicos, tais como agentes alquilantes e antimetabólicos. Os agentes alquilantes são compostos orgânicos reativos que transferem grupos alquila às bases nitrogenadas do ácido desoxirribonucléico (DNA) por terem estrutura molecular semelhante aos compostos utilizados na síntese desta molécula. Os fármacos quimioterápicos apresentam uma série de efeitos colaterais indesejáveis, em geral, estes fármacos afetam o crescimento celular, especialmente das células que se multiplicam rapidamente, como as células tumorais. Entretanto existem células normais que também têm multiplicação rápida, como as células de defesa do sangue, que combatem infecções, as células que recobrem o aparelho digestivo e as células dos folículos pilosos. Em consequência disso os pacientes apresentam sérias reações adversas, tais como menor resistência às infecções, perda de apetite, náusea, vômito, diminuição da salivação e queda de cabelo (Brown e Truscott, 1993).

O desenvolvimento de novos tratamentos que apresentem maior seletividade para o tecido neoplásico é muito importante para a melhoria dos tratamentos para o câncer. Diante dos graves efeitos colaterais e da eficiência limitada das terapias tradicionais, alternativas estão sendo constantemente propostas. Dentre estas se destaca a Terapia Fotodinâmica (TFD), outra modalidade no tratamento de câncer(Brown, Brown et al., 1999). Outras doenças podem ser tratadas com TFD, por exemplo, degeneração macular da retina, psoríase, micoses fungóides, infestações bacterianas, verrugas, síndrome da imunodeficiência adquirida(do inglês, AIDS), uma vez que têm como característica comum um crescimento anormal de tecidos (Dougherty e Marcus, 1992). 


\subsection{Terapia Fotodinâmica}

O uso da luz como terapia na medicina teve sua origem nas antigas civilizações da Grécia, Egito e Índia, que utilizavam a luz para tratar diversas doenças, incluindo psoríase e vitiligo. A fototerapia desapareceu por muitos anos e só foi redescoberta pela civilização ocidental no início do século XX por Niels Finsen, Oscar Raab e Herman von Tappeiner (Daniell e Hill, 1991; Stables e Ash, 1995). Porém a aplicação terapêutica da Terapia Fotodinâmica (TFD), que é umapromissora modalidade de tratamento do câncer, só foi utilizada em pacientes muito tempo depois. Em 1976, pesquisadores iniciaram os primeiros estudos clínicos em pacientes com câncer de bexiga, que foram tratados com hematoporfirina, após ser descoberta a habilidade fotossensibilizante desse composto, que foi chamado de fotossensibilizador (FS), de localizar o tumor e as suas propriedades fototóxicas nas células tumorais. Esta descoberta levou ao desenvolvimento da TFD (Dolmans, Fukumura et al., 2003) que é caracterizada por um conjunto de processos físicos, químicos e biológicos que ocorre após a administração do FS, que fica retido preferivelmente nos tecidos tumorais, por causa das diferentes características entre os tecidos normais e tumorais, por exemplo, a diferença de $\mathrm{pH}$ (Schuitmaker, Bass et al., 1996). Após a retenção deste FS o local é irradiado com luz visível. Desta maneira a combinação de FS e luz na presença de oxigênio molecular geram espécies citotóxicas letais como o oxigênio singlete e outros radicais livres. Como a primeira barreira para o oxigêniosinglete é a membrana celular e esta contém lipídios insaturados que podem ser danificados, a oxidação destes lipídios acaba levando à morte celular. Os hidroperóxidos que são outros radicais livres que podem ser formados na reação entre o FS e a luz podem levar à formação de espécies reativas de oxigênio (EROs) através de reações catalíticas. Uma vez que a reatividade das EROs com moléculas orgânicas não é específica, qualquer macromolécula dentro da célula pode ser um alvo em potencial para TFD.

A TFD apresenta algumas vantagens quando comparada com as terapias convencionais utilizadas para o tratamento do câncer, como por exemplo, ser considerada uma terapia ambulatorial, diferentemente da radioterapia e da quimioterapia, que podem durar semanas ou meses e da cirurgia, que pode requerer hospitalização prolongada (Chatterjee, Fong et al., 2008; Bugaj, 2011). A TFD pode ser utilizada também com outros fins, por exemplo, para o tratamento dermatológico 
(Tyrrell, Campbell et al., 2011) e na inativação de microorganismos (Perussi, 2007). Outra vantagem da TFD é ser minimamente invasiva, o que possibilita ser usada no mesmo local varias vezes (Yano, Hirohara et al., 2011).

\subsection{Mecanismo de reações da TFD - Processos Fotoquímicos}

O mecanismo de fotossensibilização consiste na interação da luz de comprimento de onda adequado ao FS e ao oxigênio molecular, resultando em espécies reativas que induzem a morte celular. Quando o FS é irradiado com luz absorve um fóton e com isso um dos seus elétrons passa para o orbital energeticamente mais alto, mas de mesmo spin, resultando em um estado excitado singlete (Figura 1). Estados excitados singletes têm tempo de vida curto (1-100 ns). Após a excitação todos os processos que contribuem para a desativação do estado excitado competem entre si. Um elétron que é excitado a um nível vibracional superior ao estado excitado tende preferencialmente a dissipar esse excesso de energia descendo até o nível vibracional zero do estado excitado correspondente (Lakowicz, 1999).

A conversão interna é o processo em que a energia de excitação é perdida por colisão com o solvente ou por dissipação através dos modos vibracionais internos. Geralmente a conversão interna e a temperatura são diretamente proporcionais, consequentemente a fluorescência decresce com o aumento da temperatura. O cruzamento intersistema é um processo isoenergético e sua troca de spin, nominalmente proibida, o que converte um singlete excitado em um estado triplete excitado, que decai prontamente para o nível vibracional T1 (Figura 1) que se converte para o estado singlete fundamental, tanto por fosforescência (emissão de energia) quanto por conversão interna. Como a transição envolvida na fosforescência envolve mudança de multiplicidade, o tempo de vida é muito mais longo que o tempo de vida de fluorescência. Um terceiro processo não radiativo denominado supressão de fluorescência é geralmente o resultado de colisões ou da formação de complexos com solutos moleculares capazes de reduzir o tempo de vida do estado excitado ou manter o complexo no estado fundamental provocando a supressão de fluorescência.

A conversão interna entre os estados singlete de energias mais altas, tal como $\mathrm{S}_{3} \longrightarrow \mathrm{S}_{2}$ é muito mais rápida que as taxas das conversões que foram 
consideradas $\left(\mathrm{S}_{1} \longrightarrow \mathrm{S}_{0}\right)$. A relaxação vibracional dos níveis vibracionais excitados de cada estado eletrônico é mais rápida que a emissão de fóton. O resultado é que toda fluorescência que se observa é normalmente originária do nível vibracional fundamental do singlete excitado.

Uma das propriedades desejáveis para um bom FS é uma alta eficiência para sofrer cruzamento intersistemas. Como o tempo de vida do estado triplete é relativamente longo $\left(10^{-3}\right.$ a $\left.10 \mathrm{~s}\right)$, o FS excitado pode interagir com moléculas vizinhas como, por exemplo, o oxigênio molecular, formando assim o radical oxigênio singlete. A Figura 1 representa o Diagrama de Jablonski, com os níveis de energia eletrônico/vibracional de um FS excitado através de uma fonte de excitação a um determinado nível de energia (Lakowicz, 1999).

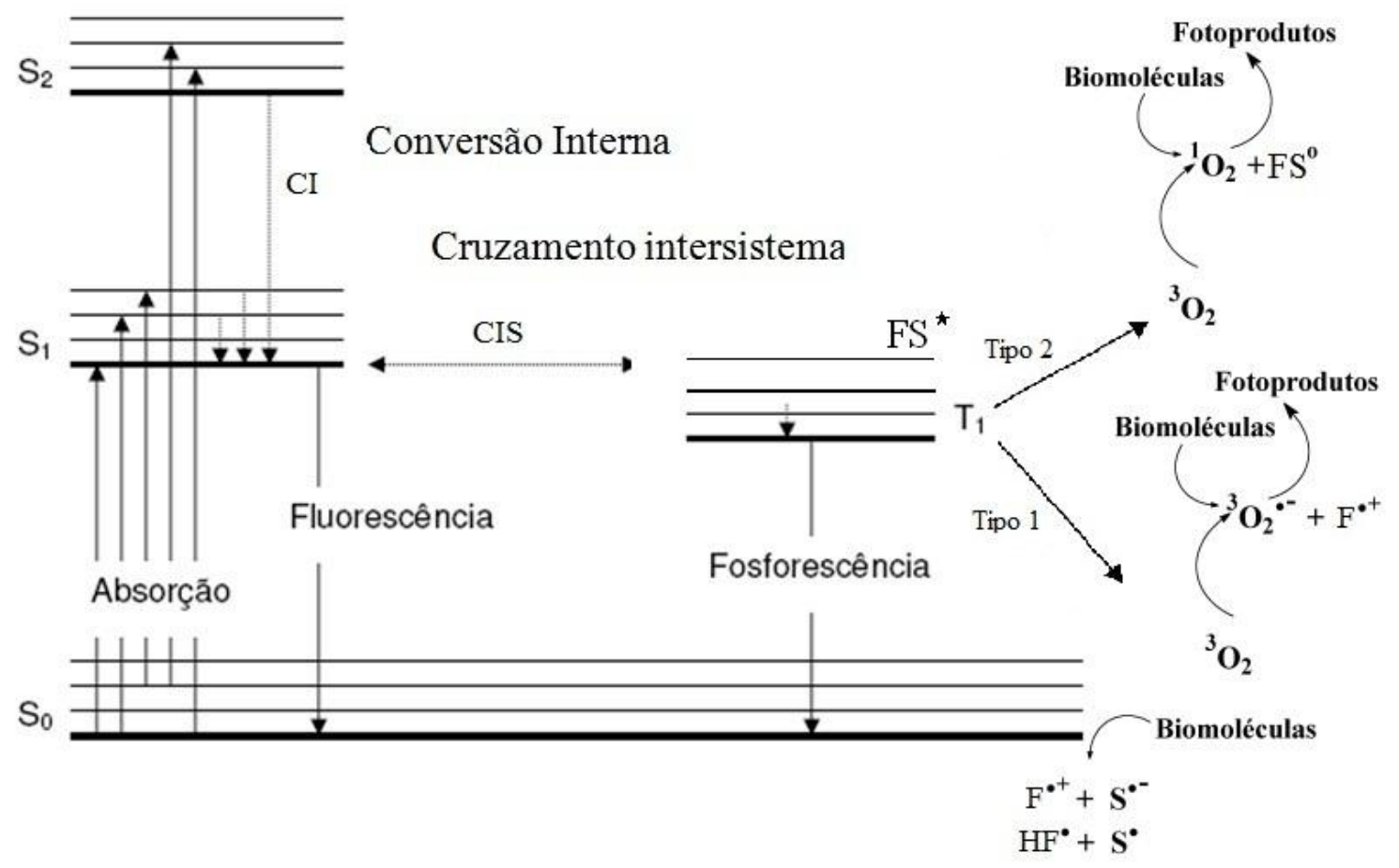

Figura 1: Diagrama de Jablonski - ilustração gráfica dos mecanismos fotoquímicos e fotofísicos em TFD (adaptado de Lakowicz, 1999).

Diversos autores revisaram e descreveram os mecanismos envolvidos na terapia fotodinâmica (Sharman, Allen et al., 1999; Sibata, Colussi et al., 2000; Dolmans, Fukumura et al., 2003; Chatterjee, Fong et al., 2008). Porém os principais mecanismos de reação estão demonstrados na Figura 1, que são chamados de mecanismos do tipo I e II. 


\subsubsection{Reações do tipo I e II}

$\mathrm{Na}$ presença de oxigênio encontrado nas células, o FS ativado pode reagir com moléculas na sua vizinhança por transferência de elétrons ou hidrogênio, levando à produção de radicais livres (reação do tipo I) ou por transferência de energia ao oxigênio (reação do tipo II), levando à produção de oxigênio singlete. Ambos os caminhos podem levar à morte celular e à destruição do tecido doente (Castano, Demidova et al., 2004; Gad, Zahra et al., 2004; Lambrechts, Aalders et al., 2005; Yano, Hirohara et al., 2011).

Reações tipo l: Formação de radicais livres $(\cdot \mathrm{OH})$ através da transferência de elétrons entre o FS no estado triplete excitado e componentes do sistema, gerando ânion-radical superóxido $\left(\cdot \mathrm{O}_{2}^{-}\right)$.

Reações tipo II: Transferência de energia do FS no estado triplete $\left({ }^{3} \mathrm{~S} 1^{\star}\right)$ com formação de oxigênio singlete $\left({ }^{1} \mathrm{O}_{2}\right)$.

$$
\begin{aligned}
& { }^{0} \mathrm{FS} \stackrel{h \mathrm{v}}{\longrightarrow}{ }^{1} \mathrm{FS}^{*} \stackrel{I S C}{\longrightarrow}{ }^{3} \mathrm{FS}^{*} \\
& { }^{3} \mathrm{FS}^{*}+{ }^{3} \mathrm{O}_{2} \rightarrow{ }^{0} \mathrm{FS}+{ }^{1} \mathrm{O}_{2} \\
& { }^{1} \mathrm{O}_{2}+\mathrm{S} \rightarrow \text { Produto fotoxidado }
\end{aligned}
$$

Onde:

${ }^{0} \mathrm{FS}=$ Fotossensibilizador no estado singlete fundamental

${ }^{1} \mathrm{FS}^{*}$ = Fotossensibilizador no estado singlete excitado

${ }^{3} \mathrm{FS}^{*}=$ Fotossensibilizador no estado triplete excitado

${ }^{1} \mathrm{O}_{2}=$ oxigênio singlete

${ }^{3} \mathrm{O}_{2}=$ oxigênio triplete (Oxigênio molecular)

$\mathrm{S}=$ substrato

ISC = Conversão intersistema

\subsubsection{Efeito biológico da TFD}

Diversos alvos celulares podem ser afetados durante a TFD, incluindo mitocôndria, lisossomos, membranas plasmáticas entre outras organelas. A morte 
celular pode ocorrer por necrose ou apoptose (Sharman, Allen et al., 1999). A eficácia da TFD no tratamento do câncer depende de muitos fatores como, por exemplo, a concentração intracelular de oxigênio e de FS, dose de luz, a eficiência fotodinâmica do FS e a localização do FS nas células, entre outros fatores (Castano, Mroz et al., 2006). A inativação do tumor pela TFD pode ocorrer através de três processos, dependendo das condições utilizadas, causando a morte celular direta por necrose ou apoptose; destruição da vasculatura no tumor e ativação da resposta imune contra as células tumorais remanentes (Castano, Demidova et al., 2005; Castano, Mroz et al., 2006).

Como mostra a Figura 2 primeiramente a interação do FS com a luz e oxigênio molecular gera espécies reativas de oxigênio como, por exemplo, o oxigênio singlete $\left({ }^{1} \mathrm{O}_{2}\right)$, que serão responsáveis pela morte celular direta das células tumorais que pode ocorrer por necrose ou apoptose, este segundo sendo mais interessante para a TFD, pois leva à morte programada das células evitando possível desenvolvimento de inflamação das células saudáveis adjacentes. 0 colapso da microvasculatura também pode ser observado logo após o tratamento fotodinâmico, a destruição da vasculatura pertinente ao tumor faz com que haja a privação local de oxigênio e nutrientes, resultando em hipóxia severa e persistente, que culmina com a morte do tumor. Além destes dois mecanismos de morte do tumor, a TFD é capaz de ativar a resposta imune contra as células tumorais, envolvendo a atividade antitumoral das células inflamatórias induzidas pela TFD e a geração de uma resposta imunológica antitumoral prolongada, por exemplo, através das células dendríticas e neutrófilos (Castano, Demidova et al., 2005).

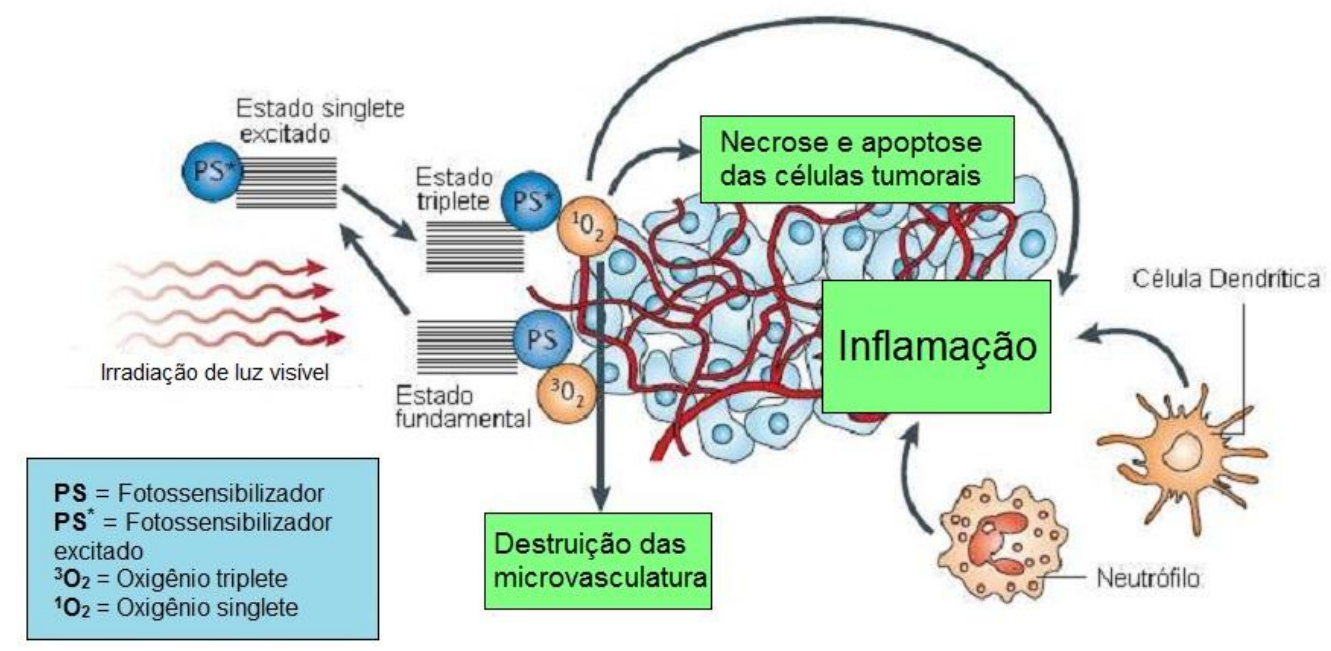

Figura 2: Mecanismos de ação da TFD nos tumores adaptado de (Castano, Mroz et al., 2006) 


\subsection{Classificação dos Fotossensibilizadores}

\subsubsection{Fotossensibilizadores de $1^{1}$ geração}

Hematoporfirina $(\mathrm{Hp})$ foi produzida pela primeira vez em 1841 por Scherer, durante investigações sobre o natureza do sangue. Scherer constatou que o tratamento do sangue com ácido sulfúrico concentrado com a remoção subsequente de ferro e depois tratando com álcool produziu $\mathrm{Hp}$ (Thudichum, et al., 1867). Os primeiros estudos demonstraram o potencial da $\mathrm{Hp}$ como uma ferramenta de diagnóstico para a detecção de câncer, no entanto, um dos principais inconvenientes era a dose elevada necessária para alcançar absorção do FS nos tumores, que resultou na fotossensibilidade do local tratado (Figge, Weiland et al., 1948; O'connor, Gallagher et al., 2009). Em 1955, Schwartz e colaboradores demonstraram que a $\mathrm{Hp}$ era impura, consistindo numa mistura de porfirinas com diferentes propriedades. Depois de diversas purificações a parte pura da $\mathrm{Hp}$ ficava pouco retida nos tumores, enquanto o resíduo da purificação ficava bem retido nos tumores (Schwartz, et al., 1955).

Estudos subsequentes demonstraram que $\mathrm{O}$ tratamento de $\mathrm{Hp}$ bruta com ácido acético e ácido sulfúrico, seguido de filtragem e neutralização com acetato de sódio e de dissolução em solução salina produzia uma substância que foi chamada de $\mathrm{HpD}$ (derivado de hematoporfirina). A propriedade de retenção no tumor da $\mathrm{HpD}$ foi obtida e considerada superior à da $\mathrm{Hp}$. Uma série de estudos realizados na década de 60 por Lipson et al. revelou que $\mathrm{HpD}$ tem a capacidade de acumular seletivamente em tecido neoplásico usando doses muito inferiores comparadas com a Hp (Lipson e Baldes, 1960). Aplicações terapêuticas da TFD foram realizadas a partir de 1972 quando Diamond et al. demonstraram que a preparação do extrato bruto de hematoporfirina resultou na regressão de tumores em ratos quando irradiados com luz branca (Diamond, Mcdonagh et al., 1972). Seis anos mais tarde, Dougherty e colaboradores relataram a resposta completa de vários tumores malignos, incluindo os carcinomas dos melanomas mama, cólon e próstata usando HpD como FS (Dougherty, Kaufman et al., 1978). Posteriormente, considerável atenção foi voltada para a determinação do componente ativo envolvido na $\mathrm{HpD}$ para o tratamento do câncer. A purificação parcial de $\mathrm{HpD}$ foi completada com sucesso produzindo uma forma liofilizada concentrada de monômeros e oligômeros 
derivados da hematoporfirina que é utilizada em tratamentos com TFD e conhecida como Photofrin® (Dougherty, Weishaupt., 1984).

Fotossensibilizadores porfirínicos de $1^{\text {a }}$ geração

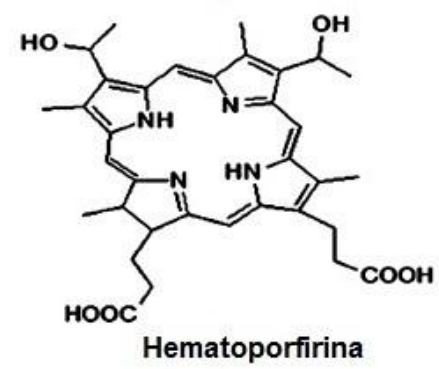

Fotossensibilizadores porfirínicos de $2^{\mathrm{a}}$ geração

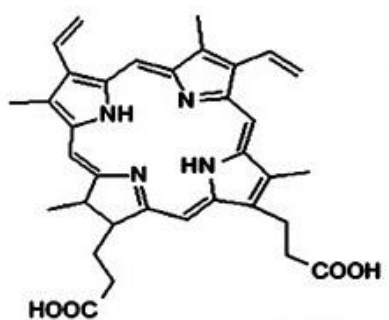

Protoporfirina IX

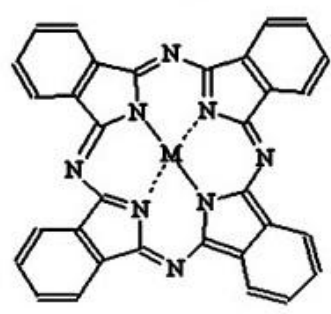

Ftalocianina

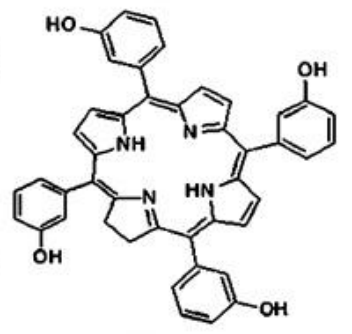

Foscan

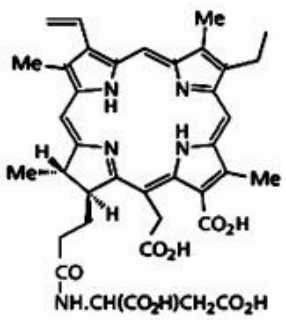

NPe6

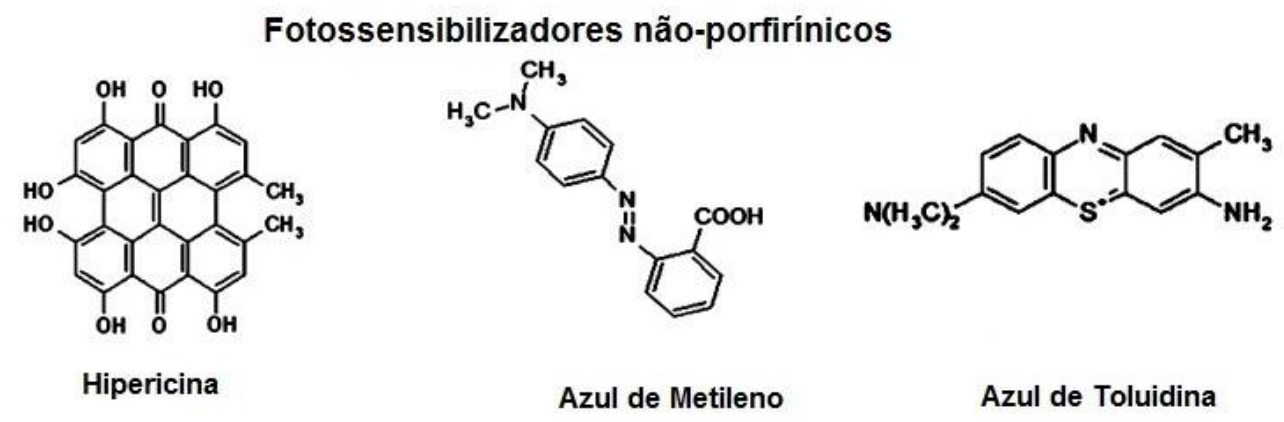

Figura 3: Classificação dos fotossensibilizadores adaptado de (O'connor, Gallagher et al., 2009)

\subsubsection{Fotossensibilizadores de $2^{\mathrm{a}}$ geração}

Diversas modificações químicas no anel tetrapirrólico das porfirinas caracterizam o grupo de FSs de segunda geração como mostra a Figura 3. São compostos quimicamente puros com composição constante, que absorvem luz em comprimentos de onda maiores ou iguais a $650 \mathrm{~nm}$ e induzem pouca fotossensibilidade da pele. O tempo de meia vida é curto e a acumulação nos tecidos é seletiva e rápida (cerca de 1 a 6 h após a aplicação sistêmica). A estrutura 
básica destes compostos é semelhante à das porfirinas e são divididos em diferentes classes (ČunderlíKová, Gangeskar et al., 1999):

$\checkmark$ ftalocianinas e naftalocianinas;

$\checkmark$ clorinas e bacterioclorinas;

$\checkmark$ purpurinas.

As ftalocianinas e naftalocianinas sintéticas são constituídas de quatronúcleos benzoindólicosunidos por pontes de nitrogênio. Estes compostos absorvem na faixa de comprimento deonda de $675-700 \mathrm{~nm}$ e podem ser ligados a uma variedade de metais, principalmentealumínio, silício e zinco, que levam a uma hexacoordenação. As ftalocianinas se acumulam namembrana plasmática, microssomos e mitocôndria e apresentam um período de fotossensibilidade de 8 a 10 dias, sendo um dos mais curtos entre todos (ČunderlíKová, Gangeskar et al., 1999).

As clorinas e bacterioclorinas são derivadas de porfirinas hidrofílicas reduzidas pela hidrogenação de uma ou mais duplas ligações dos anéis pirrólicos, apresentam um coeficiente de extinção alto, além de uma intensa banda de absorção na região de 650-800 nm. Clorinas e bacterioclorinas estão presentes em produtos naturais e, de modo geral, estes compostos apresentam duas importantes propriedades: um alto rendimento quântico de formação de oxigênio singlete e uma intensa absorção em 650-680 nm. Um exemplo de clorina é o Foscan (Figura 3), nome comercial do FS derivado de $m$-THPC (mesotetrakis(m-hidroxifenil)), produzido na Alemanha.

As purpurinas apresentam coloração púrpura, uma vez que a presença de um substituinte conjugado na posição meso da clorina altera a cor do pigmento anteriormente verde. Esses compostos absorvem fortemente na faixa de 630-715 $\mathrm{nm}$ e apresentam rendimento quântico de formação de oxigênio singlete de 0,6-0,7, sendo que a etilpurpurina de estanho $\left(\mathrm{SnEt}_{2}\right)$ é o derivado mais ativo desses compostos estudados. Vários derivados de clorina têm sido estudados, dentre eles a mono-aspartilclorina-e6 (Npe6 ou MACE) estrutura mostrada na Figura 3, produzida no Japão, que é altamente solúvel em água e absorve em $654 \mathrm{~nm}$. O rendimento quântico de formação de oxigênio singlete é de 0,77 e apresenta efetividade in vitro e in vivo com baixa fotossensibilidade do local tratado, provavelmente por causa da sua rápida eliminação do corpo (O'connor, Gallagher et al., 2009). 


\subsubsection{Fotossensibilizadores de $3^{a}$ geração}

A geração adicional de fotossensibilizadores representa uma classe emergente. Certos fotossensibilizadores de segunda geração foram conjugados dentro de moléculas transportadoras que facilitam a entrega destes fotossensibilizadores para o tecido tumoral. Tais biomoléculas de entrega incluem anticorpos monoclonais (mAbs), lipossomas e polímeros (Konan, Gurny et al., 2002b; Zeisser-Labouebe, Lange et al., 2006; Chatterjee, Fong et al., 2008). As células tumorais possuem antígenos de superfície celular, que diferem grandemente dos de células normais, assim permitindo a exploração mAbs de biomoléculas, como transportador eficiente de FS. O conjugado de fotossensibilizador com mAbs se liga seletivamente as células tumorais, facilitando a fotossensibilização do tecido tumoral e não se ligando ao tecido normal, ou seja, o tecido não danificado. Em resumo, pode-se dizer que os FS de terceira geração têm futuro promissor, com maior eficácia em relação ao FS na sua forma livre observada na maior parte dos casos. A especificidade biológica acrescida desses FSs de terceira geração em relação as outras duas gerações anteriores é a melhora na entrega do FS para o tecido alvo, assim melhorando a eficácia do tratamento, em muitos casos (O'connor, Gallagher et al., 2009).

\subsection{Uso de nanopartículas em TFD}

A imobilização de FS em materiais nanométricos também tem sido considerada como pertencente à terceira geração de FS (O'connor, Gallagher et al., 2009). A principal desvantagemem utilizar os FS livres éo espalhamento do FS pelo organismo o que torna necessário a proteção contra luz solar. Outra desvantagem em utilizar FS livres é a agregação em meio biológico devido à característica destes FS de serem hidrofóbicos. Esta agregação causa a diminuição da atividade do FS e podendo até causar a sua desativação. A imobilização dos FS em nanopartículas constitui uma excelente alternativa ao seu emprego em relação a sua forma molecular, pois, na maioria das vezes, as nanopartículas são carregadoras de FS hidrofóbicos, melhorando a dispersão destes em sistemas aquosos (Marcato e Duran, 2008). 
O sistema ideal de entrega de FS deve permitir o acúmulo seletivo dentro do tecido doente e a entrega de concentrações terapêuticas para as células tumorais com insignificante captação por células normais. O carregador deve também ser capaz de incorporar o FS sem perda ou alteração de sua atividade. Estes carregadores incluem micelas, lipossomos, nanopartículas poliméricas, nanocristais, dendrímeros, nanotubos, nanopartículas metálicas e nanopartículas cerâmicas (Konan, Gurny et al., 2002b; O'connor, Gallagher et al., 2009).

As nanopartículas poliméricas apresentam um grande potencial como agente transportador de FS e outros fármacos, pois, a sua superfície pode ser modificada quimicamente, possibilitando a incorporação de agentes terapêuticos, de agentes para obtenção de imagem por ressonância magnética, de ligantes (anticorpos) que reconheçam de forma específica as células do câncer e de sinalizadores de morte celular, possibilitado a construção de verdadeiros dispositivos multifuncionais (Faraji e Wipf, 2009).

Os lipossomas são vesículas concêntricas bilamelares que possuem uma membrana fosfolipídica na parte externa. Essas nanopartículas podem ser utilizadas para transportar FSs hidrofílicos no seu núcleo hidrofílico ou FSs hidrofóbicos em sua camada fosfolipídica. A natureza anfifílica, a facilidade de modificação superficial como, por exemplo,o revestimento com polietilenoglicol e a boa biocompatibilidade possibilita a utilização dessas nanopartículas como carregadores de fármacos em terapias químicas. Por exemplo, Jori G. et al. observou maior acúmulo no tumor de hematoporfirina encapsulada com lipossomos comparando com hematoporfirina livre em solução tampão (Konan, Gurny et al., 2002b).

\subsubsection{Tipos de Interação entre as nanopartículas e os FS}

As nanopartículas empregadas em TFD podem ser classificadas como:1) nanopartículas passivas (por exemplo, FS encapsulado com as nanopartículas poliméricas), 2) o FS ligado através de ligações covalentes às nanopartículas, 3) o FS interagindo na superfície das nanopartículas e 4) nanopartículas ativas (as nanopartículas atuando como FS), sendo que as nanopartículas ativas podem ser subdivididas em biodegradáveis (PLA e PGA, lipossomos) e não-biodegradáveis (sílica, ouro) (Konan, Gurny et al., 2002b; Chatterjee, Fong et al., 2008). 
O FS encapsulado com nanopartículas poliméricas tem varias vantagens em relação aos FS livres como, por exemplo, utilizar uma concentração menor de FS para obter os mesmos resultados dos FS livres, assim contribuindo para que a célula alvo não crie resistência. Outra vantagem é a boa seletividade dos FS encapsulados com nanopartículas poliméricas em relação aos FS livres e se o FS for insolúvel em meio aquoso o encapsulamento pode torná-lo mais solúvel (Perni, Prokopovich et al., 2011). Um exemplo de encapsulamento de FS foi descrito por Tsaiet al. usando hematoporfirina em lipossomas e micelas, sendo que o encapsulamento impediu a agregação do FS, resultando em uma maior atividade antimicrobiana (Tsai, Yang et al., 2009).

Os FS ligados covalentemente à superfície de nanopartículas representam um FS novo com propriedades melhores do que o FS original. O primeiro relato de FS imobilizado na superfície de nanopartículas foi feito por Bezman et al., que imobilizou o Rose de Bengal ligado em partículas de poliestireno. Os autores mostraram que este corante ligado às partículas de poliestireno expostas à luz branca foi capaz de inativar E. coli e um derivado de Porfirina ligado à superfície de nanotubos de carbono inativou S. Aureus. Azul de Toluidina ligado à superfície de ouro metálico e Rose de Bengal ligado à superfície de sílica foram capazes de inativar a bactéria S. Epidermidis(Bezman, Burtis et al., 1978; Perni, Prokopovich et al., 2011). A fim de ligar o FS na superfície das nanopartículas, tanto o FS quanto a superfície das nanopartículas tem que possuir alguns grupos reativos onde a ligação pode ocorrer. Geralmente, as nanopartículas não têm tais grupos reativos, portanto é necessário fazer uma funcionalização da superfície destas nanopartículas com grupos aminas ou grupos carboxílicos. O segundo passo é fazer a reação entre os grupos funcionalizados da superfície das nanopartículas e o fotossensibilizador (Bezman, Burtis et al., 1978; Gil-Tomas, Tubby et al., 2007).

O FS pode interagir com a superfície das nanopartículas, esse tipo de interação acontece quando as nanopartículas são muito grandes para penetrar na membrana celular. Essas interações podem ser físicas ou químicas entre a superfície das nanopartículas e o FS. Tem sido utilizados FSs interagindo com nanopartículas de ouro e também foi estudada a eficácia do Azul de Metileno e Azul de Toluidina interagindo com matrizes poliméricas como o silicone e o poliuretano (Perni, Prokopovich et al., 2009; Perni, Prokopovich et al., 2011). 
Algumas nanopartículas podem atuar como $\mathrm{FS}$, por exemplo, o $\mathrm{TiO}_{2}$ pode ser foto-oxidado e produzir radicais livres quando irradiado com luz no comprimento de onda de sua absorção. No entanto, o principal obstáculo para o uso de nanopartículas de $\mathrm{TiO}_{2}$ para aplicações médicas é que sua absorção é essencialmente na região do Ultra Violeta (UV) do espectro eletromagnético. A aplicação de $\mathrm{TiO}_{2}$ para a desinfecção de água contaminada com E. coli foi mostrado por Sanabria et al. Neste caso, a fonte de luz era o sol, eliminando a necessidade de uma lâmpada UV (Rengifo-Herrera, Sanabria et al., 2007). A maior parte do foco da pesquisa em relação à utilização de nanopartículas atuando como FS tem sido para mudar a absorção destes compostos para a região do visível, utilizando alguns metais como $\mathrm{Fe}^{3+}$ e $\mathrm{Er}^{3+}$ ligados a essas nanopartículas (Wang, Shang et al., 2010). Fulerenos constituem o terceiro tipo de estrutura de carbono, consiste de 60 átomos de carbono dispostos em uma estrutura esférica que podem absorvem luz. Os fulerenos também possuem características de FS e podem gerar diferentes espécies reativas de oxigênio de acordo com o solvente utilizado: em solventes polares ele produz radicais superóxido e hidroxila, enquanto que em solventes apolares geram predominantemente oxigênio singlete (Nakamura e Isobe, 2003).

\subsection{Nanopartículas Lipídicas Sólidas (NLS)}

As nanopartículas lipídicas sólidas (NLS), também chamadas de lipoesferas ou nanoesferas lipídicas sólidas, são sistemas de liberação de fármacos que reúnem as principais vantagens encontradas nos sistemas lipossomais e nas micro e nanopartículas poliméricas. Da mesma forma que as emulsões e os lipossomas, as NLS são sistemas compostos por substâncias fisiologicamente bem toleradas e que algumas já possuem aprovação para a aplicação em seres humanos (Olbrich, Bakowsky et al., 2001).

As NLS apresentam um tamanho entre 50 e 1000 nm, e são preparadas usando uma grande variedade de lipídeos, mono-, di- ou triglicerídeos, misturas de glicerídeos ou ceras, que são estabilizados por surfactantes biocompatíveis aniônicos ou catiônicos. Essas nanopartículas apresentam elevada estabilidade no meio biológico, uma vez que possuem um núcleo rígido que é sólido em temperatura ambiente e corporal, o qual é rodeado por uma camada de fosfolipídios. As NLS podem ser utilizadas para encapsular e transportar fármacos lipofílicos como, por 
exemplo, a doxorubicina e o paclitaxel (Faraji e Wipf, 2009). As nanopartículas lipídicas sólidas utilizam o sistema de entrega passivo, ou seja, utiliza o efeito de permeabilidade e retenção (EPR) aumentadas para se acumularem no tumor (Mehnert e Mader, 2001; Wissing, Kayser et al., 2004).

De maneira similar às nanopartículas poliméricas, a matriz sólida das NLS protege as substâncias ativas contra degradações químicas e permite modular a velocidade de liberação do fármaco ou FS. A grande vantagem em relação às nanopartículas poliméricas é que os componentes das NLS possuem menor citotoxicidade e possibilitam a obtenção de nanopartículas sem o uso de solventes. Além disso, sua produção também pode ser obtida em larga escala, o que é propício para a produção industrial (Olbrich, Bakowsky et al., 2001; Shah, Date et al., 2007; Mehnert e Maeder, 2012).

\subsubsection{Eficiência de Encapsulação}

A determinação da quantidade de FS associada às nanopartículas é especialmente complexa devido ao reduzido tamanho destas, o que dificulta a separação da fração de FS da fração associada. Uma boa técnica de separação bastante utilizada é a Ultracentrifugação (Santos-Magalhaes, Pontes et al., 2000), na qual a concentração de FS livre, presente na suspensão, é determinada no sobrenadante após a centrifugação. Já a concentração total de FS é geralmente determinada pela completa dissolução das nanopartículas na suspensão com um solvente adequado. Portanto a concentração de fármaco associada às nanopartículas é calculada pela diferença entre as concentrações de FS total e livre (Tiyaboonchai, Woiszwillo et al., 2001). Outra técnica muito empregada é a ultrafiltraçãocentrifugação, na qual um membrana (100 kDa) é utilizada para separar parte da fase aquosa dispersante da suspensão coloidal. A concentração do FS livre é determinada no ultrafiltrado e a fração de FS associada às nanopartículas é calculada também pela subtração das concentrações total e livre (Schaffazick, Pohlmann et al., 2003). 


\subsubsection{Tamanho da partícula e potencial zeta}

A medida do tamanho de partícula e do potencial zeta é um indicador da estabilidade. Sendo assim, estas são medidas muito utilizadas para caracterizar nanopartículas em geral e predizer algumas características macroscópicas da formulação. No caso do tamanho das NLS, formulações adequadas devem possuir baixa polidispersividade e tamanho menores que $1 \mu \mathrm{m}$. O tamanho das NLS é afetado por inúmeros parâmetros, como a composição da formulação (mistura de tensoativos, as propriedades estruturais dos lipídeos e do fármaco incorporado que neste caso se trata de FS), dos métodos de produção e das condições estabelecidas para produção, como tempo de preparo, temperatura e liofilização. Assim, estes parâmetros são definidos no intuito de melhorar o tamanho das partículas e sua polidispersividade (Uner, 2006). Por exemplo, altas proporções de tensoativo/lipídeo favorecem a formação de partículas menores. A diminuição desta proporção significa aumento do tamanho das partículas principalmente durante o período de estocagem (Lippacher, Muller et al., 2002). Outro fator relevante que interfere diretamente no tamanho das partículas é a temperatura escolhida durante o processo de obtenção de NLS por homogeinizadores de alta pressão. Baixas temperaturas tendem à formação de partículas maiores, já que uma melhor homogeneização é obtida com temperaturas perto do ponto de fusão dos lipídeos. Uner et al. observou que a utilização do homogeinizador de alta pressão a quente permitiu a produção de partículas com tamanhos menores que $500 \mathrm{~nm}$, enquanto que produzi-las a frio levou à produção de partículas maiores e com alta polidispersividade (Uner, 2006).

Outro dado importante para a caracterização das partículas é o potencial zeta. Esta análise permite a determinação da estabilidade e das interações que a partícula pode ter com o FS. O potencial zeta reflete o potencial de superfície das partículas, o qual é influenciado pelas mudanças na interface com o meio dispersante em razão da dissociação de grupos funcionais na superfície da partícula ou da adsorção de espécies iônicas presentes no meio aquoso de dispersão (Schaffazick, Pohlmann et al., 2003). A medida do potencial zeta fornece informações sobre a estabilidade da formação, principalmente durante o seu período de estocagem. Geralmente a agregação entre as partículas é menor quando há repulsão eletrostática entre elas. Para garantir a estabilidade das NLS, acredita-se que o potencial zeta deve ser 
superior ao módulo de $30 \mathrm{mV}$ (Freitas e Muller, 1998). Porém esta regra não pode ser aplicada irrestritamente, pois existem algumas formulações com estabilizantes que possuem um potencial zeta menor e são estáveis (Muller, Maassen et al., 1996).

A combinação da medida do potencial zeta com outras técnicas de caracterização resulta também em diferentes elucidações. Variando a proporção entre componentes de uma formulação é possível determinar qual destes componentes está na superfície da partícula e qual é responsável pela carga superficial desta partícula (Mosqueira, Legrand et al., 2000).

\subsubsection{Estabilidade das formulações}

Um dos maiores problemas encontrados no desenvolvimento das NLS é a sua estabilidade por longos períodos de tempo. Muitos autores têm relatado a expulsão do fármaco durante os períodos de estocagem destas formulações, principalmente devido à composição das partículas e de seus processos de produção (Souto e Müller, 2008; Pardeike, Hommoss et al., 2009).

Para contornar este fenômeno e aumentar a eficiência de encapsulação destas partículas é necessária a utilização de lipídeos que não formem cristais altamente organizados (Attama, Schicke et al., 2007). Para tanto, lipídeos formados por ácidos graxos de tamanhos variados de cadeias, líquidos e sólidos, são misturados, formando pequenos reservatórios líquidos dentro da partícula, evitando a formação de cristais altamente organizados (Muller, Radtke et al., 2002). As partículas produzidas por esta mistura de lipídeos sólidos e líquidos são denominadas de Carreadores Lipídicos Não-estruturados(Attama, Schicke et al., 2007).

\subsection{Hipericina e Nanopartículas}

A Hipericina (Hy) é um dos constituintes das plantas do gênero Hipericum, uma planta herbácea, popularmente conhecida como erva de São João encontrada por todo o mundo(Brown e Truscott, 1993; Brown, Brown et al., 1999). Sua atividade fotodinâmica foi identificada por causa do aparecimento do chamado hipericismo em alguns animais de pasto que ingeriam grandes quantidades desta planta que contém hipericina e causava fotossensibilidade nos animais quando expostos à luz solar 
(Agostinis, Vantieghem et al., 2002). Uma das vantagens da Hy (Figura 4) é o seu intenso espectro de absorção com dois picos principais em 545 e $590 \mathrm{~nm}$. Hy tem sido amplamente utilizada na forma de extratos de plantas como um antidepressivo. A fotoatividade da Hy tem sido demonstrada em vários estudos em que a $\mathrm{Hy}$ foi eficiente em combater diversos tipos de câncer em camundongos, sendo que em seres humanos também tem sido capaz de combater câncer de bexiga e câncer de ovário com alta especificidade (D'hallewin, Bezdetnaya et al., 2002; ZeisserLabouebe, Lange et al., 2006).

Como a maioria dos FSs, a Hy é caracterizada por uma alta lipofilicidade. Apesar de interessante com relação à seletividade para tecido neoplásico, a insolubilidade em meio biológico faz com que a administração desse FS seja problemática devido à agregação em meio aquoso, assim restringindo suas aplicações médicas (Konan, Gurny et al., 2002b; a). Estudos realizados por ZeisserLabouèbe e colaboradores demonstraram que os efeitos fotodinâmicos in vitro da Hy encapsulada com ácido polilático (PLA) em células tumorais foram mais efetivos do que com a Hy livre, o que permite utilizar uma concentração menor de Hy e assim diminuindo a possibilidade de causar fotossensibilidade no local (Zeisser-Labouebe, Lange et al., 2006). Segundo os autores, a fotoatividade da Hy encapsulada assim como de outros FS é dependente de alguns parâmetros de transporte, como a carga dos polímeros e dos FSs, o tempo de incubação, a dose de irradiação e da concentração de FS. Como já foi discutido anteriormente, a hidrofobicidade da Hy é um problema na administração sistêmica, portanto nanopartículas ajudam a superar estes problemas de distribuição e de estabilidade facilitando a administração intravenosa deste FS. Zeisser-Labouèbe preparou Hy incorporada em nanopartículas de PLA com tamanho médio de $268 \mathrm{~nm}$ e potencial zeta negativo e estudou a biodistribuição da Hy encapsulada em nanopartículas de PLA e Hy livre administrada de forma intravenosa em ratos para o tratamento de tumores de ovários. Os autores obtiveram resultados superiores de acumulação de $\mathrm{Hy}$ encapsulada em nanopartículas de PLA comparado com a Hy livre em solução (Zeisser-Labouebe, Delie et al., 2009).

Youssef e colaboradores incorporaram $\mathrm{Hy}$ em dois sistemas de nanopartículas lipídicas sólidas e obtiveram nanopartículas com tamanho de 200 $300 \mathrm{~nm}$, eficiência de encapsulação superior a 80\% e índice de polidispersão de 
0,27-0,42. No entanto, o efeito fototóxico em células HepG2 da Hy-NLS foi menor comparado com a Hy livre (Youssef, Fadel et al., 2012).

A Figura 4mostra a estrutura molecular e o espectro de absorção molecular da hipericina em etanol, respectivamente. A Hy possui absorção máxima em 590 $\mathrm{nm}$, por isso foi utilizado neste trabalho o LED com emissão em $590 \pm 10 \mathrm{~nm}$ para os experimentos de atividade fotodinâmica e ensaios fototóxicos.
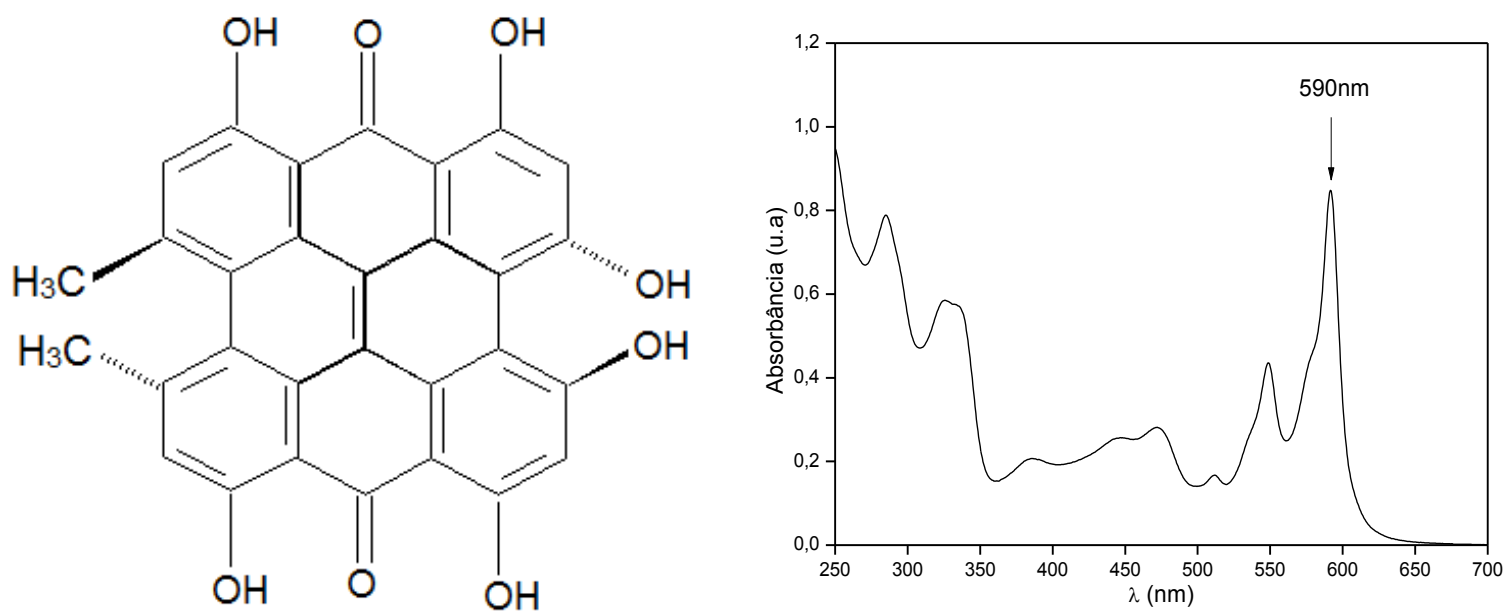

Figura 4:a) Estrutura da Hipericina e b) espectro de absorção ótica da Hipericina em etanol.

\subsection{Ftalocianinas e Nanopartículas}

Entre os fotossensibilizadores de segunda geração mais promissores estão as ftalocianinas (Nunes, Sguilla et al., 2004). As ftalocianinas apresentam propriedades como alta seletividade para os tecidos tumorais, alta eficiência citotóxica devido à fotogeração de oxigênio singlete (Sibata, Colussi et al., 2000) e alto coeficiente de absorção na faixa de 600 a $850 \mathrm{~nm}$ em energias em torno de 100 $\mathrm{J} \mathrm{cm}^{-2}$, com ótima penetração da luz no tecido (Allison, Downie et al., 2004; Nunes, Sguilla et al., 2004), resultando em elevada resposta fototerápica. A estrutura

molecular das ftalocianinas é semelhante à das porfirinas, apresentando um macrociclo tetrapirrólico com átomos de nitrogênio ligando as subunidades pirrólicas no lugar das pontes de metileno presentes nas porfirinas (Figura 5). A periferia do macrociclo é estendida por anéis benzênicos que aumentam a absorção em comprimentos de onda na região do vermelho do espectro visível, de modo que a sua absorção máxima ocorre em comprimentos de onda maiores do que 0 as porfirinas (Sharman, Allen et al., 1999). 


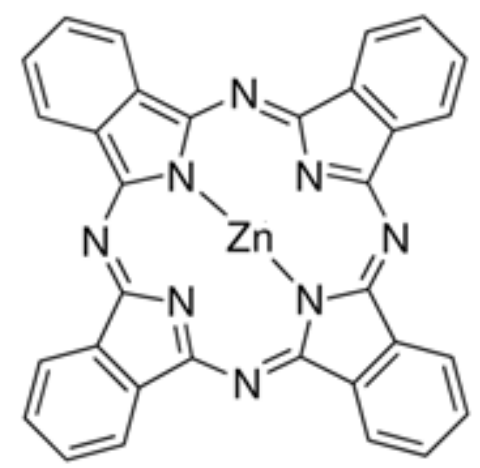

Figura 5: Estrutura molecular da ftalocianina dezinco (II) (FtZn)

No entanto, assim como a maioria dos fotossensibilizantes de segunda geração, as ftalocianinas são hidrofóbicas, altamente insolúveis em água e em solventes fisiologicamente compatíveis. A lipofilicidade dos FSs torna difícil o desenvolvimento de formulações em solventes compatíveis, especialmente para a administração intravenosa e, por isso, o principal problema da TFD está relacionado com a liberação desses fotossensibilizantes lipofílicos nas células tumorais (ZeisserLabouebe, Lange et al., 2006). Assim, para serem administradas por meio de uma injeção sistêmica in vivo, estes FSs precisam ser incorporados em sistemas de liberação adequados (Soncin, Polo et al., 1995).

Ricci-Júnior et al. encapsularam ftalocianina de zinco (II) em poli ácido lácticoglicólico (PLGA) e obtiveram um tamanho de partículas de $285 \mathrm{~nm}$, índice de polidispersividade de 0,12 e eficiência de encapsulação de $70 \%$. O efeito fototóxico da ftalocianina de zinco encapsulada em PLGA foi cerca de três vezes maior do que o efeito fototóxico causado pelo FS livre (Ricci-Junior e Marchetti, 2006). Vior et al. também observaram melhoria na eficiência fotodinâmica de um derivado de ftalocianina de zinco (II) incorporado em NLS comparado com o FS livre. Os autores obtiveram um acréscimo de cerca de duas a três vezes na solubilidade do FS incorporado em NLS comparado com o FS livre e consequentemente obtiveram valores altos de rendimento quântico de formação de ${ }^{1} \mathrm{O}_{2}$ (Garcia Vior, Monteagudo et al., 2011).

A Figura 6mostra a estrutura molecular e o espectro de absorção molecular em DMSO de um derivado da ftalocianina de zinco (Tetra-carboxiftalocianinade zinco) que foi utilizada neste estudo. Como pode ser observado a tetracarboxiftalocianina de zinco (FtZnT) possui bandas na região de maior penetração da luz na pele que é de 600 a $850 \mathrm{~nm}$ com absorção máxima em $690 \mathrm{~nm}$. No 
presente estudo foi empregado um LED com emissão em $630 \pm 10 \mathrm{~nm}$ para os experimentos de atividade fotodinâmica e ensaios fototóxicos.
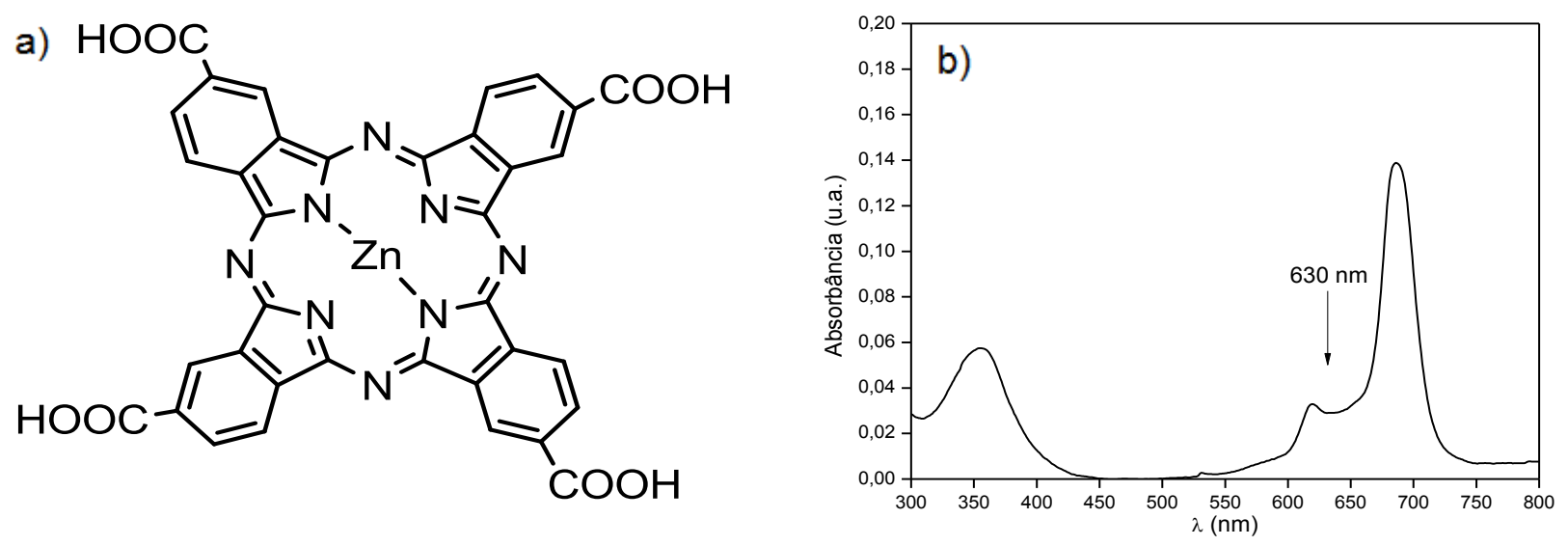

Figura 6: a) Estrutura molecular e b) espectro de absorção molecular da tetra-carboxiftalocianina de zinco em DMSO. 


\section{Objetivos}

\subsection{Objetivo Geral}

O objetivo deste estudo foi preparar e caracterizar fotossensibilizadores hidrofóbicos (Hipericina e Tetra-carboxiftalocianina de zinco) encapsulados em nanopartículas lipídicas sólidas para um potencial uso em terapia fotodinâmica.

\subsection{Objetivos Específicos}

> Preparação das NLS sem FS e com FS utilizando o método de ultra-som;

> Caracterização das nanopartículas lipídicas sólidas através da determinação do tamanho médio, do potencial zeta, do índice de polidispersão, da eficiência de encapsulação e da morfologia por Microscopia Eletrônica de Transmissão (MET);

> Avaliação da atividade fotodinâmica dos FSs encapsulados em NLS e livres em solução, através da determinação das constantes de velocidade de fotodecomposição do 1,3-Difenilisobenzofurano (DPBF) e ácido úrico (AU);

> Estudo da toxicidade e fototoxicidade dos FS livres, NLS sem FS e FS encapsulados em NLS empregando duas linhagens de células tumorais;

> Estudo de acumulação intracelular dos FS livres e encapsulados em NLS utilizando três tempos de incubação em duas linhagens de células tumorais. 


\section{Materiais e métodos}

\subsection{Reagentes e equipamentos}

Os fotossensibilizadores (Hipericina e Tetra-carboxiftalocianina de zinco) utilizados neste trabalho foram sintetizados pelo Prof. Dr. Anderson O. Ribeiro da Universidade Federal do ABC e caracterizados por Ressonância Magnética Nuclear (RMN). As soluções estoque de concentração de $500 \mu \mathrm{g} \mathrm{mL}^{-1}$ de hipericina e de tetra-carboxiftalocianina de zincoforam obtidas em etanol e DMSO respectivamente. Todos os solventes utilizados foram de grau analítico e ou grau espectroscópico e a água foi obtida no Milli-Q Plus (Millipore).

As medidas de absorção ótica foram realizadas no espectrofotômetro HITACHI U-2800 e as de fluorescência foram realizadas em espectrofluorímetro HITACHI F-4500. As cubetas utilizadas para as medidas espectroscópicas eram de quartzo com caminho ótico de $1 \mathrm{~cm}$. Um leitor de placas modelo Benchmark (BIORAD) com filtro em $550 \mathrm{~nm}$ foi empregado para a leitura da absorbância das células em placas de 96 poços para a contagem celular nos ensaios citotóxicos.

As fontes de luz utilizadas, chamadas de Biotables são constituídas de um conjunto de LEDs com emissão em $590 \pm 10 \mathrm{~nm}$ (amarelo) e em $630 \pm 10 \mathrm{~nm}$ (vermelho), ambos mostrados na Figura 7, com intensidades médias por área igual a $18 \mathrm{~mW} \mathrm{~cm}{ }^{-2}$ e $10 \mathrm{~mW} \mathrm{~cm}^{-2}$, respectivamente. Esses aparelhos são refrigerados à água e foram desenvolvidos especialmente para irradiação de células em cultura pelo Laboratório de Apoio Técnico do IFSC-USP e cedidos pelo Prof. Dr. Vanderlei S. Bagnato.

a)

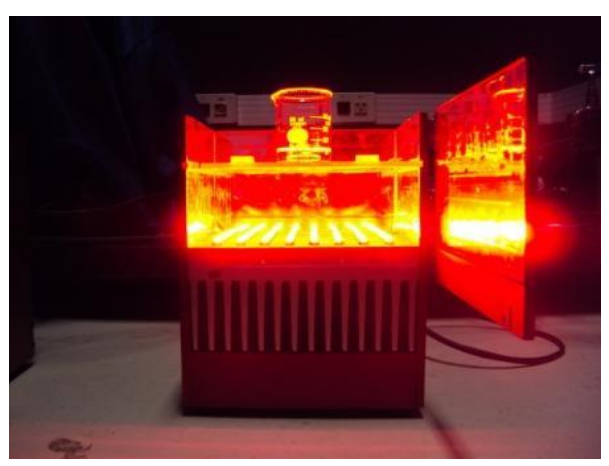

b)

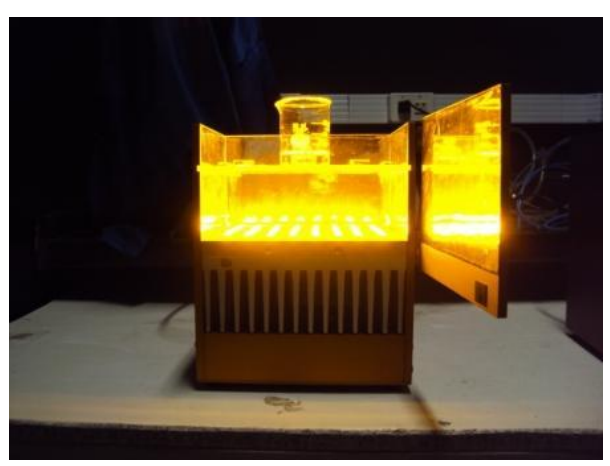

Figura 7: Fontes de luz utilizadas: a) LED com emissão em $630 \pm 10$ nm e b) LED com emissão em $590 \pm 10 \mathrm{~nm}$. 


\subsection{Preparo das Nanopartículas Lipídicas Sólidas (NLS) com Hy e FtZnT}

As NLS brancas (sem FS) e as Hy-NLS e FtZnT-NLS foram obtidas pelo método de ultra-som. Para a preparação de dispersões de Hy-NLS, a fase lipídica composta de $0,1 \%(\mathrm{~m} / \mathrm{v})$ de hipericina, $1,0 \%(\mathrm{~m} / \mathrm{v})$ de mono-estearato de glicerol (MEG) e $0,1 \%$ de lecitina $S 75$ foi fundida a cerca de $5-10{ }^{\circ} \mathrm{C}$ acima do ponto de fusão do lipídeo $\left(56-60{ }^{\circ} \mathrm{C}\right)$. Para a preparação das FtZnT-NLS foi necessário aumentar a concentração de lipídeo para 2,0\%. A fase fundida obtida foi dispersa com agitação na solução aquosa de agente tensoativo contendo $0,4 \%(\mathrm{~m} / \mathrm{v})$ de polissorbato 80 (Tween 80) aquecida à mesma temperatura. Em seguida, uma sonda de ultra-som ( $6 \mathrm{~mm}$ de diâmetro) foi introduzida na pré-emulsão através de um processador de ultra-som (Vibracells). Uma potência de saída com a amplitude de $70 \%$ foi aplicada durante 3 minutos sob banho de gelo, levando à quebra das gotas por cavitação acústica e formação posterior das nanopartículas (Patil e Pandit, 2007).

\subsubsection{Caracterização das nanopartículas lipídicas sólidas}

O tamanho das partículas, índice de polidispersão (IP) e o potencial zeta (PZ) das dispersões de nanopartículas foram medidos por Dispersão Dinâmica de Luz (DLS) num Zetasizer Nano ZS (Malvern Instruments, UK), equipado com ângulo de espalhamento $173^{\circ}$. As medições foram feitas a $25^{\circ} \mathrm{C}$, após a diluição da amostra apropriada em água ultra pura (Milli-Q, Millipore, EUA). Para medir o potencial zeta, as amostras foram colocadas em uma célula específica em que um potencial de 150 $\mathrm{mV}$ foi estabelecido. Os valores de potencial zeta foram calculados a partir da média de valores de mobilidade eletroforética utilizando a equação de Smoluchowski (Chandrasekhar, 1943).

A morfologia das NLS e Hy-NLS foi determinada por Microscopia Eletrônica de Transmissão (MET). Para tanto, a suspensão de nanopartículas diluída em água purificada $(1: 10 \mathrm{v} / \mathrm{v})$ foi depositada sobre grades de cobre revestida com carbono (CF300-Cu, EMS) e secada durante $24 \mathrm{~h}$ à temperatura ambiente. O microscópio (JEM-1011 TEM, JEOL, Peabody, MA, EUA) foi utilizado a uma tensão de 
aceleração de 100 kV. Para a análise morfológica o equipamento foi operado em modo de campo luminoso com ampliação acima de 10.000 x.

\subsubsection{Determinação do teor e eficiência de encapsulação da Hy e FtZnT}

Para a determinação do teor de FS (concentração total) nas nanopartículas, uma alíquota de cada suspensão coloidal foi quantitativamente transferida para um balão volumétrico de $1,0 \mathrm{~mL}$ e o volume final foi completado com metanol. As amostras foram centrifugadas antes das medidas de absorbância do sobrenadante para determinar a concentração total de FS na suspensão. A eficiência de encapsulação (EE \%) foi estimada como sendo a diferença entre a concentração total de FS e aquela encontrada no ultrafiltrado, obtido após ultrafiltração/centrifugação das suspensões coloidais utilizando unidades de filtração Ultrafree - MC (100.000 MWCO, Millipore, EUA) de acordo com a equação:

Eficiência de Encapsulação (\%) = Concentração total de FS - FS livre x 100

\subsection{Fotodegradação da Hy e Hy-NLS}

A fotoestabilidade do Hy-NLS foi avaliada em comparação com Hy em solução $0,1 \%$ de etanol. A fotodegradação do Hy foi monitorada através do seu espectro de absorção no intervalo de comprimento de onda de $300-700 \mathrm{~nm} .10 \mathrm{~mL}$ de Hy ou Hy-NLS em solução de etanol 0,1\% (4,0 $\left.\mu \mathrm{g} \mathrm{mL}^{-1}\right)$ foram expostas durante diferentes intervalos de tempo ao LED $590 \pm 10 \mathrm{~nm}$ de intensidade $10 \mathrm{~mW} \mathrm{~cm}^{-2}$. A absorbância da amostra foi medida antes da irradiação $(\mathrm{t}=0)$ e após a irradiação com os seguintes intervalos de tempo: 10, 20, 30 e 40 min. No caso da Hy-NLS, as amostras foram irradiadas nos mesmos intervalos de tempos e a hipericina foi então extraída das nanopartículas utilizando um volume igual de etanol a $80{ }^{\circ} \mathrm{C}$ para fundir os lipídeos seguido por abaixamento brusco da temperatura à $2{ }^{\circ} \mathrm{C}$ e centrifugação a 5000 rpm para precipitar os lipídeos. O sobrenadante contendo a Hy extraída foi filtrado através de filtros de 0,22 $\mu \mathrm{m}$ para retirar os lipídeos em suspensão. Finalmente a absorbância em $590 \mathrm{~nm}$ foi determinada. Para a correção da linha de base foi utilizado um branco de suspensão de NLS diluída apropriadamente dissolvido com etanol para eliminar qualquer possível absorção proveniente do 
lipídeo solúvel. Todo cuidado foi tomado para manter as condições experimentais semelhantes para todas as amostras. Apenas os valores de $p$ menores que 0,05 foram considerados diferença significativas. Os dados finais foram expressos como a média \pm SD $(n=3)$ (Youssef, Fadel et al., 2012).

\subsection{Dependência entre fluorescência e concentração da Hy e Hy- NLS}

Este experimento foi proposto para investigar o efeito da agregação na produção de ${ }^{1} \mathrm{O}_{2}$, pois a partir dos resultados de fluorescência foram preparados os experimentos de atividade fotodinâmica para a hipericina nestas concentrações. Várias soluções de Hy e Hy-NLS com concentração de 0-1,0 × 10-6 $\mathrm{mol} \mathrm{L}^{-1} \mathrm{em}$ tampão fosfato $\mathrm{pH} 7,0+0,001 \%$ de Tween 20 foram preparadas. Para acompanhar a agregação foi monitorada a intensidade de fluorescência com excitação em 545 nm e emissão de fluorescência em 602 nm.

\subsection{Atividade fotodinâmica da Hy e Hy-NLS}

\subsubsection{Constante de velocidade de foto-decomposição do DPBF ( $\left.\mathbf{k}_{\mathrm{DPBF}}\right)$}

1,3-Difenilisobenzofurano (DBPF) reage irreversivelmente com ${ }^{1} \mathrm{O}_{2}$, passando por uma fotodecomposição caracterizada por uma cicloadição que é detectada como uma diminuição na intensidade da banda de absorção do DPBF, por isso o DPBF foi usado como um reagente de captura de ${ }^{1} \mathrm{O}_{2}$ (Howard e Mendenhall, 1975; Fujii, Usui et al., 2004). Para o experimento, $10 \mathrm{~mL}$ de solução contendo $5,00 \times 10^{-7} \mathrm{~mol} \mathrm{~L}^{-1} \mathrm{de}$ FS e $1,85 \times 10^{-4} \mathrm{~mol} \mathrm{~L}^{-1}$ de DPBF em tampão de fosfato e $0,001 \%$ de Tween 20 foram irradiados com os LEDs amarelo e vermelho para a Hy e FtZnT, respectivamente em vários intervalos de tempo. A absorbância da solução em 416 $\mathrm{nm}$ foi medida nestes tempos de com o objetivo de determinar a constante de velocidade de fotodecomposição do DPBF. Para a correção da linha de base foi utilizado um branco constituído de uma suspensão de NLS diluída apropriadamente e dissolvida em uma solução de tampão fosfato e $0,001 \%$ de Tween 20 para eliminar qualquer possível absorção proveniente do lipídeo solúvel (Redmond e Gamlin, 1999; Rossi, Silva et al., 2008; Xiao, Gu et al., 2011). 


\subsubsection{Constante de velocidade de fotodecomposição do ácido úrico $\left(\mathbf{k}_{\mathrm{AU}}\right)$}

Amostras contendo $1,0 \times 10^{-6} \mathrm{~mol} \mathrm{~L}^{-1}$ de FS e $6,0 \times 10^{-5} \mathrm{~mol} \mathrm{~L}^{-1}$ de ácido úrico (AU) em solução de tampão fosfato e $0,001 \%$ de Tween 20 foram irradiadas com LED $590 \pm 10 \mathrm{~nm}$ (para Hy) e LED $630 \pm 10 \mathrm{~nm}$ (para FtZnT) em vários intervalos de tempo. A absorbância da solução em $291 \mathrm{~nm}$ foi monitorada nestes tempos de irradiação visando a determinação da constante de velocidade de fotodecomposição do ácido úrico. Para a correção da linha de base foi utilizado um branco contendo uma suspensão de NLS diluída apropriadamente dissolvida em uma solução de tampão fosfato e $0,001 \%$ de Tween 20 para eliminar qualquer possível absorção proveniente do lipídeo solúvel (Fischer, Graschew et al., 1998; Gerola, Semensato et al., 2012; Rabello, Gerola et al., 2012).

\subsection{Cultura celular}

\subsubsection{Linhagens celulares}

Nos ensaios citotóxicos foram utilizadas as linhagens de células epiteliais de carcinoma epidermóide de laringe humana, HEp-2 (ATCC CCL-23) e de melanoma de camundongo B16-F10 (ATCC CRL-6475).

Devido as suas morfologias, essas linhagens foram cultivadas aderidas a um substrato sólido, ou seja, garrafas de polipropileno, em meio de cultura Dulbecco modificado por Iscove com $10 \%$ de soro fetal bovino (SFB) e antibióticos como penicilina 10000 U.I. $\mathrm{mL}^{-1}$ e estreptomicina $10 \mathrm{mg} \mathrm{mL}^{-1}$, todos obtidos da Cultilab. As células foram mantidas em estufa a $37{ }^{\circ} \mathrm{C}, 95 \%$ de ar e $5 \%$ de $\mathrm{CO}_{2}$ gasoso (Freshney, R. I., 1994 e Harrison, M. A; et al., 1997). Todas as manipulações celulares foram realizadas em ambiente estéril, numa capela de fluxo laminar, com materiais esterilizados a fim de se evitar contaminação celular (Pelczar, J.R., et al, 2005).

\subsubsection{Congelamento e descongelamento das células}

Para a preservação das células instáveis em culturas bem como para a manutenção de um estoque de células que pode vir a ser utilizado por longos períodos e também em casos de uma eventual contaminação, o congelamento de 
um estoque celular é fundamental. Desta forma utiliza-se a técnica da criopreservação que consiste na estocagem de células a temperaturas muito baixas de modo a inibir qualquer atividade enzimática.

Os crioprotetores são substâncias utilizadas para prevenir danos às células durante o processo de congelamento devido principalmente ao crescimento de cristais de gelo e às trocas osmóticas. O dimetil sulfóxido (DMSO) e o glicerol são dois tipos de crioprotetores bastante utilizados, mas neste trabalho foi utilizado o DMSO (Harrison, M. A., 1997).

Para o congelamento, removeu-se as células do frasco de cultura e preparase uma suspensão com concentração de $2 \times 10^{6}$ células $\mathrm{mL}^{-1}$ em meio de cultura contendo $10 \%$ de SFB e $10 \%$ de DMSO. A seguir as células são aliquotadas em frascos criogênicos apropriados e armazenadas em nitrogênio liquido a $-196{ }^{\circ} \mathrm{C}$ ou freezer a -80C (Freshney, R. I., 1994).

O descongelamento das células é feito quando se necessitar de células para o cultivo. Para fazer esse descongelamento, retira-se os frascos com células do tambor de criogenia ou freezer, faz-se a homogeneização de seu conteúdo que é transferido para uma garrafa de cultura contendo meio de cultura com $10 \%$ de SFB e procede-se conforme descrito anteriormente (Freshney, R. I., 1994).

\subsubsection{Subcultivo das células}

O subcultivo das células foi feito a cada três dias removendo-se o meio de cultura seguido da adição de solução salina tamponada com fosfato (PBS) pH 7,4 para retirar o resto de meio de cultura e adição da enzima proteolítica tripsina com 0,03\% de etilenodiaminotetracético (EDTA) para digerir as proteínas na matriz extracelular, uma vez que é um agente quelante que liga ou quela o $\mathrm{Ca}^{2+}$ do qual depende a adesão entre as células. A tripsina pode ser prejudicial às células, portanto deve-se adicionar meio de cultura logo após a desagregação das células a fim de inativar a tripsina pela ação do soro. A seguir as células foram transferidas para um tubo cônico e centrifugadas a 1000 rpm durante 1 minuto, descartou-se o sobrenadante para posterior ressuspensão das células em meio de cultura (Freshney, R. I., 1994).

Após homogeneização das células em meio de cultura, retirou-se uma alíquota para contagem do número de células. As células foram contadas em 
hemocitômetro e distribuídas, conforme a concentração celular desejada, em frascos de cultura ou placas apropriadas para os ensaios citotóxicos e de acumulação, (www.atcc.org).

\subsubsection{Viabilidade celular}

Para a determinação da viabilidade celular foi utilizado o método da contagem em câmara de Newbauer através do teste de exclusão do corante. O "trypan blue" é um corante que é incorporado seletivamente pelas células mortas nas quais a integridade da membrana celular é danificada (rompida). Para isso foi retirada uma alíquota de $100 \mu \mathrm{L}$ da suspensão celular, $500 \mu \mathrm{L}$ de PBS como diluente e $400 \mu \mathrm{L}$ de solução $0,4 \%$ de "trypan blue". Foi retirada uma alíquota desta suspensão celular e diluída 100 vezes, para em seguida ser colocada uma alíquota desta suspensão celular na câmara de Newbauer para fazer a contagem celular. As células de todos os quadrantes foram contadas e a média dos valores obtida foi multiplicada por $10^{4} \mathrm{e}$ pelo fator de diluição 10 obtendo-se desta forma o número de células $\mathrm{mL}^{-1}$ de suspensão (Freshney, R. I., 1994).

Para a determinação da viabilidade celular, calcula-se separadamente 0 número de células vivas e mortas, levando-se em conta que as células vivas apresentam-se incolores ao microscópio, enquanto que as células mortas apresentam uma coloração violeta devido à incorporação do corante. Calcula-se a viabilidade celular em porcentagem (\%) através da seguinte relação:

$$
\% \text { Viabilidade }=\frac{\text { número de células não coradas }}{\text { número total de células }} \times 100
$$

\subsection{Ensaios citotóxicos}

Para os experimentos citotóxicos foram plaqueadas, em placas de cultura de 96 poços, $1,0 \times 10^{5}$ células $\mathrm{mL}^{-1}$ em meio de cultura e incubadas a $37^{\circ} \mathrm{C}$ e $5 \%$ de $\mathrm{CO}_{2}$ gasoso. Após 24 horas, removeu-se o meio de cultura por meio de aspiração e "lavou-se" a monocamada de células com PBS. As células então foram incubadas com diferentes faixas de concentração de FSs livres e FS-NLS por até 24 horas. Após esse período de incubação, os FSs foram retirados lavando-se novamente as 
células com PBS. Em seguida adicionou-se meio de cultura e as placas foram irradiadas com os LEDs específicos para cada FS em diferentes intervalos de tempos. Foi feito também o controle para verificar se ocorre a morte celular somente com o FS, ou seja, sem a irradiação. Após a irradiação das células estas foram mantidas na estufa de cultura por 24 horas. Esse intervalo é considerado ideal para o encerramento de ensaios de sobrevivência após tratamento fotodinâmico, já que tempos de incubação menores podem não permitir que as células se recuperem totalmente do tratamento a que foram submetidas e intervalos maiores podem acarretar um aumento muito grande no número de células dificultando a contagem (Butler, M., 1991).

\subsection{Ensaio com MTT}

Após o período de recuperação, as células foram tratadas com 3-4,5dimetiltiazol-2-il-2,5-difenil brometo de tetrazólio (MTT). Este método de contagem de células baseia-se na redução do MTT, um composto amarelo que é reduzido a um produto violeta chamado formazam que absorve em $570 \mathrm{~nm}$. A redução é feita pelas desidrogenases mitocondriais presentes somente nas células vivas. Após três horas de incubação o meio com MTT foi retirado, tendo o cuidado para não danificar os cristais de formazam formados. Após a retirada do MTT, adicionou-se $50 \mu \mathrm{L}$ de álcool etílico e $150 \mu \mathrm{L}$ de uma mistura de PBS com álcool isopropílico na proporção de 1:1. A absorbância proveniente da solução resultante de cada poço da placa foi lida em um leitor de placas com filtro em 550 nm (Denizot e Lang, 1986; Carmichael, Degraff et al., 1987). Para se obter o valor da concentração inibitória média $\left(\mathrm{IC}_{50}\right)$, que representa a concentração de FS capaz de inativar $50 \%$ da população de células, foi utilizado o programa CalcuSyn (Chou, T. C., 1996).

\subsection{Acumulação intracelular dos FSs livres e incorporados em NLS}

Esses experimentos foram realizados para comparar as diferenças de acumulação dos FS livres e FS em NLS em células tumorais verificando-se a concentração de FS que foi acumulada em cada linhagem celular em função do tempo de incubação. As concentrações dos FSs foram normalizadas pela concentração de proteína na amostra que é diretamente proporcional ao número de 
células. Para isso, a concentração de proteína foi determinada pelo método de Lowy que utiliza o reagente de Folin-Cioucalteau que se liga a aminoácidos aromáticos em tartarato de cobre alcalino resultando em uma coloração azul (Lowry, Rosebrough et al., 1951).

A curva padrão foi obtida pela absorbância de concentrações conhecidas de BSA obtendo-se um gráfico de absorbância em função da concentração de BSA $\left(0,02-0,2 \mathrm{mg} \mathrm{mL}^{-1}\right)$. A relação foi linear e assim foi possível, através da equação da reta, estimar a concentração protéica a partir da absorbância em 750 nm. Foi também determinada a curva padrão da Hy e FtZnT livres em soluções de etanol e DMSO respectivamente através da fluorescência (Huygens, Huyghe et al., 2003).

Cinco $\mathrm{ml}$ de suspensão contendo $2,0 \times 10^{5}$ células $\mathrm{mL}^{-1} 1$ em placas de Petri de $60 \mathrm{~mm}$ de diâmetro foram incubados e após 24 horas o meio de cultura foi retirado adicionando-se $0,5 \mu \mathrm{g} \mathrm{mL} \mathrm{mL}^{-1}$ de FS solubilizado em meio de cultura e após determinados intervalos de tempo de incubação (0, 30 min, 1 h e 2 h para a Hy e HyNLS) e $(0,12$ h, 18, e 24 h para a FtZnT e FtZnT-NLS) retirou-se o meio de cultura com o FS, lavou-se a monocamada celular com PBS. A diferença de tempo de acumulação entre Hy e FtZnT foi grande devido ao fato que em tempos menores de acumulação não ocorreu a incorporação da FtZnT pelas células estudadas. Adicionou-se $1 \mathrm{~mL}$ de tripsina/EDTA e após 1 minuto foi feita a transferência da suspensão celular para um tubo cônico. A suspensão foi centrifugada por 1 minuto a 1000 rpm e o sobrenadante foi retirado. Adicionou $1 \mathrm{~mL}$ de PBS ao sedimento celular, agitou-se levemente o tubo que foi centrifugado novamente. Este ultimo procedimento foi repetido novamente. Logo após, adicionou-se $500 \mu \mathrm{L}$ de PBS e resuspendeu-se o sedimento celular, Uma alíquota de $100 \mu \mathrm{L}$ foi retirada para determinação de proteína. O restante foi centrifugado, retirou-se o sobrenadante e adicionou-se $1 \mathrm{~mL}$ de etanol para extrair a Hy e $1 \mathrm{~mL}$ de DMSO para extrair a FtZnT. Após leve agitação aguardou-se 1 hora e fez-se nova centrifugação por 10 minutos a 1000 rpm, procedendo-se a leitura de fluorescência (Soncin, Fabris et al., 2002). Dessa forma, pode-se determinar a concentração intracelular do FS normalizada pela concentração de proteína. 


\subsection{Cálculo da média amostral e do desvio padrão e análise estatística dos dados experimentais}

Os valores experimentais foram expressos como média \pm desvio padrão sendo que os cálculos foram realizados segundo as equações abaixo (Barros et al,1996):

$$
\overline{X i}=\frac{\sum_{i=1}^{n} x i}{n}
$$$$
S j=\sqrt{\frac{\sum_{i=1}^{n}(x i-\overline{X j})^{2}}{n-1}}
$$

Sendo:

$\overline{\mathrm{Xi}}=$ média amostral

$\mathrm{Xi}=\mathrm{i}$-ésima observação

$\mathrm{n}=$ número total de observações

$\mathrm{S} j$ = estimativa do desvio padrão

O número de experimentos é dado na legenda de cada figura. A análise estatística dos valores experimentais foi feita utilizando-se o test-t de Student para mostrar a significância da diferença entre pares de médias. O nível de significância foi de $p<0,05$ para todas as análises estatísticas. Todos os tratamentos estatísticos foram realizados no programa Microsoft Office Excel 2007. 


\section{Resultados e discussões}

\subsection{Hipericina}

\subsubsection{Preparação e caracterização das Nanopartículas lipídicas sólidas (NLS) e Hy-NLS}

No preparo das NLS brancas (sem hipericina) e das NLS contendo o FS (HyNLS) foram obtidas partículas esféricas com poucos aglomerados (Figura 8) e tamanho médio de $129 \pm 10$ e $153 \pm 6 \mathrm{~nm}$, respectivamente, como mostra a Tabela 1.

a)

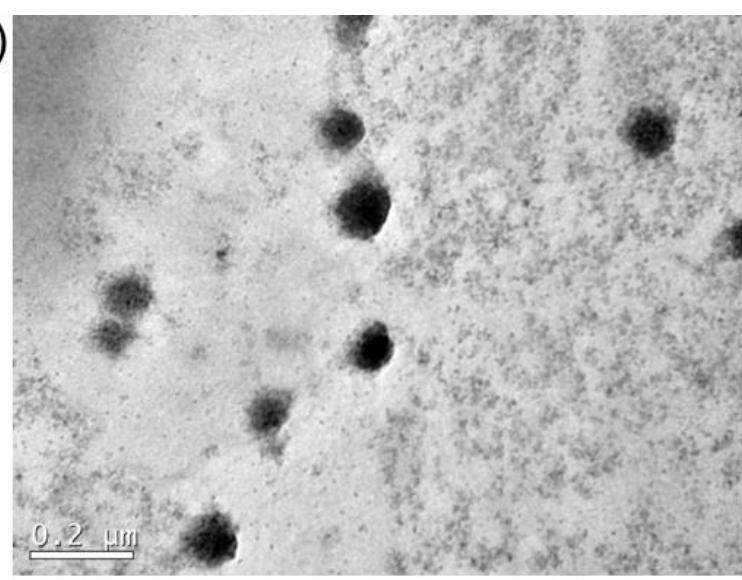

b)

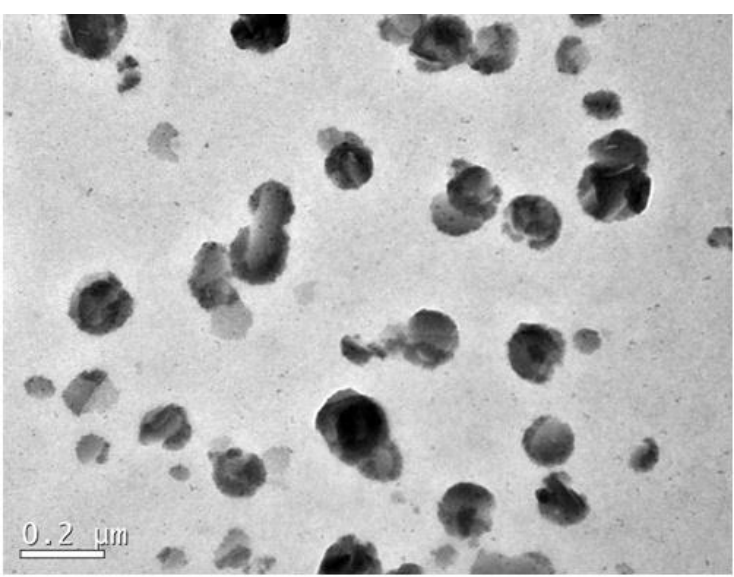

Figura 8: Microscopia eletrônica de transmissão das nanopartículas (barras $=0,2 \mu \mathrm{m}$ ). a) NLS e b) Hy-NLS.

Tabela 1:Características dos NLS: tamanho médio, índice Polidispersão (IP), potencial Zeta (PZ) e Eficiência de Encapsulação das Hy-NLS (média \pm desvio padrão, $n=3$ ).

\begin{tabular}{ccccc}
\hline NLS & $\begin{array}{c}\text { Diâmetro } \\
\text { médio }(\mathbf{n m})\end{array}$ & $\begin{array}{c}\text { Índice de } \\
\text { polidispersão }\end{array}$ & $\begin{array}{c}\text { Potencial } \\
\text { Zeta }(\mathbf{m V})\end{array}$ & $\begin{array}{c}\text { EE } \\
\mathbf{( \% )}\end{array}$ \\
\hline NLS & $129 \pm 10$ & $0,26 \pm 0,01$ & $-18,3 \pm 2$ & - \\
Hy-NLS & $153 \pm 6$ & $0,28 \pm 0,02$ & $-18,5 \pm 1$ & $83,5 \pm 2$ \\
\hline
\end{tabular}

Não se observou alteração significativa $(p>0,05)$ entre os índices de polidispersão das NPs com e sem a hipericina. A eficiência de encapsulação é outra medida usada para a caracterização de nanopartículas, sendo o valor obtido para a EE de 83,5 $\pm 2 \%$, considerado um valor alto segundo a literatura (Schaffazick, Pohlmann et al., 2003; Zeisser-Labouebe, Lange et al., 2006), pois significa que a 
maior parte do FS está incorporado nas nanopartículas, evitando assim a agregação na sua forma livre. Os valores negativos do potencial zeta foram provenientes da lecitina utilizada para estabilizar as nanopartículas, ou seja, estes valores negativos ajudam a estabilizar as nanopartículas por repulsão de cargas e evitando a aglomeração das NLS. Os valores de PZ das NLS brancas e Hy-NLS foram de -18,3 \pm 2 e -18,5 $\pm 1 \mathrm{mV}$ respectivamente não mostrando alteração significativa $(p>0,05)$.

A encapsulação de compostos em NLS sejam eles fármacos ou FSs, tem levado a resultados satisfatórios quanto ao tamanho, índice de polidispersão, potencial Zeta e eficiência de encapsulação. Guo e colaboradores encapsularam 2methoxy-estradiol (2-ME) em NLS e obtiveramtamanho inferior a $200 \mathrm{~nm}$, EE acima de $85 \%$ e potencial zeta em torno de - $40 \mathrm{mV}$ (Guo, Xing et al., 2012). Youssef e colaboradores encapsularam Hy em NLS e obtiveram um diâmetro médio acima de $200 \mathrm{~nm}$, a eficiência de encapsulação foi maior que $80 \%$ e o índice de polidispersão obtido foi acima de 0,30 , porém os resultados de fototoxicidade em células HepG2 foram menos eficientes comparado com a Hy livre (Youssef, Fadel et al., 2012).

A Figura 9 mostra os espectros de absorção de Hy e Hy-NLS em tampão fosfato $\mathrm{pH} 7,0$, é possível observar o aumento da absorção no espectro da Hy encapsulada em NLS. Isso pode ser explicado pela diminuição na formação de agregados de Hy em meio aquoso e assim aumentando a absorção da hipericina (Rossi, Silva et al., 2008).
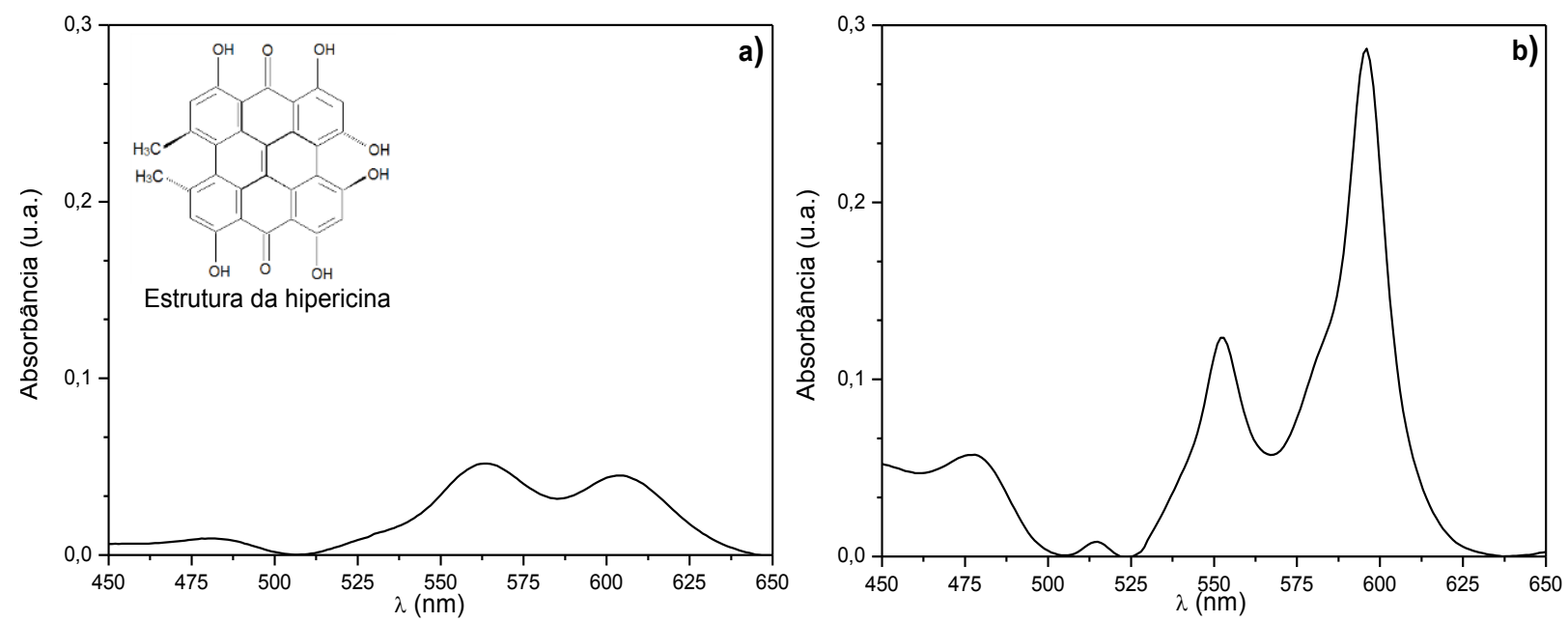

Figura 9: Espectro de absorção de 5,0 $\mathrm{gg} \mathrm{mL}^{-1}$ de a) Hy e b) Hy-NLS em tampão fosfato $\mathrm{pH}$ 7,0. 


\subsubsection{Fotodegradação da Hy e Hy-NLS}

Como mostra a Figura 10, após a foto-irradiação da Hy e da Hy encapsulada com NLS em $0,1 \%$ de etanol com LED $590 \pm 10 \mathrm{~nm}$ e intensidade de luz de $10 \mathrm{~mW} \mathrm{~cm}^{-2}$ por vários intervalos de tempo (0 a $40 \mathrm{~min}$ ) a fotodegradação da Hy livre foi significativamente maior que a Hy-NLS com valor de $p<0,05$.
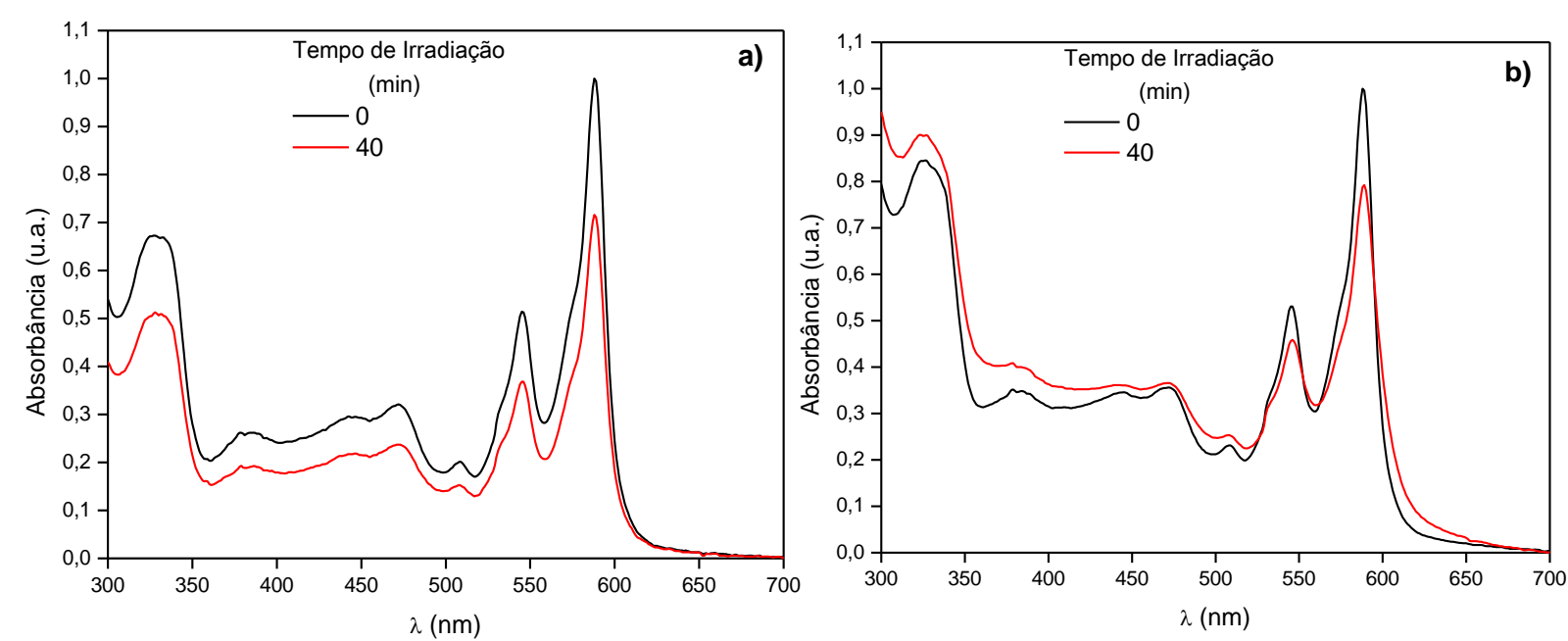

Figura 10: Espectro de absorção de 4,0 $\mathrm{g} \mathrm{mL}^{-1}$ de a) Hy e b) Hy-NLS em etanol antes e depois da irradiação com LED $590 \pm 10 \mathrm{~nm}, \mathrm{I}=10 \mathrm{~mW} \mathrm{~cm}^{-2}$ por vários intervalos de tempos de irradiação $(0,5$, $10,15,20,25,30,35$ e 40 minutos).

Após 40 minutos de irradiação ocorreu uma fotodegradação significativa daHy livre e Hy-NLS $(p<0,05)$ com valores de $37,6 \pm 3 \%$ e 18,5 \pm 0,2\%, respectivamente, como mostra a Figura 11. O encapsulamento da Hy em NLS aumentou a fotoestabilidade uma vez que diminuiu sua fotodegradação em comparação com a Hy livre. 


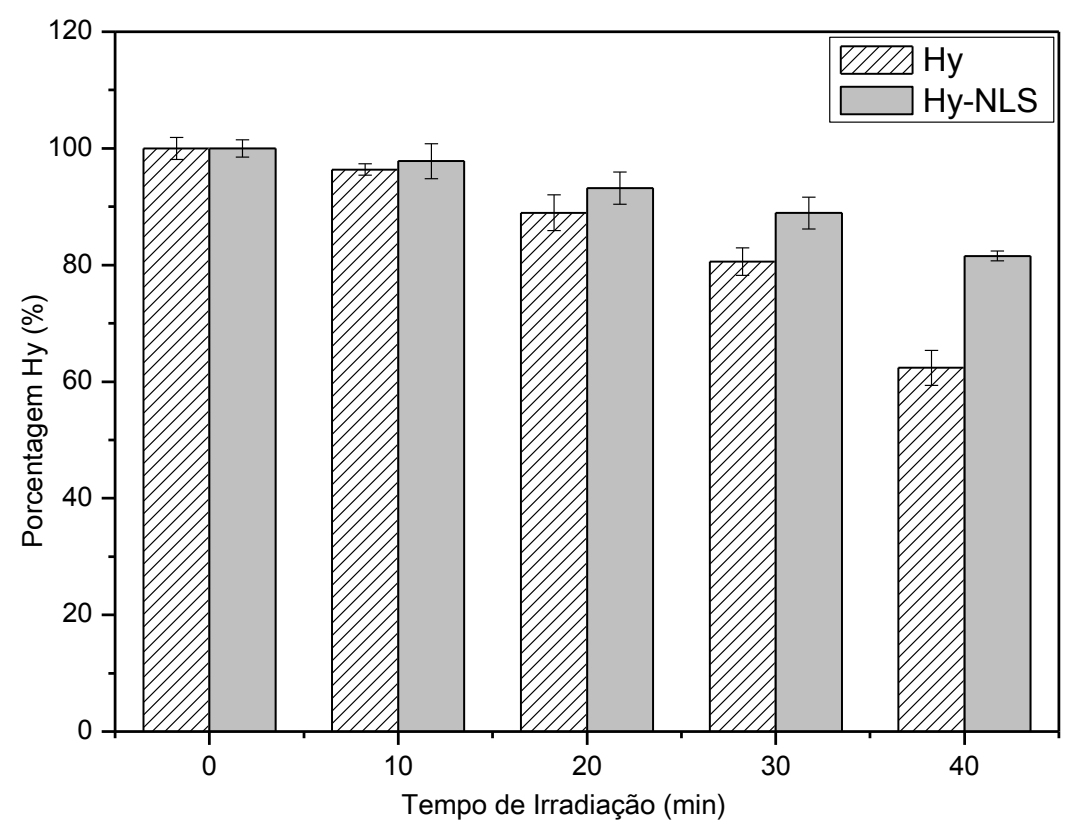

Figura 11: Porcentagem de Hy e Hy-NLS remanescentes após a irradiação com LED $590 \pm 10 \mathrm{~nm}$, I $=10 \mathrm{~mW} \mathrm{~cm}^{-2}$ por vários intervalos de tempos de irradiação $(0,10,20,30$ e 40 minutos) em solução $0,1 \%$ de etanol.

Shah e colaboradores fizeram a fotodegradação de tretinoína livre e encapsulada em NLS, obtendo $88 \%$ de fotodegradação de tretinoína livre e $29 \%$ de fotodegradação de tretinoína em NLS com irradiação por 180 minutos (Shah, Date et al., 2007). Youssef e colaboradores fizeram a fotodegradação da Hy livre e encapsulada em NLS, obtendo $15,6 \%$ de fotodegradação para Hy livre e $6 \%$ de fotodegradação para Hy em NLS após a irradiação com LED de 550 nm e intensidade de luz de $80 \mathrm{~mW} \mathrm{~cm}^{-2}$ durante 35 minutos (Youssef, Fadel et al., 2012).

A melhoria da foto-estabilidade da Hy indica que o FS fica mais protegido da fotodegradação quando este está incorporado em matrizes de NLS. Portanto a encapsulação da Hy em nanopartículas lipídicas sólidas apresentou um bom potencial para melhorar a foto-estabilidade da hipericina, assim podendo ser utilizada como uma estratégia de entrega de medicamentos e fotossensibilizadores por exemplo.

\subsubsection{Dependência entre fluorescência e concentração da Hy e Hy-NLS}

A Hy é insolúvel em tampão fosfato $\mathrm{pH}$ 7,0, portanto para fazer os experimentos de determinação das constantes de foto-oxidação do ácido úrico e do DPBF, foi necessário utilizar o Tween 20 como surfactante. Foram preparadas várias 
concentrações de Hy e Hy-NLS em tampão fosfato pH 7,0 contendo $0,001 \%$ de Tween 20 para as medidas de fluorescência, com excitação em 545 nm e emissão de fluorescência em 602 nm como apresenta a Figura 12.
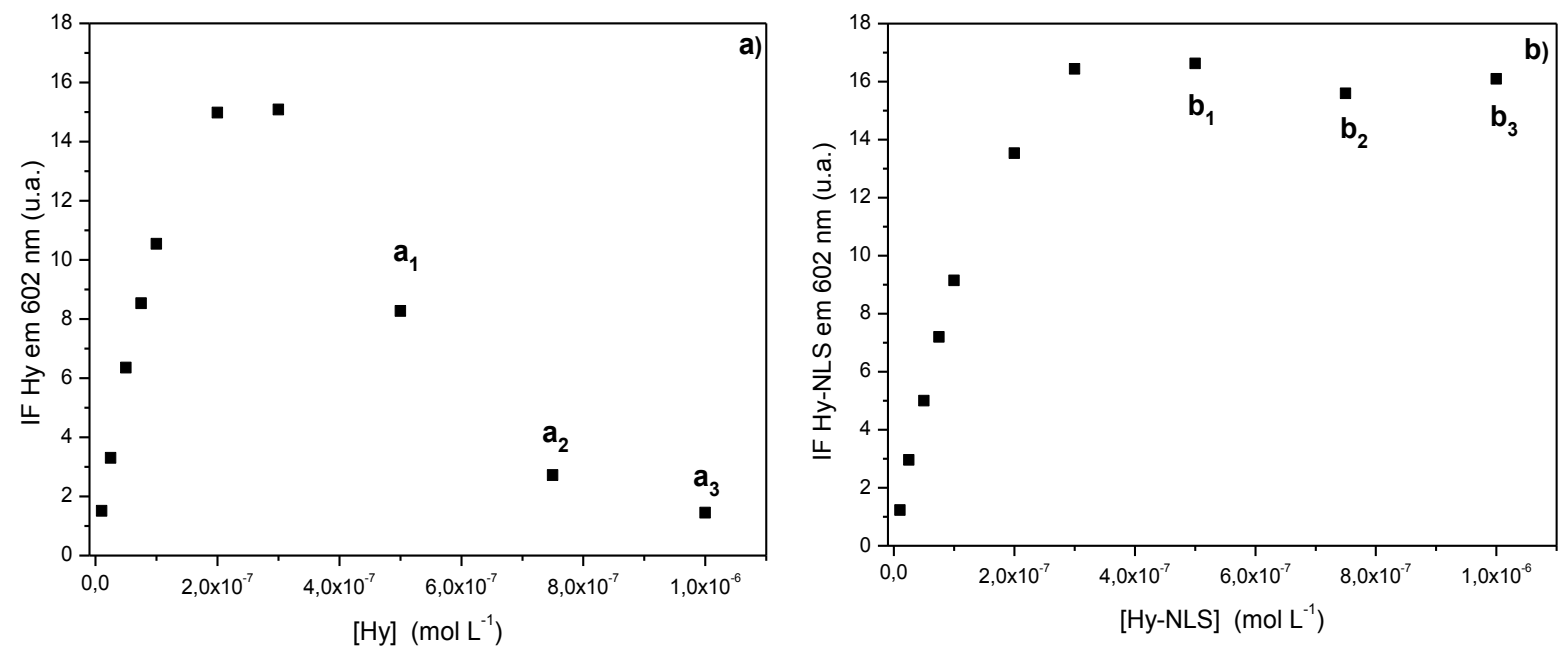

Figura 12: Intensidade de fluorescência da Hy em função de sua concentração em tampão fosfato $\mathrm{pH}$

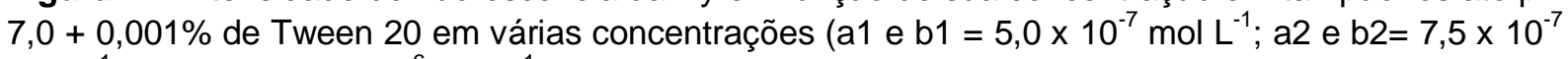
mol L-1; a3 e b3 $=1,0 \times 10^{-6} \mathrm{~mol} \mathrm{~L}^{-1}$ ) de a) Hy e b) Hy-NLS.

Após as medidas de fluorescência foram escolhidas as três concentrações de Hy e Hy-NLS em que ocorreram maior agregação $\left(5,0 \times 10^{-7}, 7,5 \times 10^{-7}\right.$ e $1,0 \times 10^{-6}$ mol $\mathrm{L}^{-1}$ ) para determinar as constantes de foto-oxidação do DPBF e do AU que foram obtidas observando-se 0 decaimento da fluorescência para altas concentrações dos fotossensibilizadores. Observando a Figura 12 pode-se perceber que a Hy sofre maior agregação a partir da concentração $2,5 \times 10^{-7} \mathrm{~mol} \mathrm{~L}^{-1}$ do que a Hy encapsulada em NLS, pois segundo a literatura somente os monômeros fluorescem, portanto quanto maior a formação de agregados menor será a intensidade de fluorescência emitida pelos FSs(Margalit e Cohen, 1983; Margalit, Shaklai et al., 1983; Margalit e Rotenberg, 1984).

\subsubsection{Atividade Fotodinâmica da Hy e Hy-NLS}

\section{Constante de velocidade de fotodecomposição do DPBF ( $\left.k_{\mathrm{DPBF}}\right)$}

A geração de oxigênio singlete por um FS pode ser caracterizada utilizando um captador de ${ }^{1} \mathrm{O}_{2}$. Spiller e colaboradores utilizaram o 1,3 Difenilisobenzofurano (DPBF) para determinar a eficiência na geração de ${ }^{1} \mathrm{O}_{2}$ para uma série de $\mathrm{FS}$. $\mathrm{O}$ 
DPBF reage irreversivelmente $\operatorname{com}{ }^{1} \mathrm{O}_{2}$, gerado pela foto-excitação do $\mathrm{FS}$, formando um endoperóxido (Figura 13) (Matheson, 1979; Spiller, Kliesch et al., 1998).

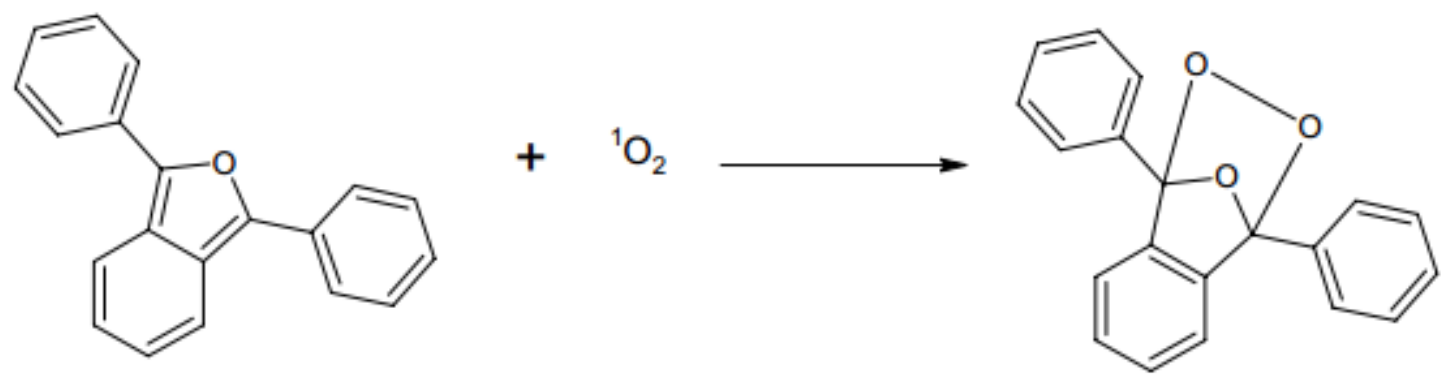

Figura 13: Reação do DPBF com oxigênio singlete levando a formação do endoperóxido (Matheson, 1979; Spiller, Kliesch et al., 1998).

Essa reação pode ser monitorada espectrofotometricamente pelo desaparecimento da banda de absorção característica do DPBF em torno de 410 nm. A absorção da luz emitida pelo LED $590 \pm 10 \mathrm{~nm}$ é proveniente apenas do FS, pois o DPBF não absorve na região de emissão do LED como mostra a Figura 14.

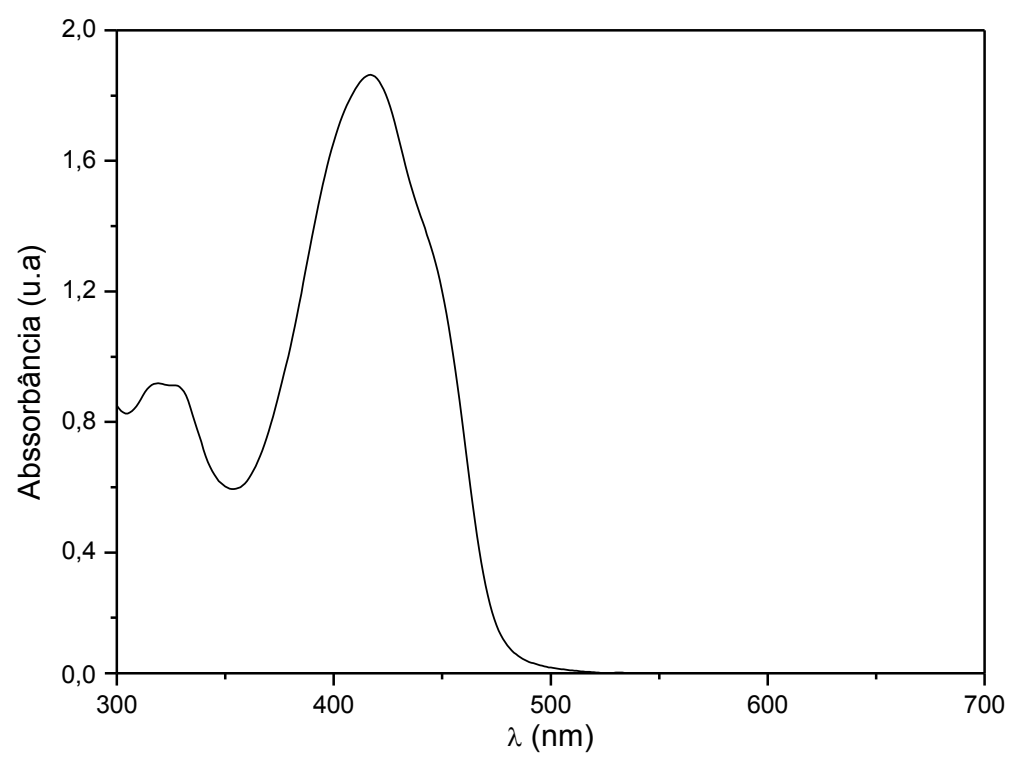

Figura 14: Espectro de absorção de $1,85 \times 10^{-4} \mathrm{~mol} \mathrm{~L}^{-1}$ de DPBF em tampão fosfato $\mathrm{pH} 7,0+0,001 \%$ Tween 20

A fotodecomposição do DPBF foi obtida após vários tempos de irradiação

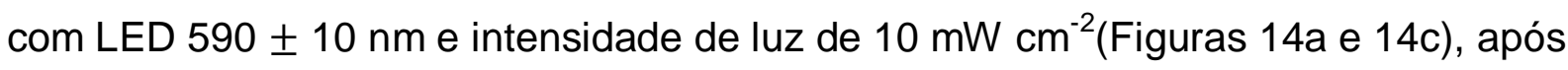
esta etapa foi determinado a $\mathrm{K}_{\mathrm{DPBF}}$ para os FSs e obteve-se os valores de $1,75 \pm$ $0,03 \times 10^{-3}$ e 2,80 $\pm 0,07 \times 10^{-3} \mathrm{~s}^{-1}$ para Hy livre e Hy-NLS em tampão fosfato $\mathrm{pH} 7,0$ com $0,001 \%$ Tween 20 , respectivamente (Figuras $14 \mathrm{~b}$ e $14 \mathrm{~d}$ ). Pode ser observado 
naTabela 2que o acréscimo da eficiência fotodinâmica utilizando a concentração de $5,0 \times 10^{-7} \mathrm{~mol} \mathrm{~L}^{-1}$ para a Hy e Hy-NLS foi de $60 \%$.
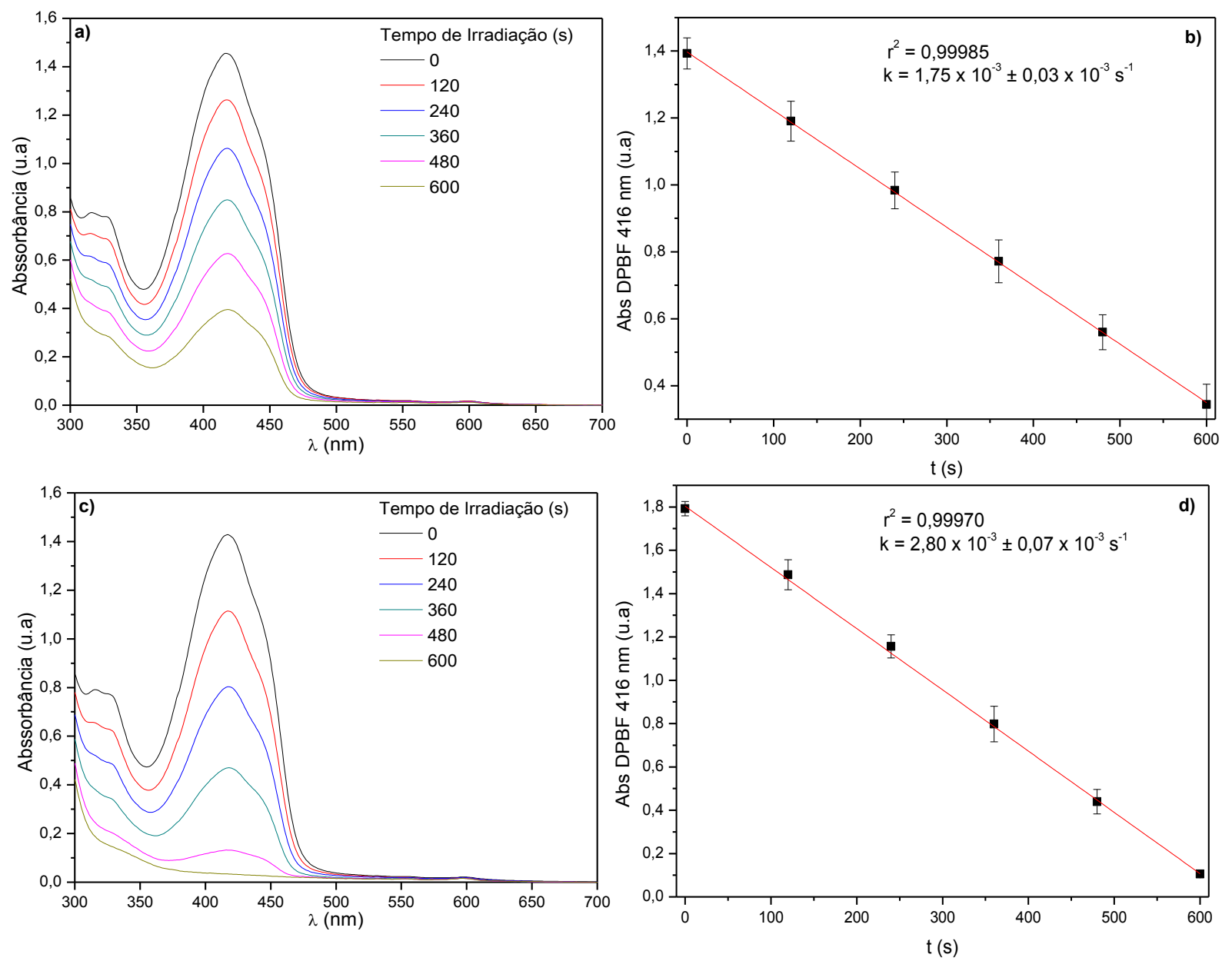

Figura 15: Espectros de absorção de $1,85 \times 10^{-4} \mathrm{~mol} \mathrm{L-1}$ de DPBF na presença de 5,00 $\times 10^{-7} \mathrm{~mol} \mathrm{~L}^{-1}$ de a) Hy e c) Hy-NLS em tampão fosfato $\mathrm{pH} \mathrm{7,0+0,001 \%} \mathrm{Tween} \mathrm{20.} \mathrm{Constantes} \mathrm{de} \mathrm{velocidade} \mathrm{de}$ decomposição do DPBF para b) Hy e d) Hy-NLS.

As figuras 15a e 15c mostram a decomposição do DPBF após vários tempos de irradiação com LED $590 \pm 10 \mathrm{~nm}$ e intensidade de luz de $10 \mathrm{~mW} \mathrm{~cm}{ }^{-2}$, após a irradiação foi determinado a $\mathrm{k}_{\mathrm{DPBF}}$ e foram obtidos os valores de 1,68 $\pm 0,03 \times 10^{-3} \mathrm{e}$ $3,12 \pm 0,23 \times 10^{-3} \mathrm{~s}^{-1}$ para Hy livre e Hy-NLS em tampão fosfato $\mathrm{pH} 7,0$ com $0,001 \%$ Tween 20 respectivamente como mostra as figuras $15 \mathrm{~b}$ e 15d. O aumento da eficiência fotodinâmica utilizando a concentração de $7,5 \times 10^{-7} \mathrm{~mol} \mathrm{~L}^{-1}$ (Hy e Hy-NLS) foi de $86 \%$ (Tabela 2). 

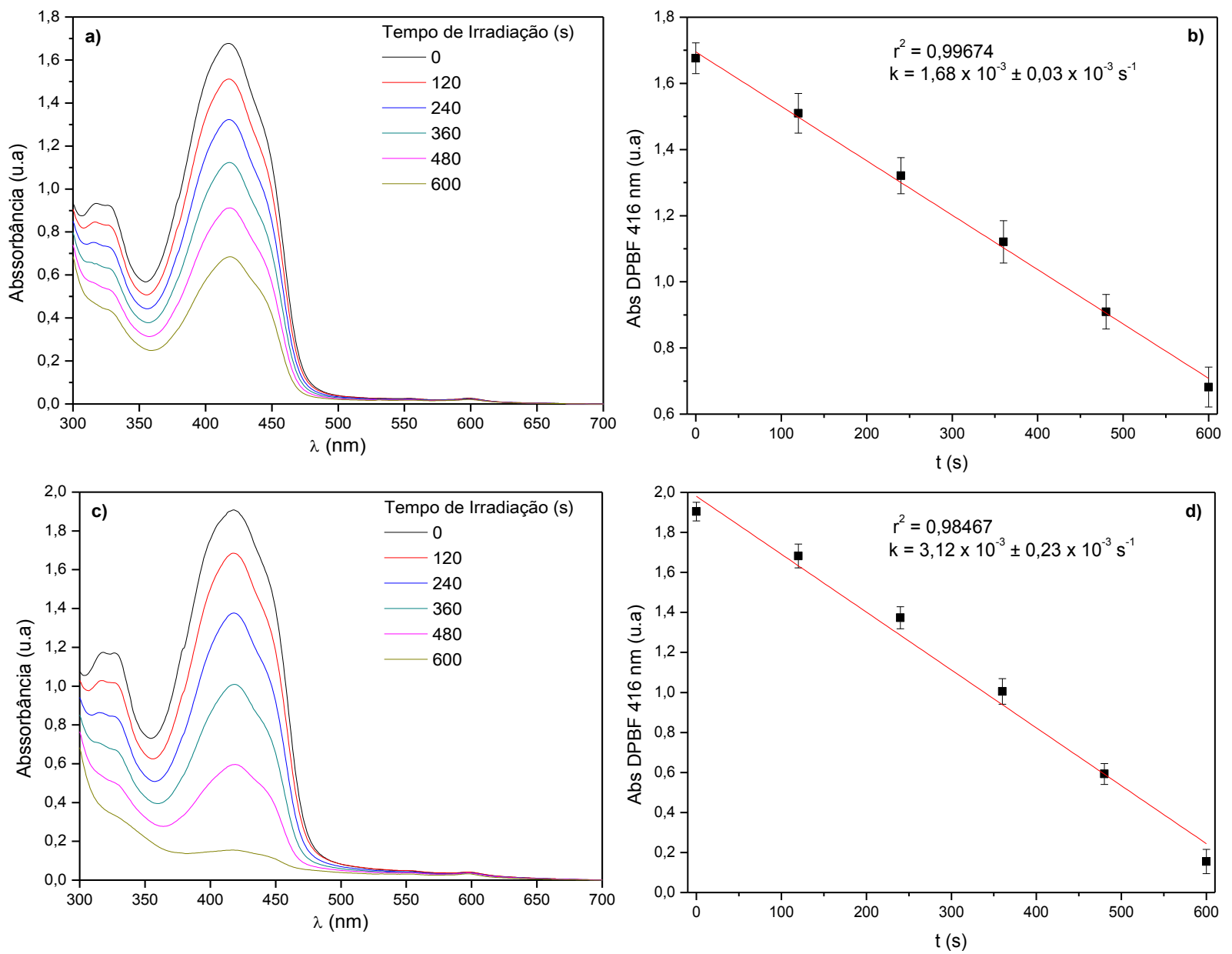

Figura 16: Espectros de absorção de 1,85 $\times 10^{-4} \mathrm{~mol} \mathrm{~L}^{-1}$ de DPBF na presença de $7,50 \times 10^{-7} \mathrm{~mol} \mathrm{~L}^{-1}$ de a) Hy e c) Hy-NLS em tampão fosfato $\mathrm{pH} \mathrm{7,0+0,001 \%} \mathrm{Tween} \mathrm{20.} \mathrm{Constantes} \mathrm{de} \mathrm{velocidade} \mathrm{de}$ decomposição do DPBF para b) Hy e d) Hy-NLS.

Para a concentração de $1,0 \times 10^{-6} \mathrm{~mol} \mathrm{~L}^{-1} \mathrm{O}$ aumento da eficiência fotodinâmica da Hy incorporada em NLS comparando com a Hy livre foi de $138 \%$ como é mostrado naTabela 2. 

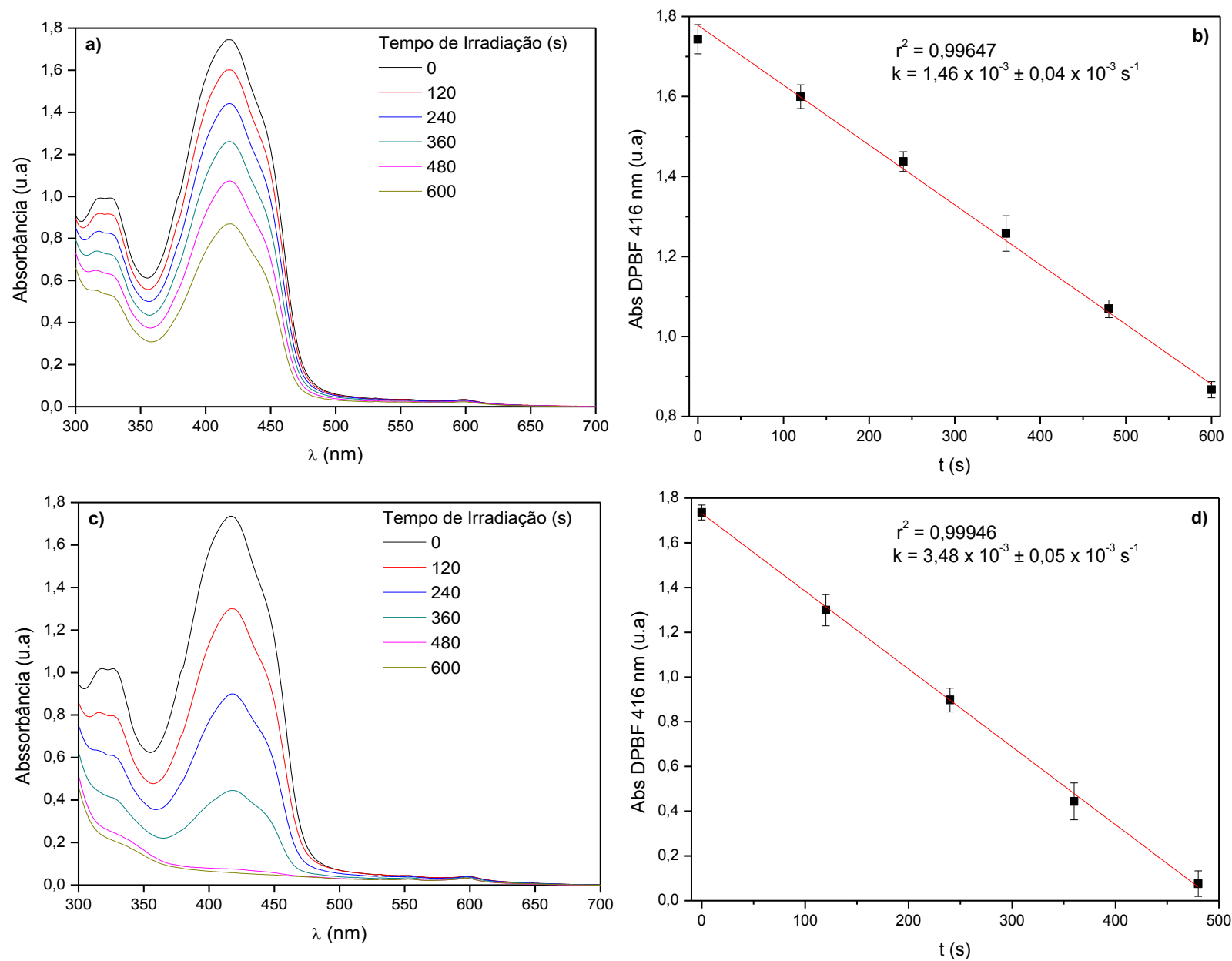

Figura 17: Espectros de absorção de $1,85 \times 10^{-4} \mathrm{~mol} \mathrm{~L}^{-1}$ de DPBF na presença de $1,00 \times 10^{-6} \mathrm{~mol}^{\mathrm{L}-}{ }^{1}$

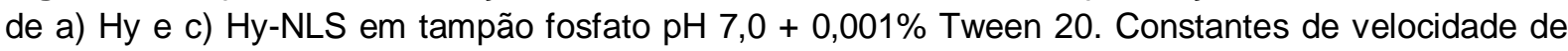
decomposição do DPBF para b) Hy e d) Hy-NLS.

Foram determinadas as constantes de decomposição do DPBF para três concentrações de Hy e Hy-NLS em que ocorrem maior agregação $\left(5,0 \times 10^{-7}, 7,5 \mathrm{x}\right.$ $10^{-7}$ e $1,0 \times 10^{-6} \mathrm{~mol} \mathrm{~L}^{-1}$ ) como foi discutido no item 4.1.3. Conforme foi aumentando a concentração de Hy livre, a intensidade de fluorescência foi diminuindo, enquanto que para a Hy-NLS a diminuição foi menos efetiva, isto ocorreu devido a maior agregação da Hy em comparação com a Hy encapsulada em NLS. Assim como mostram as figuras 14, 15 e 16 quando foi elevando a concentração dos FSs a $k_{D P B F}$ para a Hy foi diminuindo e a $\mathrm{k}_{\mathrm{DPBF}}$ foi acrescendo como mostra a Tabela 2. Segundo Rossi e colaboradores quanto maior for a agregação do FS, menor será a produção de oxigênio singlete e consequentemente sua eficiência será diminuída (Rossi, Silva et al., 2008). 
Tabela 2: Constantes de velocidade de decomposição do DPBF para a Hy e Hy-NLS variando a concentração de FS. Os valores são as médias \pm desvio padrão $(n=3)$, os valores referentes à HyNLS foram significativamente maior do que a Hy livre $(p<0,05)$.

\begin{tabular}{|c|c|c|c|}
\hline & & $k\left(10^{-3} \mathrm{~s}^{-1}\right)$ & \\
\hline 15 & $5,0 \times 10^{-7} \mathrm{~mol} \mathrm{~L}^{-1}$ & $7,5 \times 10^{-7} \mathrm{~mol} \mathrm{~L}^{-1}$ & $1,0 \times 10^{-6} \mathrm{~mol} \mathrm{~L}^{-1}$ \\
\hline $\begin{array}{c}\text { Hy } \\
\text { Hy-NLS } \\
\text { Aumento \% }\end{array}$ & $\begin{array}{c}1,75 \pm 0,03 \\
2,80 \pm 0,07 \\
60\end{array}$ & $\begin{array}{c}1,68 \pm 0,03 \\
3,12 \pm 0,2 \\
\mathbf{8 6}\end{array}$ & $\begin{array}{c}1,46 \pm 0,04 \\
3,48 \pm 0,05 \\
\mathbf{1 3 8}\end{array}$ \\
\hline
\end{tabular}

\section{Constante de velocidade de fotodecomposição do Ácido Úrico ( $\left.\mathbf{k}_{\mathrm{AU}}\right)$}

$\mathrm{O}$ ácido úrico $(\mathrm{AU})$ reage irreversivelmente $\operatorname{com}{ }^{1} \mathrm{O}_{2}$, gerado pela fotoexcitação do $\mathrm{FS}$, sendo usado como dosímetro químico para a determinação quantitativa da atividade fotodinâmica de FSs(Fischer, Graschew et al., 1998).

O ácido úrico apresenta duas bandas de absorção ótica em 235 e 292 nm, mas neste estudo foi acompanhado apenas o decréscimo da banda de maior absorção. O AU não exibe bandas de absorção em 590 nm, comprimento de onda da irradiação com LED utilizado, o que garantiu que a interação com a luz fosse restrita aos FSs como mostra aFigura 18.

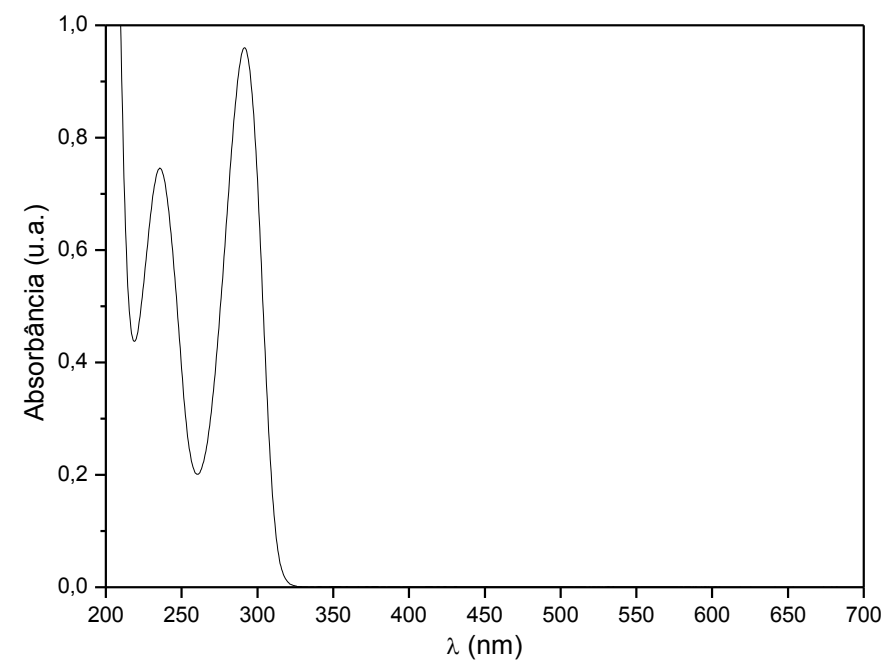

Figura 18: Espectro de absorção de $6,00 \times 10^{-5} \mathrm{~mol} \mathrm{~L}^{-1}$ de $\mathrm{AU}$ em tampão fosfato $\mathrm{pH} 7,0+0,001 \%$ Tween 20

Afotodecomposição do $\mathrm{AU}$ foi acompanhada em função do tempo de irradiação com LED $590 \pm 10 \mathrm{~nm}$ e intensidade de luz de $32 \mathrm{~mW} \mathrm{~cm}{ }^{-2}$ (Figuras 18a e $18 \mathrm{c})$, após a irradiação das amostras foram determinado as $\mathrm{k}_{\mathrm{AU}}\left(3,00 \pm 0,07 \times 10^{-4} \mathrm{e}\right.$ $3,15 \pm 0,03 \times 10^{-4} \mathrm{~s}^{-1}$ ) para Hy livre e Hy-NLS respectivamente como podem ser observadas nas figuras $18 \mathrm{~b}$ e $18 \mathrm{~d}$. O aumento da eficiência fotodinâmica utilizando a concentração de $5,0 \times 10^{-7} \mathrm{~mol} \mathrm{~L}^{-1}$ de Hy e Hy-NLS foi de $5 \%$. 

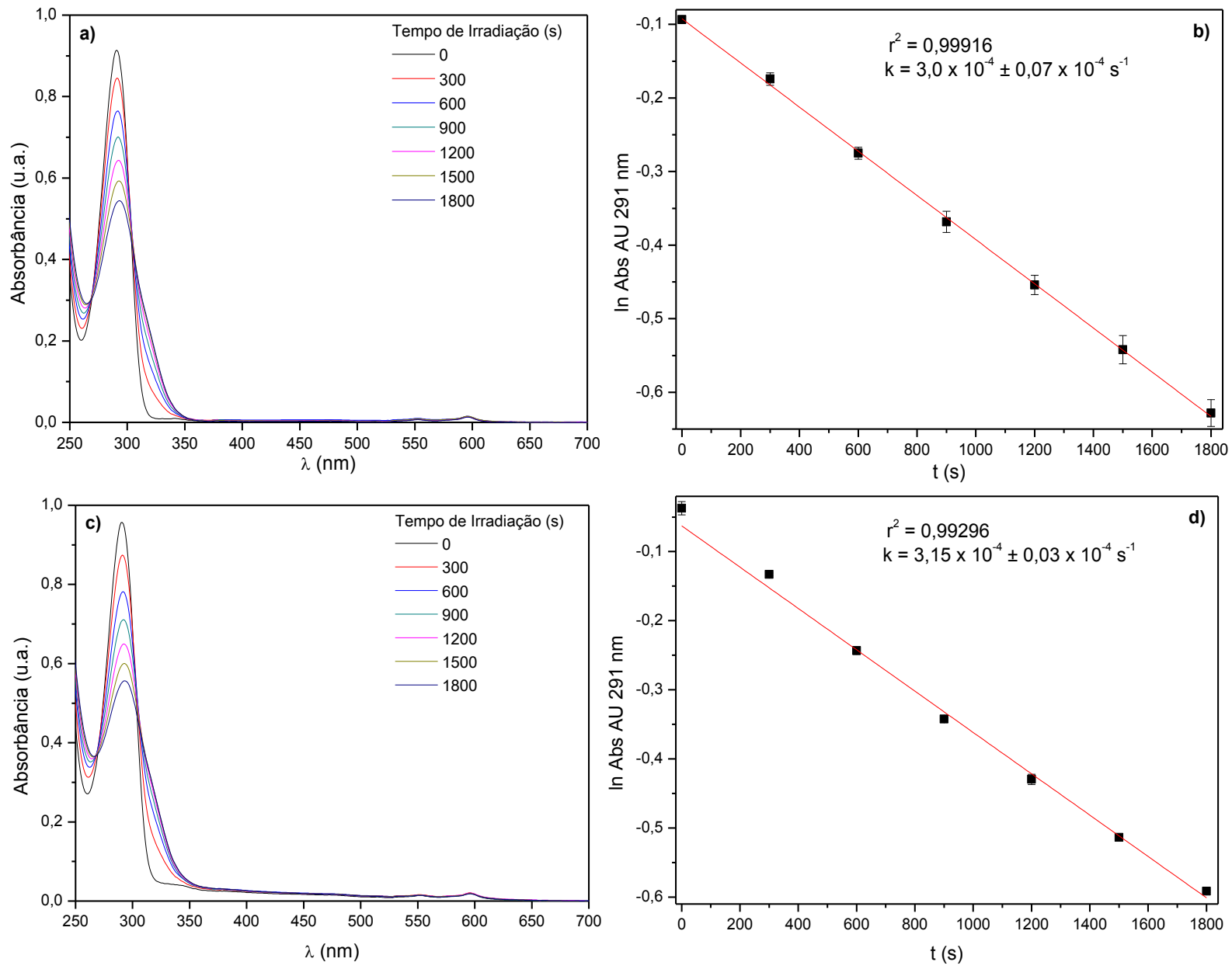

Figura 19:Espectros de absorção de $6,00 \times 10^{-5} \mathrm{~mol} \mathrm{~L}^{-1}$ de AU na presença de 5,00 $\times 10^{-7} \mathrm{~mol} \mathrm{~L}^{-1}$ de a) Hy e c) Hy-NLS em tampão fosfato $\mathrm{pH} 7,0+0,001 \%$ Tween 20. Constantes de velocidade de decomposição do AU para b) Hy e d) Hy-NLS.

Para a concentração de $7,5 \times 10^{-7} \mathrm{~mol} \mathrm{~L}^{-1} \mathrm{o}$ aumento da eficiência fotodinâmica da Hy encapsulada em NLS comparada com a Hy livre foi de $50 \%$ como é mostrado na Tabela 3. 

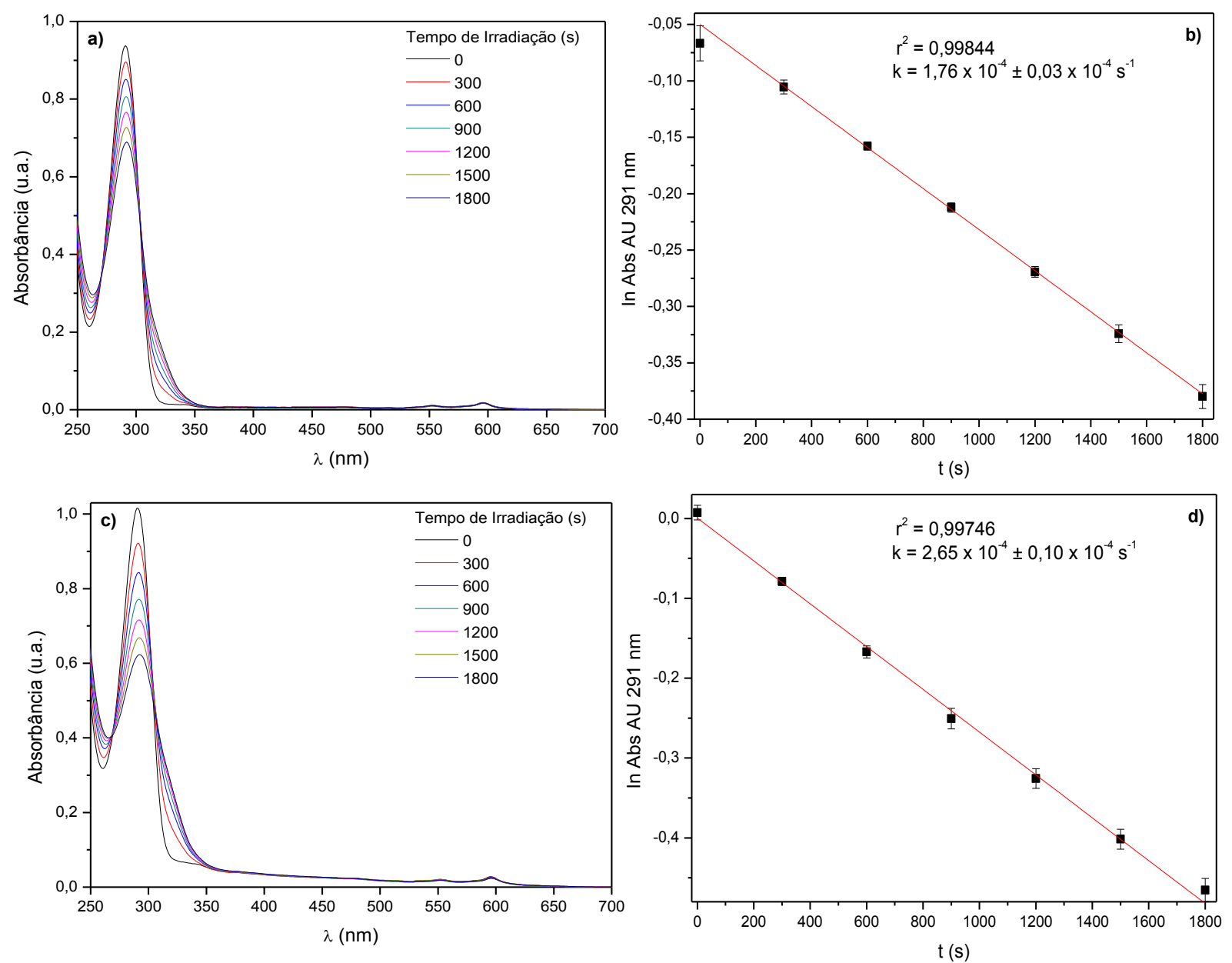

Figura 20:Espectros de absorção de 6,00 $\times 10^{-5} \mathrm{~mol} \mathrm{~L}^{-1}$ de AU na presença de 7,50 $\times 10^{-7} \mathrm{~mol} \mathrm{~L}^{-1}$ de a) Hy e c) Hy-NLS em tampão fosfato $\mathrm{pH} \mathrm{7,0+0,001 \%} \mathrm{Tween} \mathrm{20.} \mathrm{Constantes} \mathrm{de} \mathrm{velocidade} \mathrm{de}$ decomposição do AU para b) Hy e d) Hy-NLS.

As figuras 20a e 20c mostram a decomposição do AU após váriostempos de irradiação, após estes períodos foram determinados ask $\mathrm{AU}_{\mathrm{AU}}$ e obteve-se os valores de $1,12 \pm 0,03 \times 10^{-4}$ e 2,35 $\pm 0,10 \times 10^{-4} \mathrm{~s}^{-1}$ para Hy livre e Hy-NLS respectivamente como mostra as figuras $20 \mathrm{~b}$ e $20 \mathrm{~d}$. O aumento da eficiência fotodinâmica utilizando a concentração de $1,0 \times 10^{-6} \mathrm{~mol} \mathrm{~L}^{-1}$ de Hy e Hy-NLS foi de $110 \%$ como mostra a Tabela 3. 

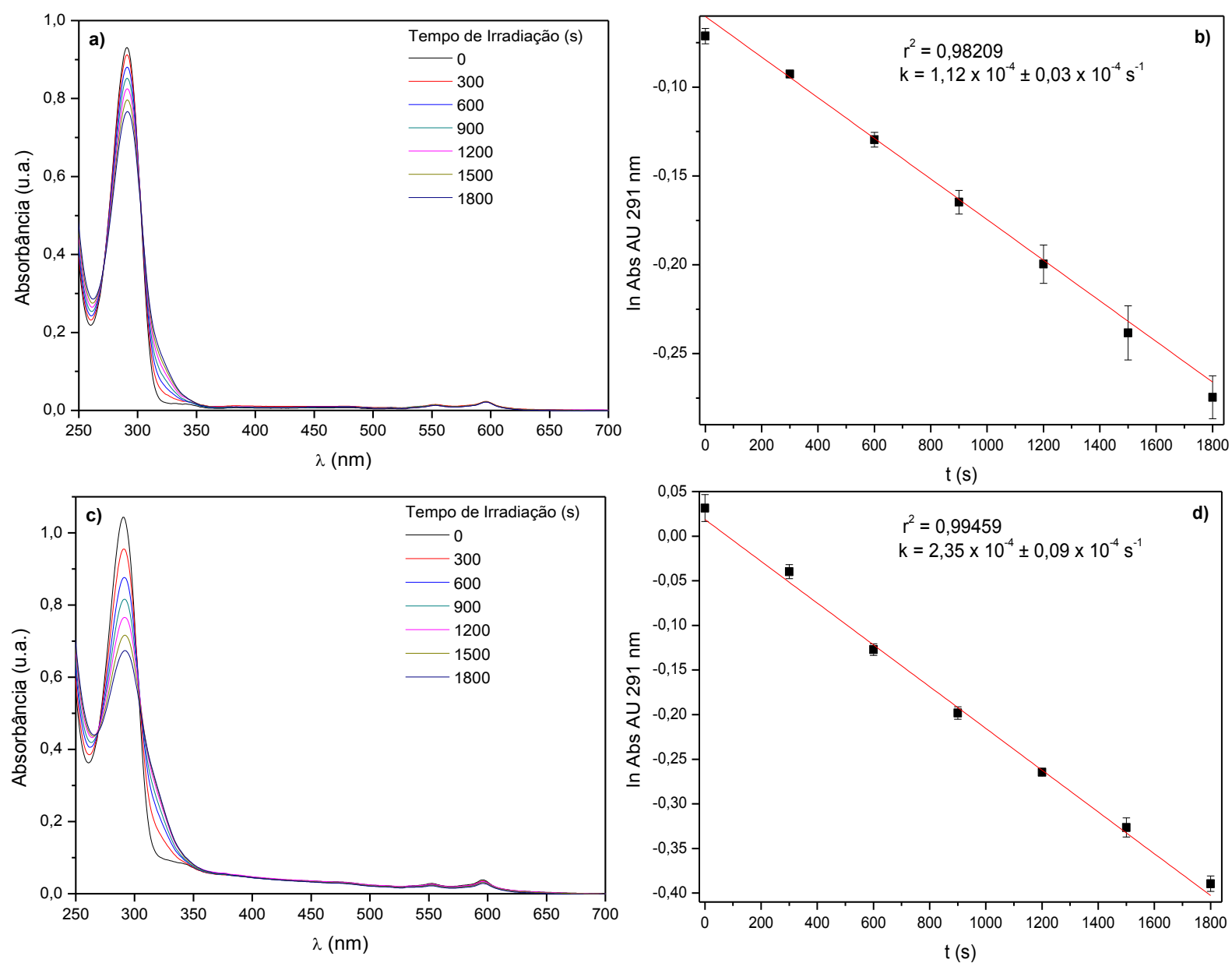

Figura 21:Espectros de absorção de $6,00 \times 10^{-5} \mathrm{~mol} \mathrm{~L}^{-1}$ de AU na presença de $1,00 \times 10^{-6} \mathrm{~mol} \mathrm{~L}^{-1}$ de a) Hy e c) Hy-NLS em tampão fosfato $\mathrm{pH} \mathrm{7,0+0,001 \%} \mathrm{Tween} 20$ depois. Constantes de velocidade de decomposição do AU para b) Hy e d) Hy-NLS.

Assim como na determinação da $\mathrm{K}_{\mathrm{DPBF}}$, neste experimento foram determinadas as constantes de decomposição do $\mathrm{AU}$ para as mesmas três

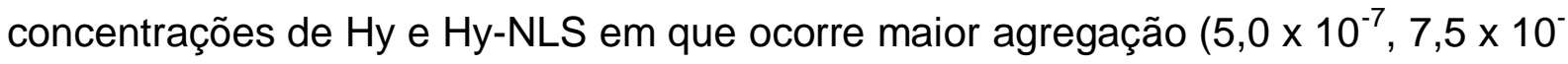
7 e $1,0 \times 10^{-6} \mathrm{~mol} \mathrm{~L}^{-1}$ ) como já foi discutido no item 4.1.3. Os mesmos resultados persistiram neste experimento, ou seja, aumentando a concentração dos FSs a diferença entre os $\mathrm{k}_{\mathrm{AU}}$ para a Hy e Hy-NLS foram acrescidas como foi mostrado naTabela 3. Vior e colaboradores prepararam tetrakis-(1-adamantylsulfanyl) phthalocyaninatozinc(II) incorporada em NLS e obtiveram um aumento de cerca de duas a três vezes na solubilidade do FS incorporado em NLS comparado com o FS livre e também obtiveram excelentes valores de rendimento quânticos de formação de oxigênio singlete (Garcia Vior, Monteagudo et al., 2011).A diminuição da agregação da Hy encapsulada em NLS e consequentemente a elevação da 
atividade fotodinâmica comparada com a Hy livre foi devido ao aumento da solubilidade em meio aquoso.

Tabela 3: Constantes de velocidade de decomposição do ácido úrico para a Hy e Hy-NLS variando a concentração de FS. Os valores são as médias \pm desvio padrão $(n=3)$, os valores referentes à HyNLS foram significativamente maior do que a Hy livre $(p<0,05)$.

\begin{tabular}{|c|c|c|c|}
\hline \multirow{2}{*}{ FS } & \multicolumn{3}{|c|}{$k\left(10^{-4} \mathrm{~s}^{-1}\right)$} \\
\hline & $5,0 \times 10^{-7} \mathrm{~mol} \mathrm{~L}^{-1}$ & $7,5 \times 10^{-7} \mathrm{~mol} \mathrm{~L}^{-1}$ & $1,0 \times 10^{-6} \mathrm{~mol} \mathrm{~L}^{-1}$ \\
\hline Hy & $3,00 \pm 0,07$ & $1,76 \pm 0,03$ & $1,12 \pm 0,03$ \\
\hline Hy-NLS & $3,15 \pm 0,03$ & $2,65 \pm 0,10$ & $2,35 \pm 0,09$ \\
\hline Aumento \% & 5 & 50 & 110 \\
\hline
\end{tabular}

\subsubsection{Acumulação intracelular}

A preferência dos FSs de se acumularem em células tumorais é um dos principais fatores na eficiência da TFD, portanto o conhecimento da concentração intracelular dos FSs pode ser considerado como um fator prognóstico para a determinação dos resultados terapêuticos (Kiesslich, Krammer et al., 2006).

Foram realizados ensaios com as linhagens celulares HEp-2 e B16-F10 para a determinação da concentração intracelular de Hy livre e Hy-NLS em três tempos de incubação (30 min, 1 e 2 h). Primeiramente foi obtida uma curva padrão da absorbância da BSA em função da concentração, esta relação foi linear e assim foi possível, através da equação da reta, estimar a concentração proteica a partir da absorbância em 750 nm (Lowry, Rosebrough et al., 1951). A Figura 22apresenta a curva padrão de absorbância em 750 nm em função da concentração de BSA.

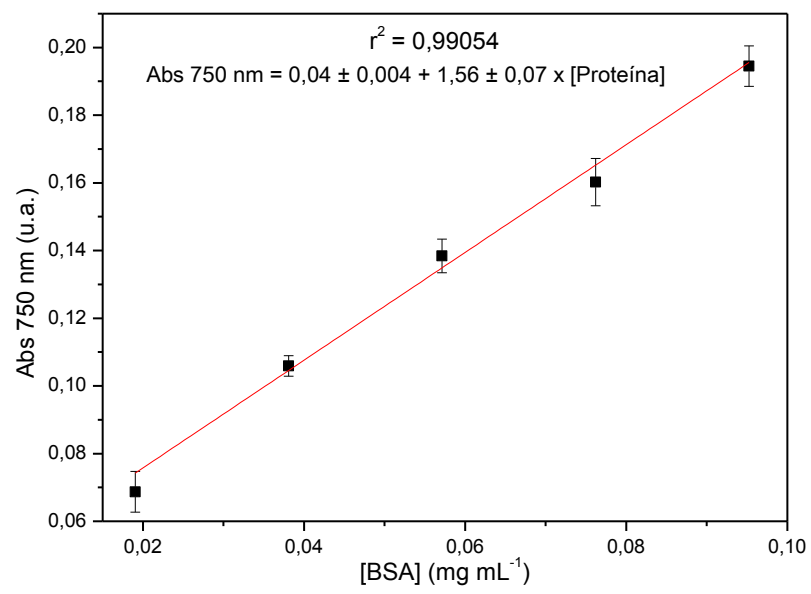

Figura 22: Curva padrão da absorbância em $750 \mathrm{~nm}$ em função da concentração de BSA $\left(\mathrm{mg} \mathrm{mL}^{-1}\right)$. As médias de absorbância foram obtidas de dois ensaios realizados em triplicata. 
As curvas analíticas foram obtidas da emissão de fluorescência de diferentes concentrações de Hy em etanol (Figura 23).
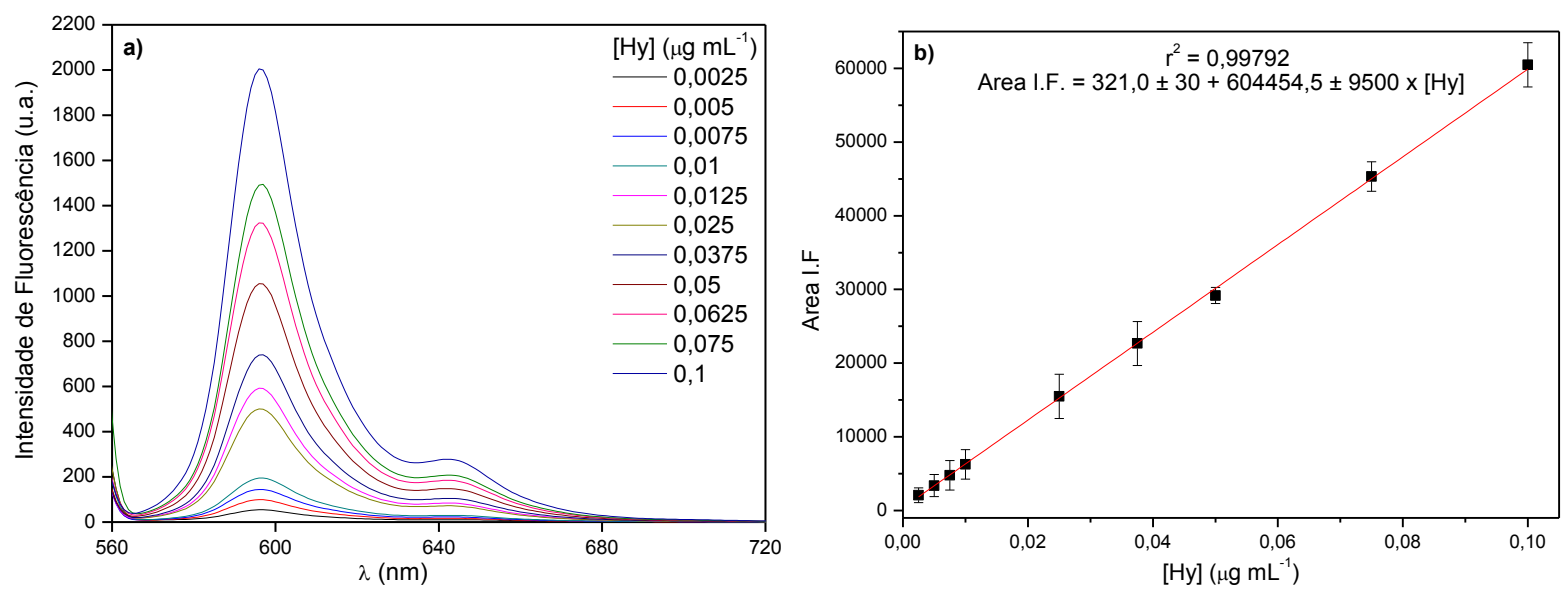

Figura 23:a) Espectro de emissão variando a concentração da Hy em etanol com excitação em 545 nm e emissão em $560-800 \mathrm{~nm}$. b) Curva analítica para a Hy obtida a partir das intensidades de fluorescência em $597 \mathrm{~nm}(\mathrm{n}=3)$.

Todas as relações determinadas apresentaram-se linear, portanto foi possível, através da equação da reta, estimar a concentração de Hy previamente incubada com as células HEp-2 e B16-F10 com Hy e Hy-NLS após a extração com etanol.

Com o objetivo de determinar a concentração intracelular de Hy e Hy-NLS em diferentes tempos de incubação nas células em estudo, foram realizados experimentos incubando-se os FSs em três tempos (30 min, 1 e 2 h) com as linhagens celulares. Após a extração do FS das células com etanol, a intensidade de fluorescência foi medida, a concentração do FS determinada e normalizada pela concentração de proteína, obtida pelo método de Lowry. Os resultados de acumulação de Hy e Hy-NLS nas células HEp-2 e B16-F10 em função do tempo de incubação estão apresentados na Figura 24 e na tabela 4. 

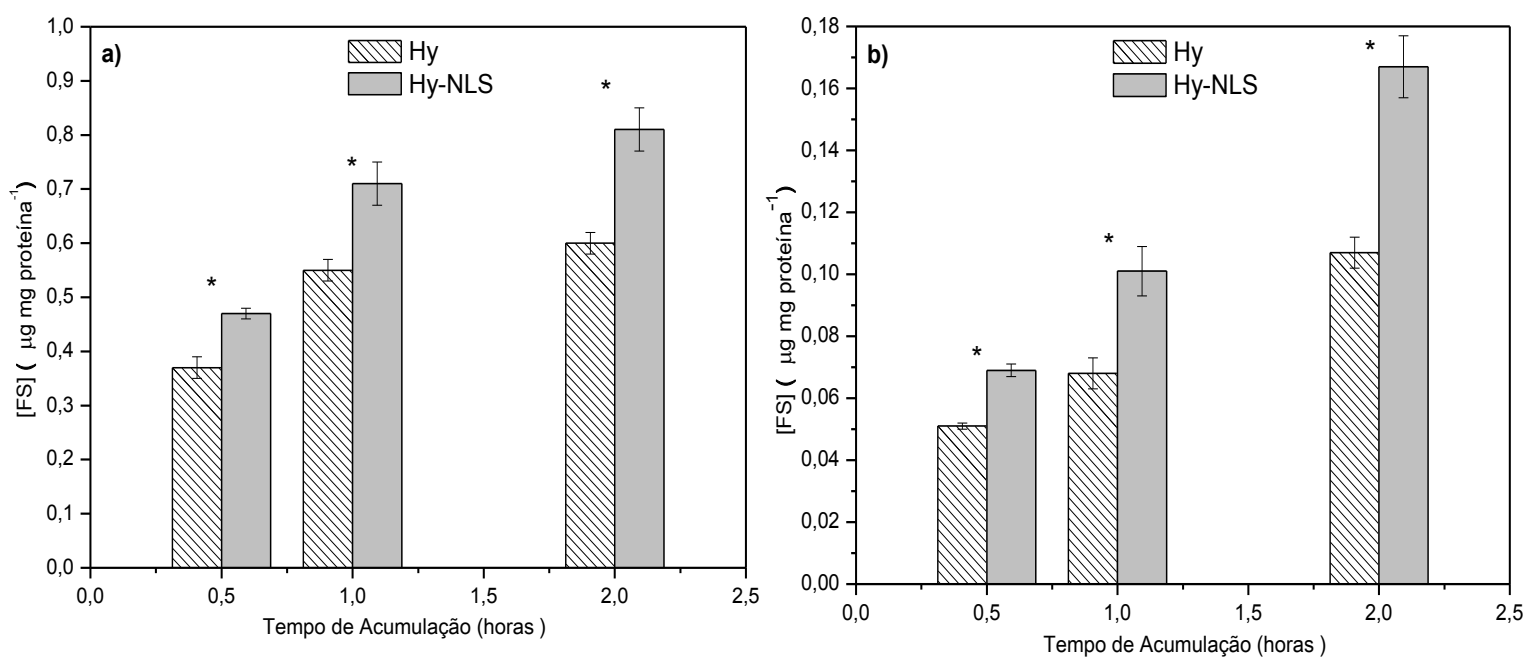

Figura 24: Acumulação intracelular de Hy e Hy-NLS nos tempos de incubação de 30 minutos, 1 hora e 2 horas nas células a) HEp-2 e b) B16-F10. Os valores são as médias \pm desvio padrão $(n=3)$. * As diferenças foram significativas $(p<0,05)$.

Após a encapsulação da Hy em NLS obteve-se um aumento significativo ( $p>$ $0,05)$ na acumulação intracelular em todos os casos estudados, ou seja, em três tempos de acumulação e duas linhagens celulares. Este acréscimo na acumulação quando a Hy foi incorporada em NLS ocorreu por causa do aumento da solubilidade das Hy-NLS em meio aquoso (Figura 9) e do caráter biocompatível que as nanopartículas lipídicas sólidas possuem assim facilitando a entrega de FSs lipofílicos às células-alvo. Existem trabalhos na literatura que explicam essa melhora na eficiência da acumulação de compostos hidrofóbicos em células tumorais após a incorporação em NLS. Zhu e colaboradores incorporaram um fármaco chamado fosfo-sulindac (OXT-328) em NLS utilizando a técnica de evaporação de emulsão e foram feitos estudos farmacocinéticos em ratos e em modelos de xenoenxertos de câncer de pulmão. Com a incorporação do OXT-328 em NLS os autores obtiveram um aumento de 14 vezes na acumulação em xenoenxertos A549 e consequentemente um efeito fototóxico maior comparado com o OXT-328 livre(Zhu, Cheng et al., 2012). 
Tabela 4: Acumulação intracelular de Hy e Hy-NLSnos tempos de incubação de 0,5 horas, 1,0 horas e 2,0 horas nas células HEp-2 e B16-F10. Os valores são as médias \pm desvio padrão $(n=3)$. As diferenças foram significativas $(p<0,05)$.

\begin{tabular}{|c|c|c|c|c|c|c|}
\hline \multirow{4}{*}{ FS } & \multicolumn{6}{|c|}{$\begin{array}{c}\text { Acumulação intracelular de FS } \\
\left(\mu \mathrm{g} \mathrm{mg} \mathrm{proteína}{ }^{-1}\right)\end{array}$} \\
\hline & \multicolumn{3}{|c|}{ HEp-2 } & \multicolumn{3}{|c|}{ B16-F10 } \\
\hline & \multicolumn{6}{|c|}{ Tempo de Acumulação (h) } \\
\hline & 0,5 & 1,0 & 2,0 & 0,5 & 1,0 & 2,0 \\
\hline Hy & $0,37 \pm 0,02$ & $0,55 \pm 0,02$ & $0,60 \pm 0,02$ & $0,051 \pm 0,001$ & $0,068 \pm 0,005$ & $0,107 \pm 0,005$ \\
\hline Hy-NLS & $0,47 \pm 0,01$ & $0,71 \pm 0,03$ & $0,81 \pm 0,01$ & $0,069 \pm 0,002$ & $0,101 \pm 0,008$ & $0,167 \pm 0,010$ \\
\hline $\begin{array}{c}\text { Variação } \\
(\%)\end{array}$ & 27 & 29 & 35 & 35 & 48 & 56 \\
\hline
\end{tabular}

\subsubsection{Ensaios citotóxicos}

Foram realizados experimentos citotóxicos, como descrito no item 3.7 , com as linhagens HEp-2 e B16-F10 nos quais as células foram irradiadas com três doses de luz com o LED $590 \pm 10 \mathrm{~nm}$ e intensidade de $10 \mathrm{~mW} \mathrm{~cm}{ }^{-2}$, após $2 \mathrm{~h}$ de incubação com Hy e Hy-NLS. Ensaios citotóxicos na ausência de irradiação foram feitos a fim de se verificar a toxicidade intrínseca dos FSs nas células, ou seja, a citotoxicidade no escuro e também controles da sobrevivência celular após irradiação da luz visível na ausência do FSs.

Os valores de $\mathrm{IC}_{50}$ apresentados nas tabelas que se seguem correspondem a um parâmetro inversamente proporcional à citotoxicidade, ou seja, quanto maior o valor de $\mathrm{IC}_{50}$ menor é a citotoxicidade do FS.

\section{Citotoxidade da Luz nas células tumorais}

Foram realizados ensaios para verificar o efeito da luz em três diferentes doses de luz nas linhagens HEp-2 e B16-F10 com concentração celular de $1 \times 10^{5}$ célulasmL ${ }^{-1}$. As doses de luz foram 6,12 e $18 \mathrm{~J} \mathrm{~cm}^{-2}$ para o LED $590 \pm 10 \mathrm{~nm}$ e intensidade de $10 \mathrm{~mW} \mathrm{~cm}^{-2}$. Cincotta e colaboradores observaram a ocorrência de pequena morte celular em função da irradiação na ausência de FS com várias linhagens celulares e atribuíram este efeito à fotólise mediada por cromóforos celulares endógenos(Cincotta, Foley et al., 1987). Portanto este ensaio foi realizado como um controle do efeito da luz sobre a mortalidade das células na ausência dos 
FSs (Figura 25), pois em TFD somente a luz na ausência do FS não deve apresentar efeito tóxico às células.

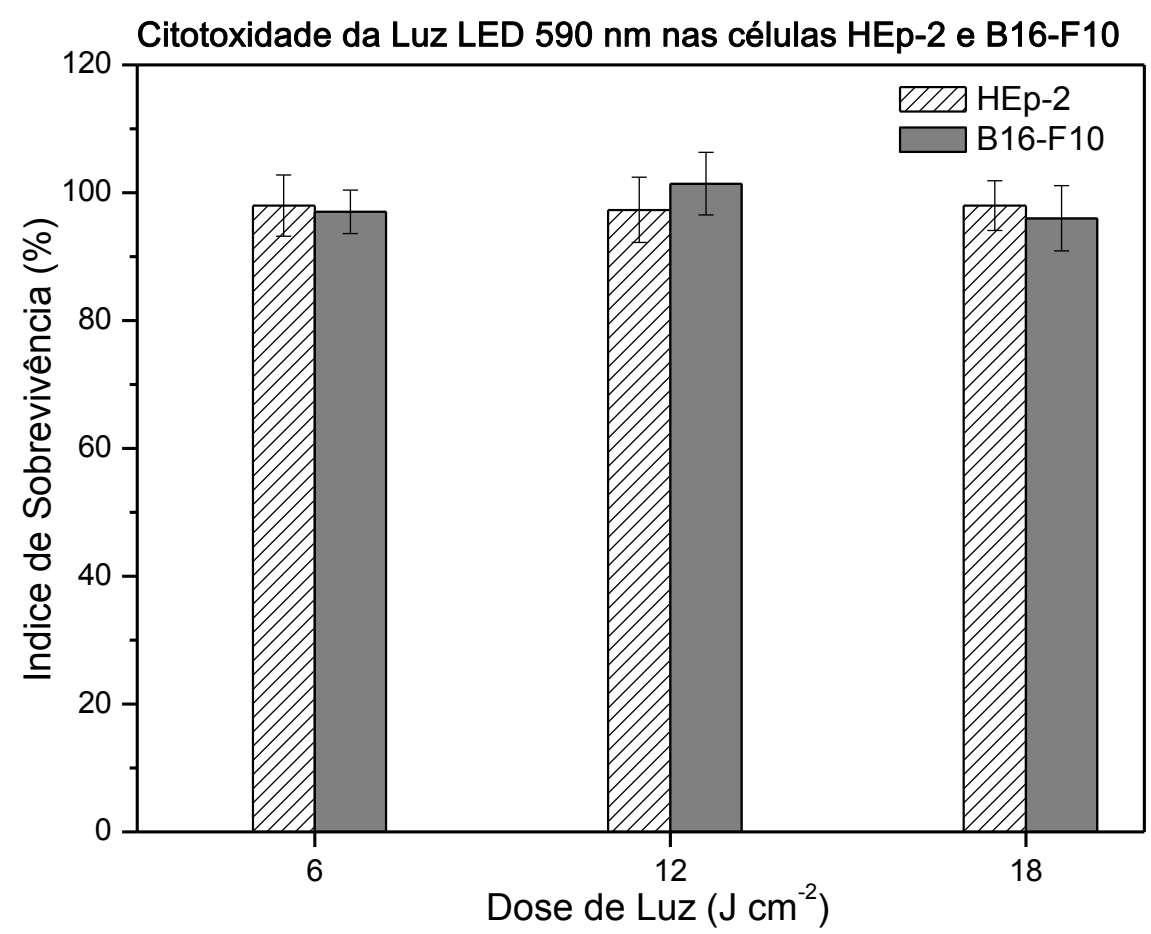

Figura 25: O efeito da dose de luz sobre a viabilidade de célula HEp-2 e B16-F10. Os valores são as médias \pm desvio padrão $(n=18)$ o resultado não foi significativamente diferente (teste t de Student, $p>0,05)$.

A intensidade de luz pode ser definida como a quantidade de energia transmitida ao alvo por unidade de tempo e é expressa em $\mathrm{mW} \mathrm{cm}^{-2}$. A quantidade de energia transmitida durante todo o intervalo de tempo é definida como dose de luz, que por sua vez é expressa em $\mathrm{J} \mathrm{cm}^{-2}$. A relação entre intensidade de luz, dose de luz e tempo de irradiação é dada pela equação abaixo (Resnick, et al., 1979):

$$
I=\frac{D}{t}
$$

onde: $\mathrm{I}=$ intensidade de luz em $\mathrm{m} \mathrm{W} \mathrm{cm}^{-2}$

$D=$ dose de luz em $\mathrm{J} \mathrm{cm}^{-2}$

$\mathrm{t}=$ tempo de irradiação em segundos

sendo que $1 \mathrm{~J}=1 \mathrm{~W} \times$ segundo 
A utilização de altas doses de luz pode causar um aquecimento local resultando em alterações nos níveis dos constituintes celulares sensíveis às variações de temperatura, tais como proteínas, DNA ou RNA, podendo levar a inibição do crescimento celular.

Nas condições experimentaisempregadas nesse estudo não houve alterações significativas $(p>0,05)$ na sobrevivência das células (Figura 25), isso indica que a dose de luz não foi alta o suficiente para causar alterações nos níveis dos constituintes celulares sensíveis às variações de temperatura. Desse modo, nos estudos citotóxicos na presença de luz, utilizou-se LED com tempo de irradiação máxima correspondendo a dose máxima de $18 \mathrm{~J} \mathrm{~cm}^{-2}$ para garantir que o efeito da luz não apresentasse efeito tóxico significativo às células.

\section{Citotoxidade da Hy livre, NLS e Hy-NLS nas células HEp-2 e B16-F10 sem a presença de luz}

Hy livre, NLS branca e Hy-NLS foram incubados por $2 \mathrm{~h}$ em uma concentração celular de $1 \times 10^{5}$ células $\mathrm{mL}^{-1}$ na ausência de luz. Após este período a incubação com o FSs foi interrompida. Após $24 \mathrm{~h}$ na estufa celular, tempo de recuperação das células, foi realizado o ensaio com MTT para averiguar se ocorreu morte significativa das células tumorais. Ao término do experimento foi possível confirmar que não houve morte significativa das células HEp-2 e B16-F10 valor de $p$ foi maior que 0,05 , como mostra as (Figura 26).
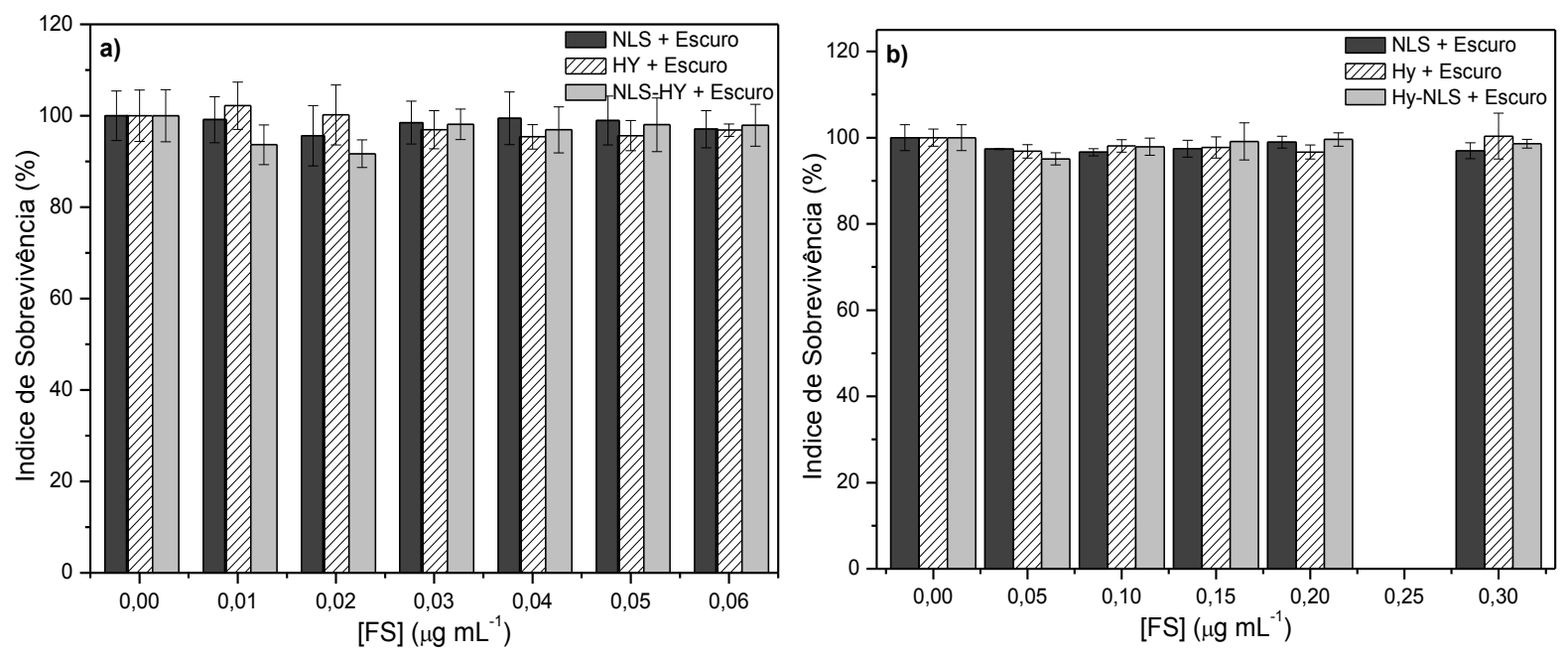

Figura 26: Viabilidade celular após 2 horas de incubação com diferentes concentrações de Hy, HyNLS e NLS no escuro para a) HEp-2 e b) B16-F10. Os valores são as médias \pm desvio padrão ( $n=$ 18) a resultado não foi significativamente diferente (teste t de Student, $p>0,05$ ). 
Esses resultados estão de acordo com resultados já descritos na literatura por Konan e colaboradores que analisaram a toxicidade e a fototoxicidade de nanopartículas vazias ou contendo porfirina meso-tetra(4-hidroxifenil) encapsulada após a incubação em cultura de células tumorais (EMT-6) e não observaram citotoxicidade significativa no escuro em nenhuma das condições analisadas (Konan, Berton et al., 2003). O mesmo resultado foi descrito por Zeisser-Labouèbe e colaboradores, que incubaram células NuTu-19 (câncer ovariano de ratos) com nanopartículas de PLA e PLGA vazias ou com hipericina e não obtiveram morte significativa das células estudadas (Zeisser-Labouebe, Lange et al., 2006). Da Silva e colaboradores analisaram a atividade fotodinâmica de nanopartículas contendo um derivado porfirínico em células de tumor de próstata humana e também verificaram baixa toxicidade dos fotossensibilizantes utilizados após a incubação no escuro (Da Silva, Inada et al., 2009).

\section{> Efeito da dose de irradiação na fototoxicidade da Hy, NLS e Hy-NLS nas células HEp-2 e B16-F10}

Nos estudos citotóxicos na presença de luz utilizou-se irradiação com LED em $590 \pm 10 \mathrm{~nm}$, intensidade de $10 \mathrm{~mW} \mathrm{~cm}^{-2}$ com os tempos de irradiação de 10, $20 \mathrm{e}$ $30 \mathrm{~min}$ equivalentes às doses de luz de 6,12 e $18 \mathrm{~J} \mathrm{~cm}^{-2}$. As células foram incubadas por $2 \mathrm{~h}$ com Hy e Hy-NLS em várias concentrações $\left(0-0,08 \mu \mathrm{gL}^{-1}\right)$ para as células HEp-2 e $\left(0-0,30 \mu \mathrm{g} \mathrm{mL}{ }^{-1}\right)$ para as células B16-F10 em meio de cultura, como mostra a figura 27. 

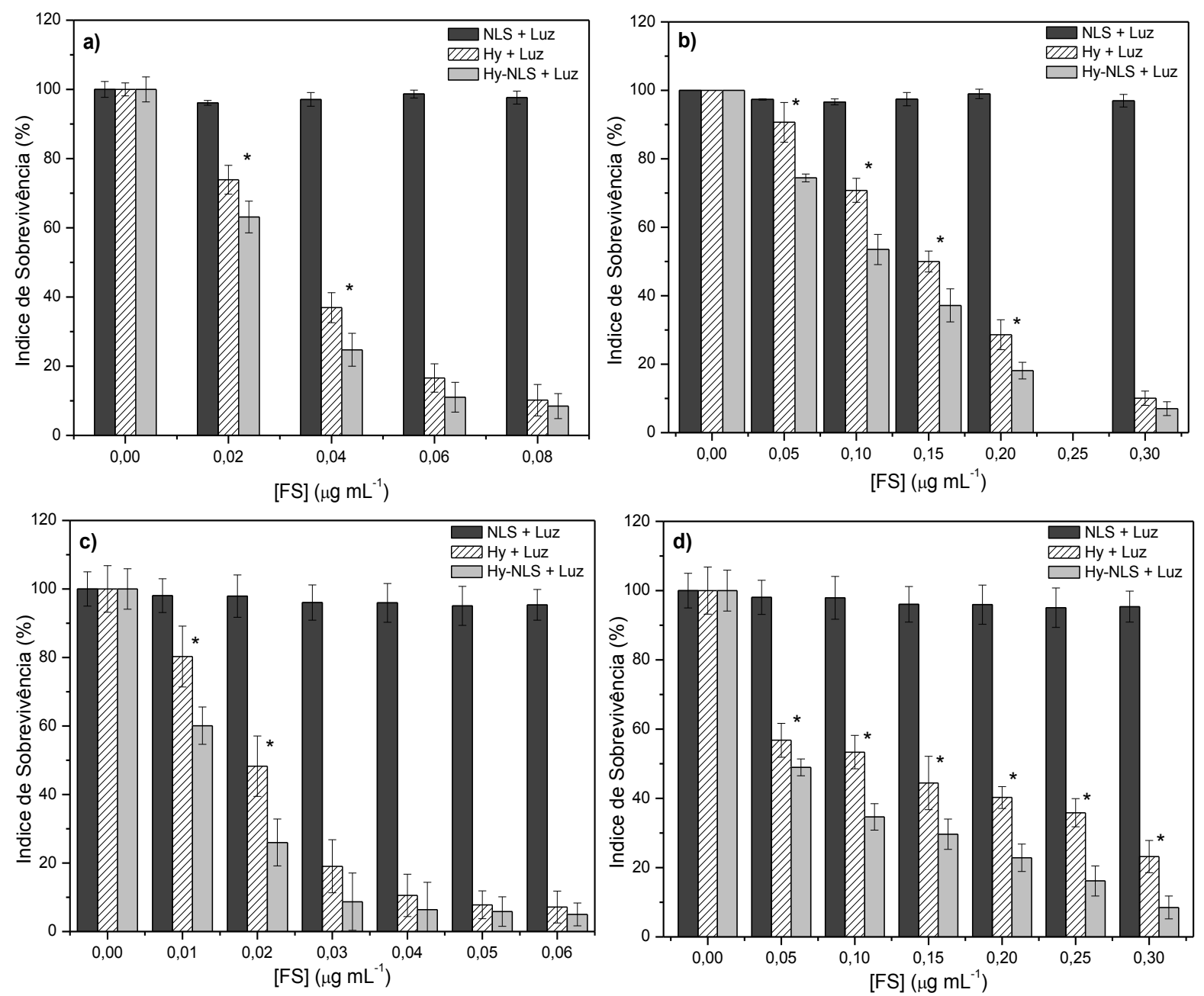

Figura 27:O efeito fototóxicos de diferentes concentrações de Hy, Hy-NLS e NLS sobre duas linhagens celulares sob irradiação com LED $590 \pm 10 \mathrm{~nm}$, intensidade de luz de $10 \mathrm{~mW} \mathrm{~cm}{ }^{-2}$ e tempo de incubação de 2 horas. a) e c) para as células HEp-2 nas doses de luz de 6 e $12 \mathrm{~J} \mathrm{~cm}^{-2}$ e b) e d) para as células B16-F10 nas doses de luz de 6 e $12 \mathrm{~J} \mathrm{~cm}^{-2}$. Os valores são as médias \pm desvio padrão $(n=18),{ }^{*}$ resultadossignificativamente diferentes (teste t de Student, $p<0,05$ ).

Após a irradiação com luz e o ensaio com MTT foram determinados os valores de $\mathrm{IC}_{50}$ utilizando o programa CalcuSyn (Chou, Hayball., 1996) para Hy e Hy-NLS para as células HEp-2 e B16-F10 nas três doses de luz utilizadas (Tabela $5)$. 
Tabela 5:A concentração média inibitória $\left(\mathrm{IC}_{50}\right)$ de Hy e Hy-NLS nas células tumorais HEp-2 e B16F10 na presença de luz ( 6 e $12 \mathrm{~J} \mathrm{~cm}^{-2}$ ) com LED $590 \pm 10 \mathrm{~nm}$, intensidade de luz de $10 \mathrm{~mW} \mathrm{~cm} \mathrm{~cm}^{-2} \mathrm{e}$ tempo de incubação de 2 horas. Os valores são as médias \pm desvio padrão $(n=18)$. As diferenças são consideradas estatisticamente significantes quando $p<0,05$ (teste t de Student).

\begin{tabular}{|c|c|c|c|c|}
\hline \multirow{4}{*}{ FS } & \multicolumn{4}{|c|}{$\mathrm{IC}_{50}(\mathrm{nM})$} \\
\hline & \multicolumn{2}{|c|}{ HEp-2 } & \multicolumn{2}{|c|}{ B16-F10 } \\
\hline & \multicolumn{4}{|c|}{ Dose de Luz $\left(\mathrm{J} \mathrm{cm}^{-2}\right)$} \\
\hline & 6 & 12 & 6 & 12 \\
\hline Hy & $56 \pm 6$ & $33 \pm 3$ & $228 \pm 6$ & $200 \pm 10$ \\
\hline Hy-NLS & $42 \pm 4$ & $21,2 \pm 2$ & $154 \pm 2$ & $115 \pm 4$ \\
\hline Variação no $\mathrm{IC}_{50}(\%)$ & 25 & 36 & 32 & 42 \\
\hline
\end{tabular}

Os valores de $\mathrm{IC}_{50}$ mostrados na Tabela 5 foram sofrendo decréscimo em função do aumento da dose de luz, o que indica a dependência da dose de luz para a morte celular. A viabilidade celular também é dependente da concentração do FS o que pode ser observado na figura 27 , sendo que esta dependência se manteve para as duas linhagens celulares utilizadas neste estudo.

Os valores de $\mathrm{IC}_{50}$ para a Hy-NLS foram menores em comparação com a $\mathrm{Hy}$ livre o que indica que a Hy encapsulada com NLS tornou-se significativamente $(\mathrm{p}<$ $0,05)$ mais fototóxica do que a Hy livre devido a uma menor agregação, assim levando a um aumento no tempo de vida do estado tripleto, como pode ser observado nos resultados das constantes de velocidade de fotodecomposição do DPBF e ácido úrico (Tabelas 3 e 4). Outro fator que contribui para aumentar a eficiência fototóxica da Hy-NLS foi a maior acumulação intracelular (Figura 24) comparando com a Hy em solução como já foi discutido no item4.1.5. Cohen et al (Cohen, Ding et al., 2010) prepararam a 5,10,15,20-tetraquis (meso-hidroxifenil) porfirina (mTHPP) em micelas de PEG-PLA e observaram um aumento da solubilidade e citotoxicidade de mTHPP, devido a diminuição na formação de agregados, levando ao aumento na citotoxicidade. De acordo com ZeisserLabouèbe e colaboradores a Hy encapsulada em nanopartículas poliméricas de PLA teve um aumento na fototoxicidade de $28 \%$ em células tumorais. No presente estudo, utilizando Hy encapsulada em NLS observou-se resultados semelhantes, isto é, um aumento na fototoxicidade de 30\% comparado com a Hy livre (ZeisserLabouebe, Lange et al., 2006).

Youssef e colaboradores prepararam Hy incorporada em dois tipos de NLS com tamanhos superiores a $220 \mathrm{~nm}$, nos estudos de fototoxicidade sobre as células HepG2 obtendo um menor efeito fototóxico da Hy-NLS comparada com a Hy livre. 
Resultado diferente do obtido neste trabalho, que em todos os casos estudados, ou seja, variando a linhagem celular, a dose de luz e também a concentração do FS, a fototoxicidade da Hy-NLS foi maior que a Hy livre. Isto aconteceu provavelmente devido ao tamanho das partículas, pois estes autoresobtiveram partículas com tamanho superior a $220 \mathrm{~nm}$ e no presente trabalho foram obtidas partículas com tamanho médio de $150 \mathrm{~nm}$ para a hipericina em NLS. Partículas menores têm maior mobilidade para alcançar as células alvo e possui uma maior permeabilidade e efeito de retenção (Youssef, Fadel et al., 2012; Zhu, Cheng et al., 2012), o que corrobora com os resultados obtidos neste estudo.

\subsection{Tetra-carboxiftalocianinade zinco}

\subsubsection{Preparação e caracterização das Nanopartículas lipídicas sólidas} (NLS) e FtZnT-NLS

Primeiramente a FtZnT-NLS foi preparada na mesma formulação da Hy-NLS ( $1 \%$ de lipídeo e 1\% de FS) porém os resultados de índice de polidispersão obtidos foram elevados (acima de 0,50). Portanto, na preparação da FtZnT-NLS foi utilizado uma concentração maior de lipídeo ( $2 \%$ de monoestearato de glicerila)e assim, obteve-se índice de polidispersão abaixo de 0,30 e eficiência de encapsulação acima de $80 \%$ utilizando esta formulação. As medidas de caracterização para a FtZnT incorporada em NLS estão descritas naTabela 6.

Tabela 6: Características dos NLS: tamanho médio, índice Polidispersão, potencial zeta e eficiência de encapsulação das FtZnT-NLS (média \pm desvio padrão, $n=3$ ).

\begin{tabular}{ccccc}
\hline NLS & $\begin{array}{c}\text { Diâmetro } \\
\text { médio }(\mathbf{n m})\end{array}$ & $\begin{array}{c}\text { Índice de } \\
\text { polidispersão }\end{array}$ & $\begin{array}{c}\text { Potencial } \\
\text { Zeta(mV) }\end{array}$ & $\begin{array}{c}\text { EE } \\
(\%)\end{array}$ \\
\hline NLS & $179 \pm 8$ & $0,26 \pm 0,02$ & $-17,0 \pm 0,7$ & - \\
FtZnT-NLS & $245 \pm 5$ & $0,29 \pm 0,02$ & $-17,5 \pm 0,9$ & $85,5 \pm 3$ \\
\hline
\end{tabular}

Foi preparada NLS branca, ou seja, sem FtZnT para ser utilizada como controle nos ensaios citotóxicos e também para usar como linha de base nos experimentos espectrofotométricos. Observou-se que o tamanho das nanoparticulas contendo a ftalocianina foi maior do que contendo a Hipericina. Os índices de polidispersão não tiveram alteração significativa $(p>0,05)$ após o preparo das FtZnTNLS, sendo que os valores obtidos ficaram abaixo de 0,30 , que são características 
pretendidas quando utiliza-se nanopartículas para uso em TFD como já descrito (Uner, 2006). A eficiência de encapsulação é outra medida usada para a caracterização de nanopartículas em geral, o valor obtido para a EE foi de 85,5 \pm $3 \%$, um valor muito próximo do obtido para a Hy incorporada em NLS que foi de 83,5 $\pm 2 \%$, valores relativamente altos (Schaffazick, Pohlmann et al., 2003; ZeisserLabouebe, Lange et al., 2006).

$\mathrm{Na}$ literatura tem-se utilizado nanopartículas lipídicas sólidas para o transporte de muitos compostos lipofílicos como FSs e fármacos em geral. Ricci-Júnior et al encapsularam ftalocianina de zinco (II) em poli ácido láctico glicólico (PLGA) e obtiveram um tamanho das partículas de $285 \mathrm{~nm}$, índice de polidispersividade de 0,12 e eficiência de encapsulação de 70\% (Ricci-Junior e Marchetti, 2006). Guo et al encapsularam 2-metoxiestradiol (2-ME) em NLS e obtiveram tamanho inferior a 200 $\mathrm{nm}$, EE acima de $85 \%$ e potencial zeta de - $40 \mathrm{mV}$ (Guo, Xing et al., 2012). Assim como nas Hy-NLS os valores negativos do potencial zeta, para a FtZnT-NLS, foram provenientes da lecitina utilizada para estabilizar as nanopartículas, isso pode ser observado através dos valores de PZ das NLS brancas e FtZnT-NLS que foram de $17,0 \pm 0,7$ e $-17,5 \pm 0,9 \mathrm{mV}$ respectivamente como mostra a Tabela 6.

\subsubsection{Atividade Fotodinâmica da FtZnT e FtZnT-NLS}

\section{Constante de velocidade de fotodecomposição do DPBF}

A FtZnTapresentou pequena atividade fotodinâmica em solução aquosa, por este motivo não foi necessário utilizar um surfactante para aumentar a solubilidade deste FS, como foi feito com os experimentos para determinação das constantes de velocidade de fotodecomposição do DPBF e do AU para a hipericina. A reação do DPBF com o ${ }^{1} \mathrm{O}_{2}$ formado após a irradiação da FtZnT e FtZnT-NLS com LED $630 \pm$ $10 \mathrm{~nm}$ e intensidade de $70 \mathrm{~mW} \mathrm{~cm}^{-2}$ foi monitorada espectrofotometricamente pelo desaparecimento da banda de absorção do DPBF (420 nm), ocorrendo um pequeno deslocamento em comparação com a Hy em tampão fosfato e surfactante devido à mudança do solvente. A absorção da luz emitida pelo LED $630 \pm 10 \mathrm{~nm}$ foi proveniente apenas do $\mathrm{FS}$, pois o DPBF não absorve na região da emissão como mostra a Figura 14.

A Figura 28 mostra a decomposição do DPBF após vários tempos de irradiação com LED $630 \pm 10 \mathrm{~nm}$ e intensidade de luz de $70 \mathrm{~mW} \mathrm{~cm}{ }^{-2}$, nos dois 
casos observou-se o decréscimo da banda do DPBF, indicando que em ambos FSs ocorre a reação de decomposição desta molécula pelo oxigênio singlete formado pelos FSs excitados. Após a irradiação foi determinado o valor de $\mathrm{K}_{\mathrm{DPBF}}$ obtendo os valores de 1,53 $\pm 0,2 \times 10^{-4}$ e 5,57 $\pm 0,2 \times 10^{-4} \mathrm{~s}^{-1}$ para FtZnT livre e FtZnT -NLS respectivamente.
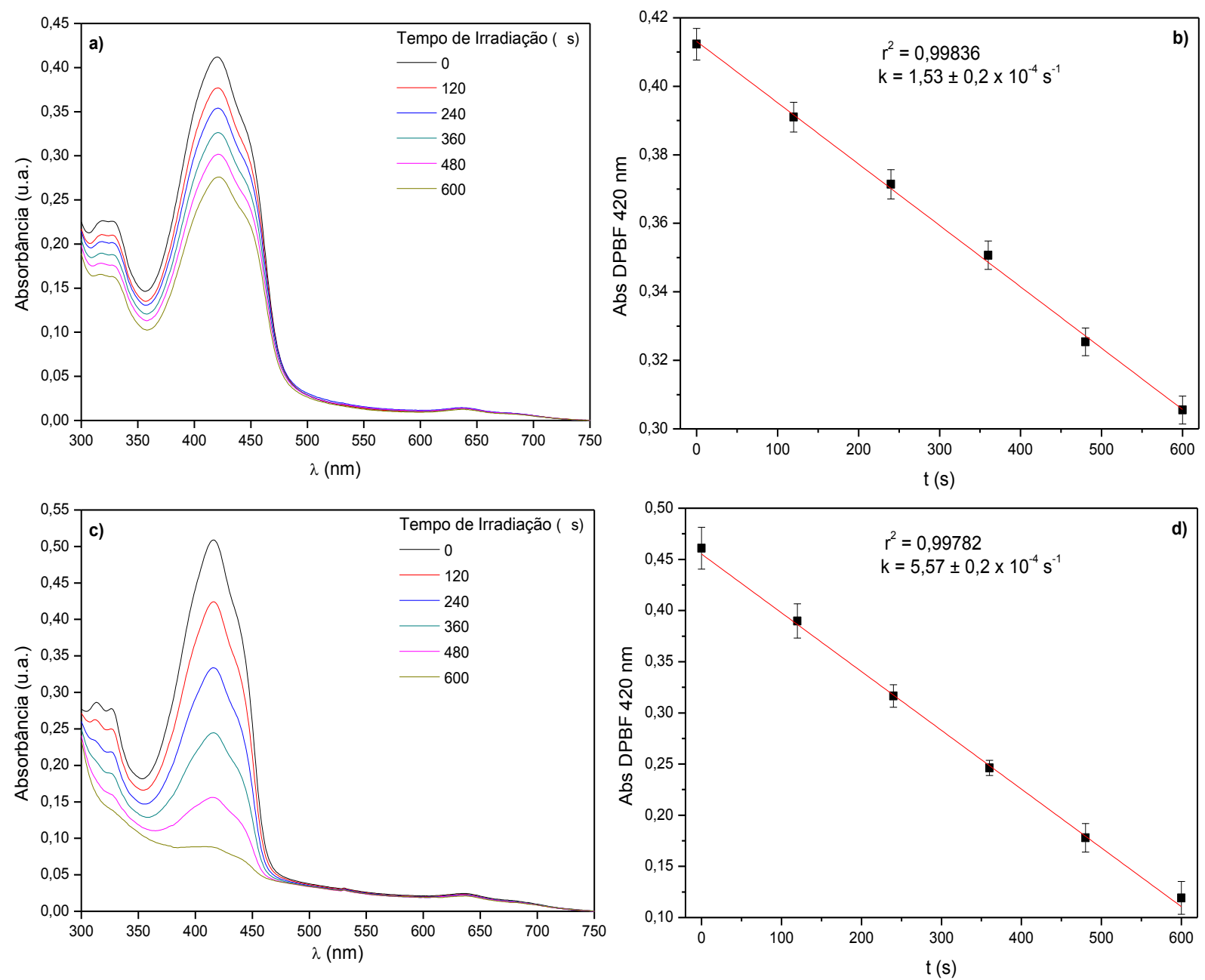

Figura 28:Espectros de absorção de $3,70 \times 10^{-5} \mathrm{~mol} \mathrm{~L}^{-1}$ de DPBF na presença de $2,65 \times 10^{-7} \mathrm{~mol} \mathrm{~L}^{-1}$ de a) FtZnT e c) FtZnT-NLS em tampão fosfato $\mathrm{pH}$ 7,0 depois de diferentes tempos de irradiação com LED vermelho $630 \pm 10 \mathrm{~nm}$. Constantes de velocidade de decomposição do DPBF para b) FtZnT e d) FtZnT-NLS.

O aumento da eficiência fotodinâmica utilizando o DPBF como captador de oxigênio singlete para a FtZnT encapsulada em NLS foi de $264 \%$ como mostra a Tabela 7. 
Tabela 7: Constantes de velocidade de fotodecomposição do DPBF para a FtZnT e FtZnT-NLS. Os valores são as médias \pm desvio padrão $(n=3)$, os valores referentes à FtZnT-NLS foram significativamente maior do que a FtZnT livre (teste t de Student, $p<0,05$ ).

\begin{tabular}{cc}
\hline FS & $\mathbf{k}\left(\mathbf{s}^{-1}\right) \times \mathbf{1 0}^{-4}$ \\
\hline FtZnT & $1,5 \pm 0,2$ \\
FtZnT-NLS & $5,6 \pm 0,2$ \\
Variação no valor de $\mathbf{k}(\%)$ & 264 \\
\hline
\end{tabular}

Este acréscimo de $264 \%$ no valor da constante de velocidade de fotodecomposição do DPBF em NLS foi provavelmente devido ao aumento da solubilidade e consequentemente uma diminuição na formação de agregados. Assim, aumentando o tempo de vida do estado tripleto do FS e como conseqüência uma maior formação de ${ }^{1} \mathrm{O}_{2}$ e maior fotodegradação do captador de oxigênio singlete. Resultados semelhantes foram obtidos com a hipericina como já foi discutido, indicando que para os dois tipos de FSs, Hy e FtZnT encapsulados com NLS, a produção de oxigênio singlete foi melhorada levando ao aumento da constante de velocidade de fotodecomposição do DPBF.

Rossi e colaboradores incorporaram a protoporfirina IX (Pp IX) em nanopartículas de sílica e obtiveram um acréscimo de $50 \%$ no rendimento quântico de formação de oxigênio singlete (Rossi, Silva et al., 2008). Segundo os autores, quanto maior for a agregação do FS, menor será a produção de oxigênio singlete e consequentemente diminuirá a eficiência fotodinâmica do FS. Vior et al também observaram melhoria na eficiência fotodinâmica de um derivado de ftalocianina de zinco (II) incorporado em NLS comparado com o FS livre. Os autores obtiveram um acréscimo de cerca de duas a três vezes na solubilidade do FS incorporado em NLS comparado com o FS livre e consequentemente obtiveram valores altos de rendimento quânticos de formação de ${ }^{1} \mathrm{O}_{2}$ (Garcia Vior, Monteagudo et al., 2011).

\section{Constante de velocidade de fotodecomposição do AU}

Como foi discutido anteriormente, o ácido úrico assim como o DPBF, reage irreversivelmente com ${ }^{1} \mathrm{O}_{2}$ gerado pela foto-excitação do $\mathrm{FS}$ de modo que este também é usado como dosímetro químico para a determinação quantitativa da ação fotodinâmica de FSs (Fischer, Graschew et al., 1998). Assim como foi feito com a 
hipericina, neste experimento foi acompanhado apenas a banda de absorção ótica do AU em $291 \mathrm{~nm}$. O ácido úrico não possui bandas de absorção em $630 \mathrm{~nm}$, comprimento de onda da irradiação, o que garantiu que a interação com a luz fosse restrita aos FSs como mostra Figura 18.

Foi observada uma diminuição da banda de absorção característica do AU em $291 \mathrm{~nm}$, após irradiação com LED $630 \pm 10 \mathrm{~nm}$ na intensidade de $70 \mathrm{~mW} \mathrm{~cm}{ }^{-2}$, indicando que ocorreu reação de fotodecomposição do $\mathrm{AU}$ pelo ${ }^{1} \mathrm{O}_{2}$ formado pelos FSs excitados. Após a irradiação foi determinada a constante de velocidade de fotodecomposição do AU obtendo-se os valores de 1,43 $\pm 0,09 \times 10^{-4}$ e 2,41 $\pm 0,06$ $x 10^{-4} \mathrm{~s}^{-1}$ para FtZnT livre e FtZnT-NLS respectivamente Figura 29 eTabela 8.
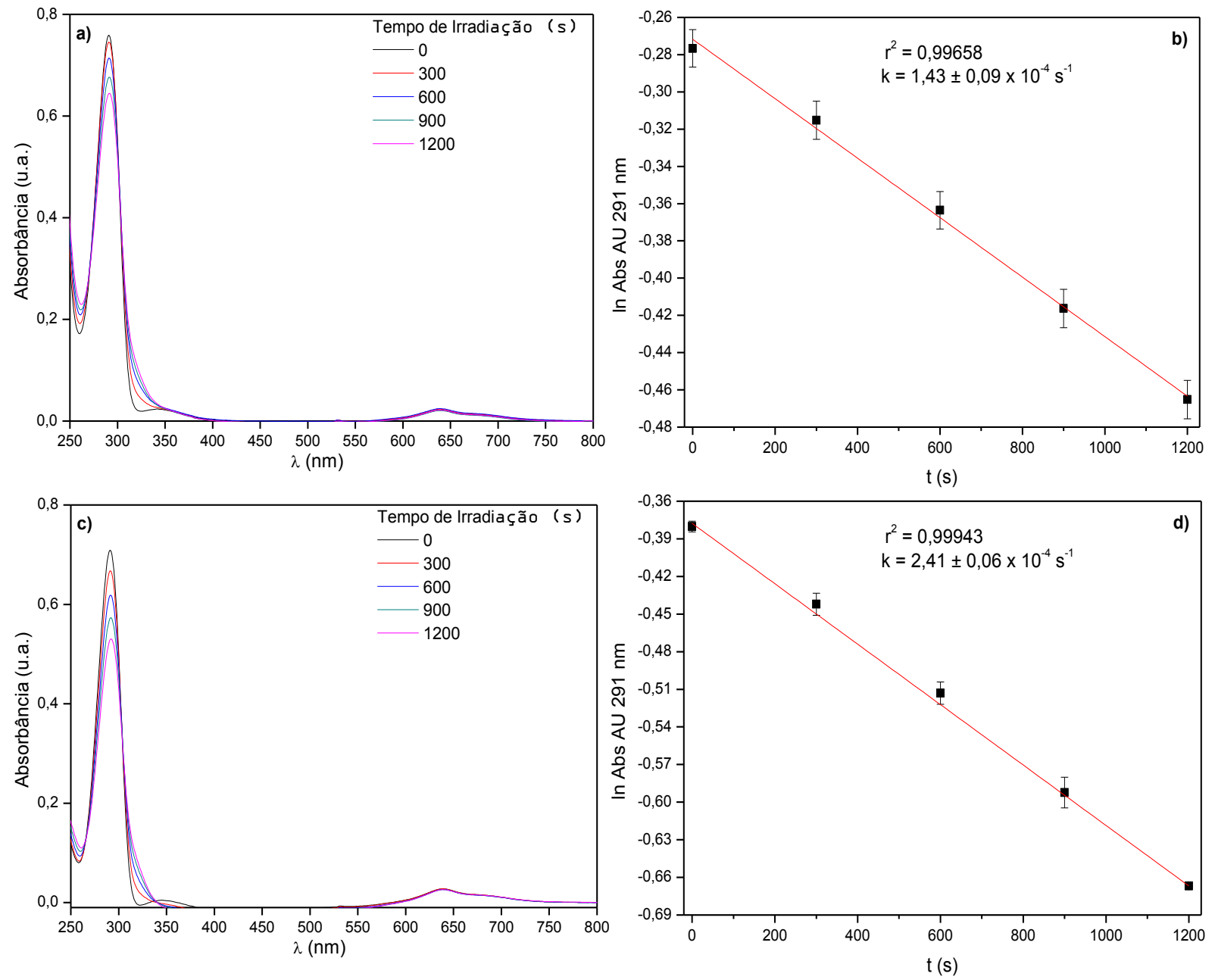

Figura 29:Espectros de absorção de 5,95 $\times 10^{-5} \mathrm{~mol} \mathrm{~L}^{-1}$ de AU na presença de $6,65 \times 10^{-7} \mathrm{~mol} \mathrm{~L}^{-1}$ de a) FtZnT e c) FtZnT-NLS em tampão fosfato $\mathrm{pH} 7,0$ depois de diferentes tempos de irradiação com LED vermelho $630 \pm 10 \mathrm{~nm}$. Constantes de velocidade de decomposição do AU para b) FtZnT e d) FtZnT-NLS. 
O aumento da eficiência fotodinâmica utilizando o ácido úrico como dosímetro químico de oxigênio singlete para a FtZnT e FtZnT-NLS foi de 69\% como apresentado na Tabela 8.

Tabela 8: Constantes de velocidade de decomposição do ácido úrico para a FtZnT e FtZnT-NLS. Os valores são as médias \pm desvio padrão $(n=3)$, os valores referentes à FtZnT-NLS foram significativamente maior do que a FtZnT livre (teste t de Student, $p<0,05$ ).

\begin{tabular}{cc}
\hline FS & $\mathbf{k}\left(\mathbf{s}^{-1}\right) \mathbf{~ 1 0 ^ { - 4 }}$ \\
\hline FtZnT & $1,4 \pm 0,1$ \\
FtZnT-NLS & $2,4 \pm 0,1$ \\
Variação no valor de $\mathbf{k}(\%)$ & 69 \\
\hline
\end{tabular}

Os resultados obtidos com este experimento condizem com os resultados referentes as constantes obtidas para Hy livre e Hy-NLS, ou seja, em todos os casos ocorreram aumentos significativos $(p<0,05)$ para os FS encapsulados em NLS condizente com a literatura (Konan, Gurny et al., 2002b; Rossi, Silva et al., 2008; Garcia Vior, Monteagudo et al., 2011; Perni, Prokopovich et al., 2011).

\subsubsection{Acumulação intracelular}

O conhecimento da concentração intracelular dos FSs pode ajudar a prever os resultados terapêuticos, pois quanto maior a acumulação intracelular de um FS maior será sua eficiência fotodinâmica (Kiesslich, Krammer et al., 2006).

Foram realizados os experimentos para determinar a concentração intracelular de FtZnT livre e FtZnT-NLS em três tempos de incubação (12, 18 e 24 horas) nas mesmas linhagens celulares utilizadas para a hipericina que foram as linhagens HEp-2 e B16-F10.

Como a curva padrão para a concentração de proteína já havia sido obtida, foi necessário fazer apenas a curva padrão para a FtZnT. A Figura 30apresenta os espectros de emissão das soluções de FtZnT em DMSO e a curva analítica para a FtZnT respectivamente.A relação obtida apresentou uma boa linearidade, portanto foi possível, através da equação da reta estimar a concentração de FtZnT previamente incubado com as células com FtZnT e FtZnT -NLS após a extração com DMSO. Não foi utilizado o etanol para fazer a extração da FtZnT do interior das células como foi feito para a Hy, porque o etanol foi testado e não foi possível extrair com alta eficiência a FtZnT do interior das células. 

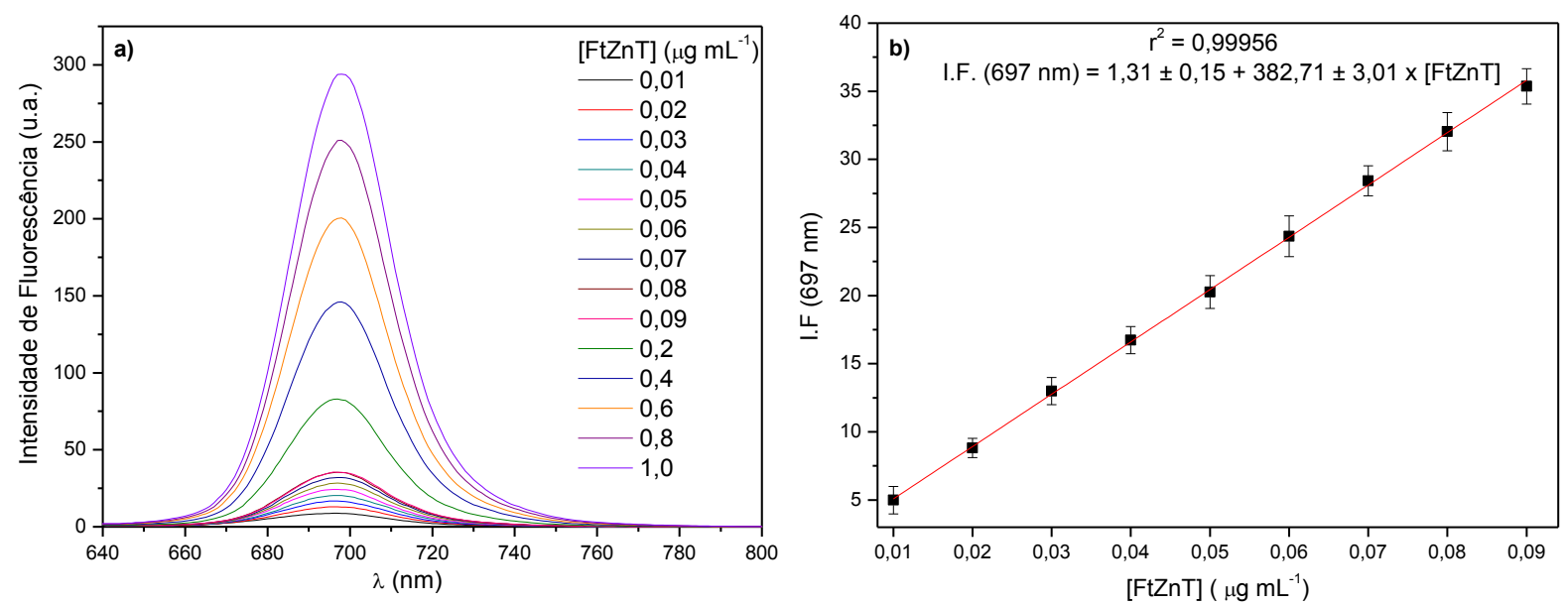

Figura 30:a) Espectro de emissão variando a concentração da FtZnT em DMSO com excitação em $620 \mathrm{~nm}$ e emissão em $630-800 \mathrm{~nm}$. b) Curva analítica para a FtZnT obtida a partir das intensidades de fluorescência em $697 \mathrm{~nm}$. Experimentos foram realizados em triplicata $(n=3)$.

Com o objetivo de determinar a concentração intracelular de FtZnT e FtZnTNLS em três tempos de incubação (12, 18 e 24 h), nas células HEp-2 e B16-F10, foram realizados ensaios incubando-se os FSs nestes tempos de acumulação com estas duas linhagens celulares. Após a extração dos FSs das células com DMSO, a fluorescência foi obtida e através deste valor a concentração do FS foi determinada utilizando a curva padrão e depois normalizada pela concentração de proteína, obtida pelo método de Lowry. Os resultados de acumulação de FtZnT e FtZnT-NLS nas células HEp-2 e B16-F10 em função do tempo de incubação estão apresentados naFigura 31 e Tabela 9.
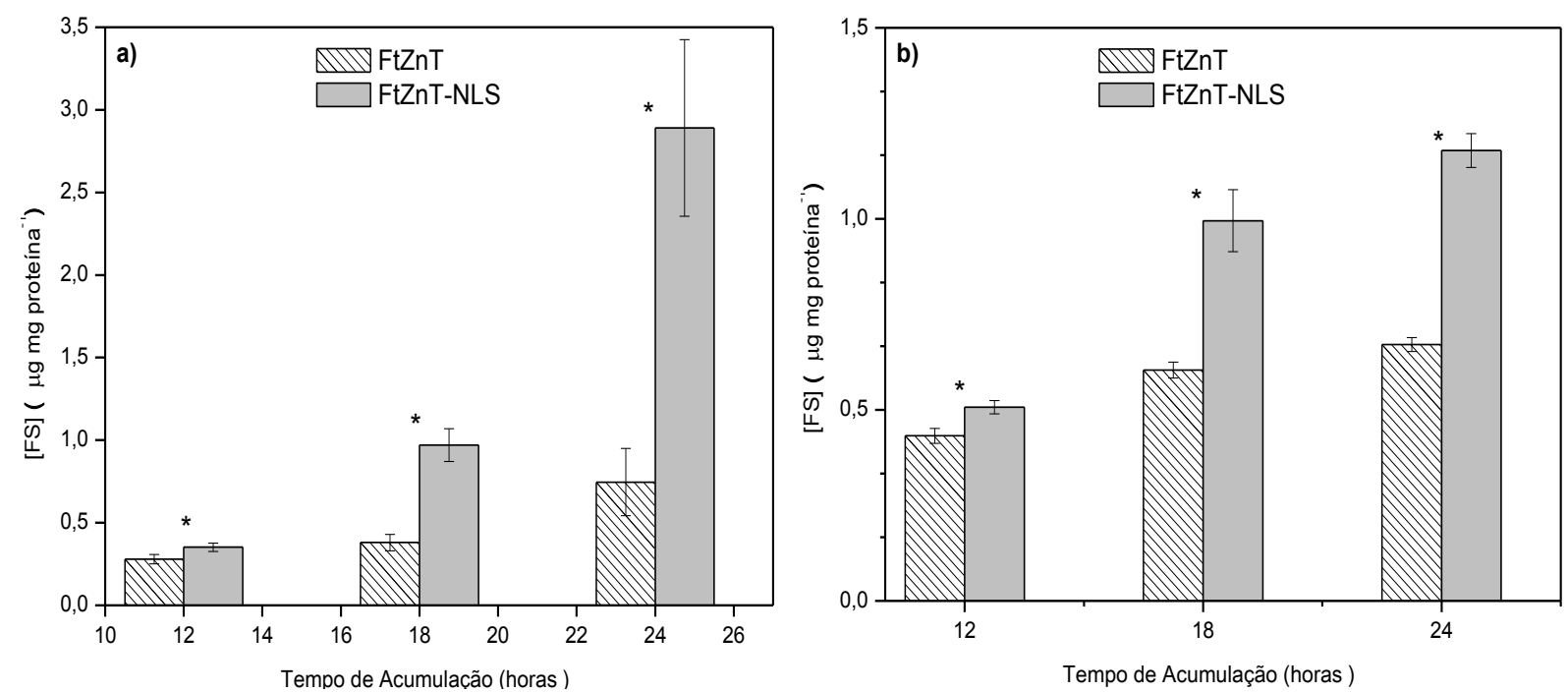

Figura 31:Acumulação intracelular de FtZnT e FtZnT-NLS nos tempos de incubação de 12, 18 e 24 horas nas células a) HEp-2 e b) B16-F10. Os valores são as médias \pm desvio padrão $(n=3)$. As diferenças são consideradas estatisticamente significantes quando ${ }^{*} p<0,05$ (teste t de Student). 
Os resultados da acumulação intracelular do FS nas linhagens celulares HEp2 e B16-F10 incubado em três tempos de incubação diferentes estão mostrados na Tabela 9.

Tabela 9:Acumulação intracelular de FtZnT e FtZnT-NLS nos tempos de incubação de 12 horas, 18 horas e 24 horas nas células HEp-2 e B16-F10. Os valores são as médias \pm desvio padrão $(n=3)$. As diferenças são consideradas estatisticamente significantes quando $p<0,05$ (teste t de Student).

\begin{tabular}{c|ccc|ccc}
\hline \multirow{3}{*}{ FS } & \multicolumn{5}{|c}{ Acumulação intracelular ( $\boldsymbol{\mu g}$ mg proteína ${ }^{-1}$ ) } \\
\cline { 2 - 7 } & \multicolumn{5}{|c}{ HEp-2 } & \multicolumn{3}{c}{ B16-F10 } \\
\cline { 2 - 7 } & \multicolumn{6}{c}{ Tempo de Acumulação (h) } \\
\cline { 2 - 7 } & $\mathbf{1 2}$ & $\mathbf{1 8}$ & $\mathbf{2 4}$ & $\mathbf{1 2}$ & $\mathbf{1 8}$ & $\mathbf{2 4}$ \\
\hline FtZnT & $0,28 \pm 0,03$ & $0,38 \pm 0,05$ & $0,75 \pm 0,20$ & $0,43 \pm 0,02$ & $0,60 \pm 0,02$ & $0,67 \pm 0,02$ \\
FtZnT-NLS & $0,35 \pm 0,03$ & $0,97 \pm 0,10$ & $2,90 \pm 0,54$ & $0,51 \pm 0,02$ & $1,00 \pm 0,10$ & $1,18 \pm 0,04$ \\
Variação (\%) & 25 & 155 & 287 & 19 & 67 & 76 \\
\hline
\end{tabular}

A diferença de acumulação entre a FtZnT livre e a FtZnT-NLS aumentou conforme os FSs foram incubados por maior tempo. Os resultados mostraram que após o encapsulamento da FtZnT em NLS houve uma maior acumulação nas células tumorais, este resultado também foi obtido com a incorporação da hipericina neste mesmo sistema de NLS, conforme já discutido. Este acréscimo na acumulação intracelular da Hy-NLS e da FtZnT-NLS comparado com a Hy e a FtZnT livres, ocorreu provavelmente por causa do aumento da solubilidade das Hy-NLS em meio aquoso e da biocompatibilidade das nanopartículas lipídicas sólidas, assim facilitando a entrega destes FSs lipofílicos às células-alvo. Esse aumento na acumulação de FSs incorporados em NLS já foi observado em outros estudos descritos na literatura (Garcia Vior, Monteagudo et al., 2011; Martins, Costa-Lima et al., 2012; Zhu, Cheng et al., 2012). Ocorreu uma diferença maior na acumulação nas células HEp-2 em 24 horas, por causa da maior sensibilidade desta linhagem celular exposta a um tempo prolongado ao FS.

\subsubsection{Ensaios citotóxicos}

Os experimentos de fototoxicidade das FtZnT livre e FtZnT-NLS foram realizados com as linhagens HEp-2 e B16-F10. Este ensaio não foi realizado nas mesmas condições utilizadas para a hipericina, como dose luz e tempo de 
incubação, pois estas condições foram testadas e não tiveram efeitos fototóxicos. Por esta razão foi necessário buscar outras condições experimentais para poder comparar a eficiência da FtZnT encapsulada em NLS com a FtZnT livre. Foram utilizadas três doses de luz $\left(50,100\right.$ e $\left.150 \mathrm{~J} \mathrm{~cm}^{-2}\right)$, ou seja, três tempos de irradiação (12, 24 e $36 \mathrm{~min})$ com o LED $630 \pm 10 \mathrm{~nm}$ na intensidade de $70 \mathrm{~mW} \mathrm{~cm}{ }^{-2}$, após $18 \mathrm{~h}$ de incubação com FtZnT e FtZnT-NLS. Ensaios citotóxicos na ausência de irradiação foram feitos a fim de se verificar a toxicidade intrínseca dos FSs nas células, ou seja, a citotoxicidade no escuro e também controles da sobrevivência celular após irradiação da luz visível na ausência do FSs.

\section{Citotoxidade da Luz nas células tumorais}

Foram realizados ensaios para verificar o efeito da luz nas três diferentes doses de luz (50, 100 e $150 \mathrm{~J} \mathrm{~cm}^{-2}$ ) utilizadas para este experimento emitidas com LED $630 \pm 10 \mathrm{~nm}$ na intensidade de $70 \mathrm{~mW} \mathrm{~cm}^{-2}$ nas linhagens HEp-2 e B16-F10. Tais estudos foram feitos para certificar que a luz sem FS não poderia causar amorte das células (Figura 32).

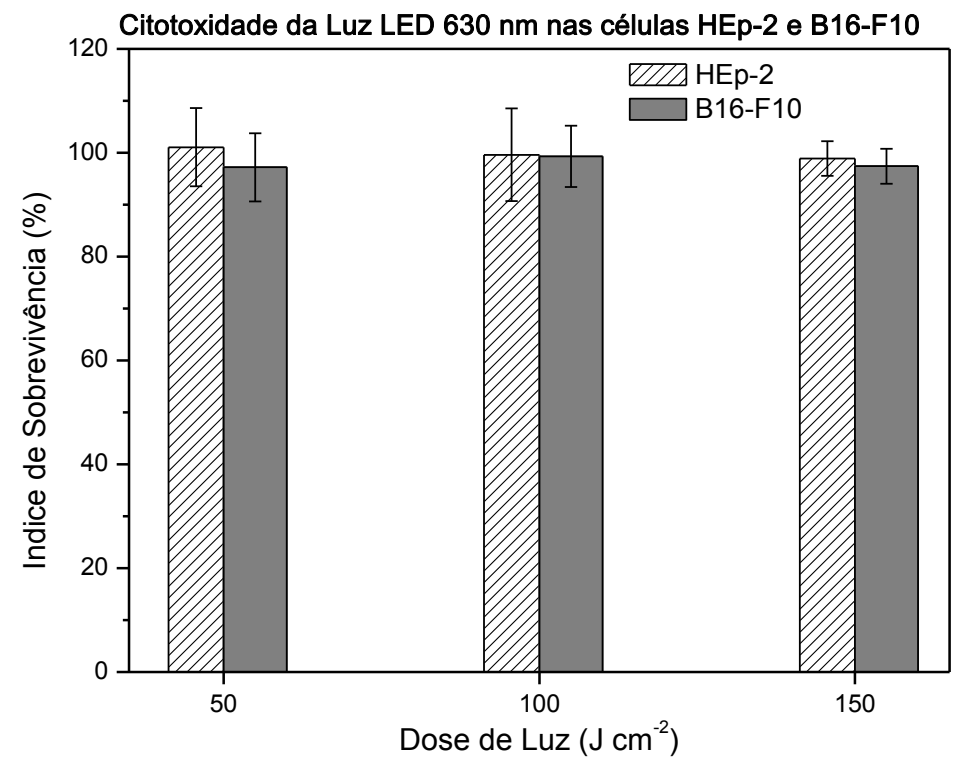

Figura 32: O efeito da dose de luz sobre a viabilidade celular HEp-2 e B16-F10. Os valores são as médias \pm desvio padrão $(n=18)$ a resultado não foi significativamente diferente (teste t de Student, $p$ $>0,05)$.

Como foi discutido anteriormente, a utilização de altas doses de luz pode causar um aquecimento local resultando em alterações nos níveis dos constituintes 
celulares sensíveis às variações de temperatura, tais como proteínas, DNA ou RNA, podendo causar a inibição do crescimento celular. Porem pode-se observar que não houve alterações significativas na sobrevivência das células ( $p>0,05)$. Desse modo, nos estudos fototóxicos, utilizou-se LED com tempo de irradiação máximo correspondendo a dose de $150 \mathrm{~J} \mathrm{~cm}^{-2}$, sendo a duração da irradiação de 36 min para garantir que o efeito da luz não apresentasse efeito tóxico significativo às células.

\section{Citotoxidade da FtZnT livre, NLS e FtZnT-NLS nas células HEp-2 e B16- F10 no escuro}

Foram incubadas por 18 horas FtZnT livre, NLS branca e FtZnT-NLS com suspensão de $1 \times 10^{5}$ células $\mathrm{mL}^{-1}$ sem a presença de luz. Após este período o FS foi retirado e após $24 \mathrm{~h}$ foi realizado o ensaio com MTT. Foi possível confirmar que não ocorreu morte significativa das células HEp-2 e B16-F10 $(p>0,05)$ como apresentado na Figura 33.
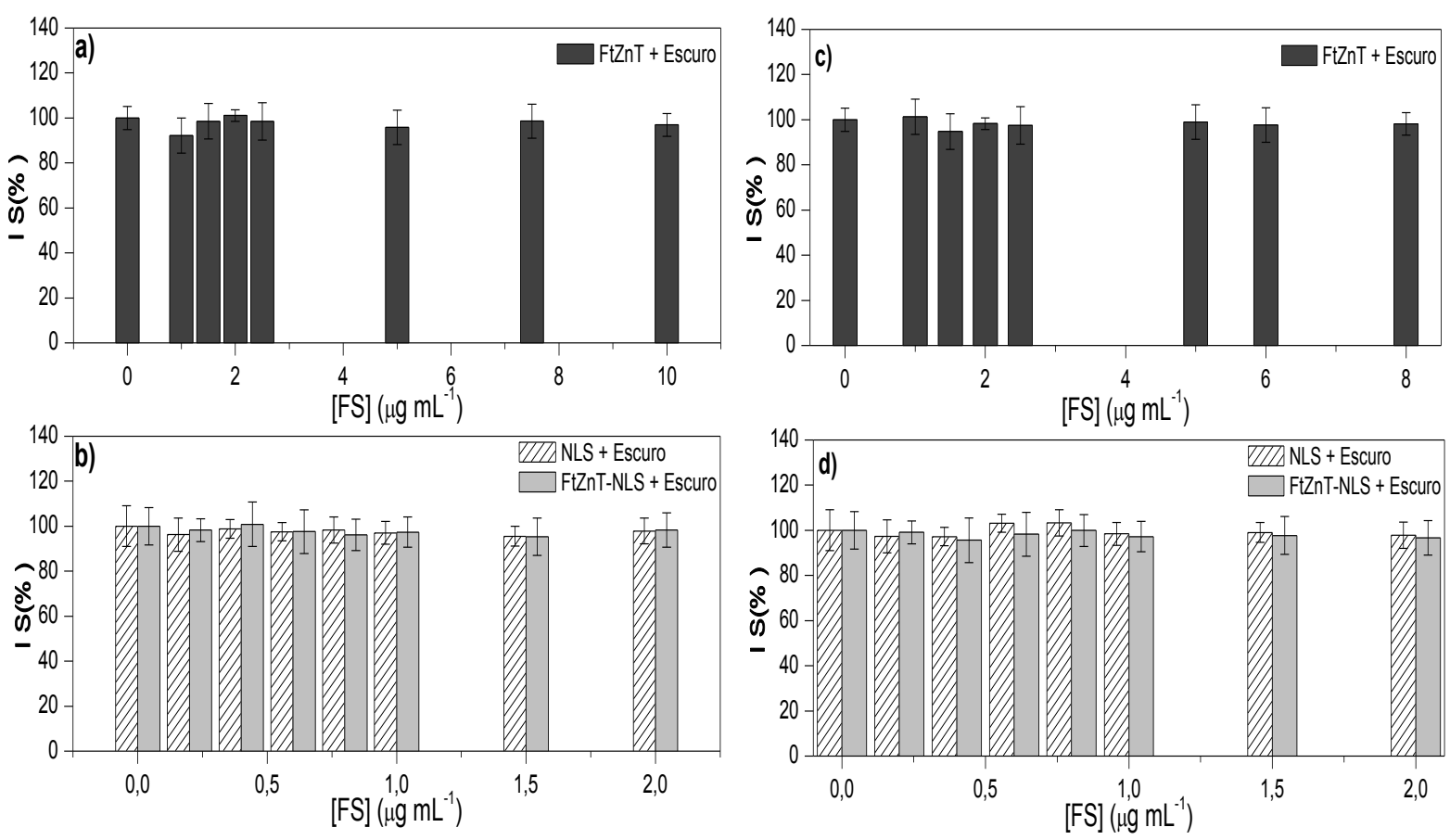

Figura 33: Viabilidade celular após 18 horas de incubação com diferentes concentrações de FtZnT, FtZnT-NLS e NLS no escuro para HEp-2 (a, b) e para B16-F10 (c, d). Os valores são as médias \pm desvio padrão $(n=18)$ o resultado não foi significativamente diferente (teste $t$ de Student, $p>0,05)$.

FtZnT livre e FtZnT-NLS também não provocaram morte significativa no escuro. Esses resultados estão de acordo com resultados já descritos na literatura 
(Konan, Berton et al., 2003; Zeisser-Labouebe, Lange et al., 2006; Da Silva, Inada et al., 2009), portanto a morte celular foi proveniente da interação da luz, FS e oxigênio.

Efeito da dose de irradiação na fototoxicidade da FtZnT, NLS e FtZnTNLS nas células HEp-2 e B16-F10

Nos ensaios citotóxicos na presença de luz foram utilizados tempos de irradiação de 12, 24 e 36 min equivalentes as doses de luz de 50, 100 e $150 \mathrm{~J} \mathrm{~cm}^{-2}$. As células HEp-2 foram incubadas por $18 \mathrm{~h}$ com os FSs em várias concentrações (0 - $\left.10 \mu \mathrm{g} \mathrm{mL}^{-1}\right)$ para FtZnT e $\left(0-2 \mu \mathrm{g} \mathrm{m}^{-1}\right)$ para FtZnT-NLS e NLS branca em meio de cultura, como mostra a figura 34. 

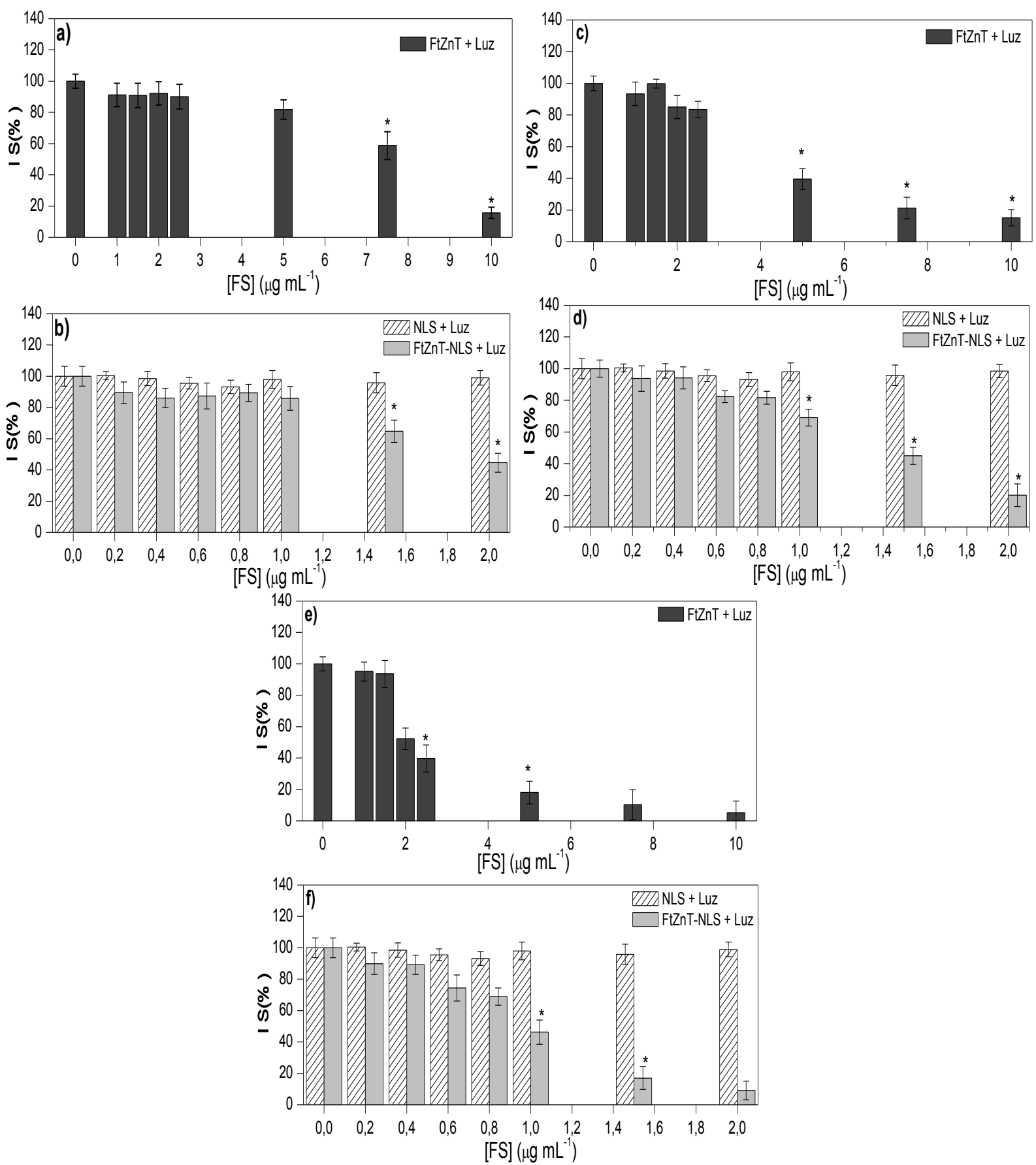

Figura 34:O efeito fototóxico nas células HEp-2 de diferentes concentrações de FtZnT e FtZnT-NLS, 18 horas de incubação e utilizando três doses de luz diferentes sob irradiação com LED $630 \pm 10 \mathrm{~nm}$ com. Para a FtZnT e doses de luz de a) 50 , c) 100 , e) $150 \mathrm{~J} \mathrm{~cm}^{-2}$ e para FtZnT-NLS b) 50 , d) 100 , f) $150 \mathrm{~J} \mathrm{~cm}^{-2}$. Os valores são as médias \pm desvio padrão $(\mathrm{n}=18){ }^{*}$ resultado foi significativamente diferente (teste t de Student, $p<0,05$ ).

Após irradiação com LED $630 \pm 10 \mathrm{~nm}$ e do ensaio com MTT foram determinados os valores de $I_{50}$ utilizando o programa CalcuSyn nas três doses de luz utilizadas (Tabela 10). 

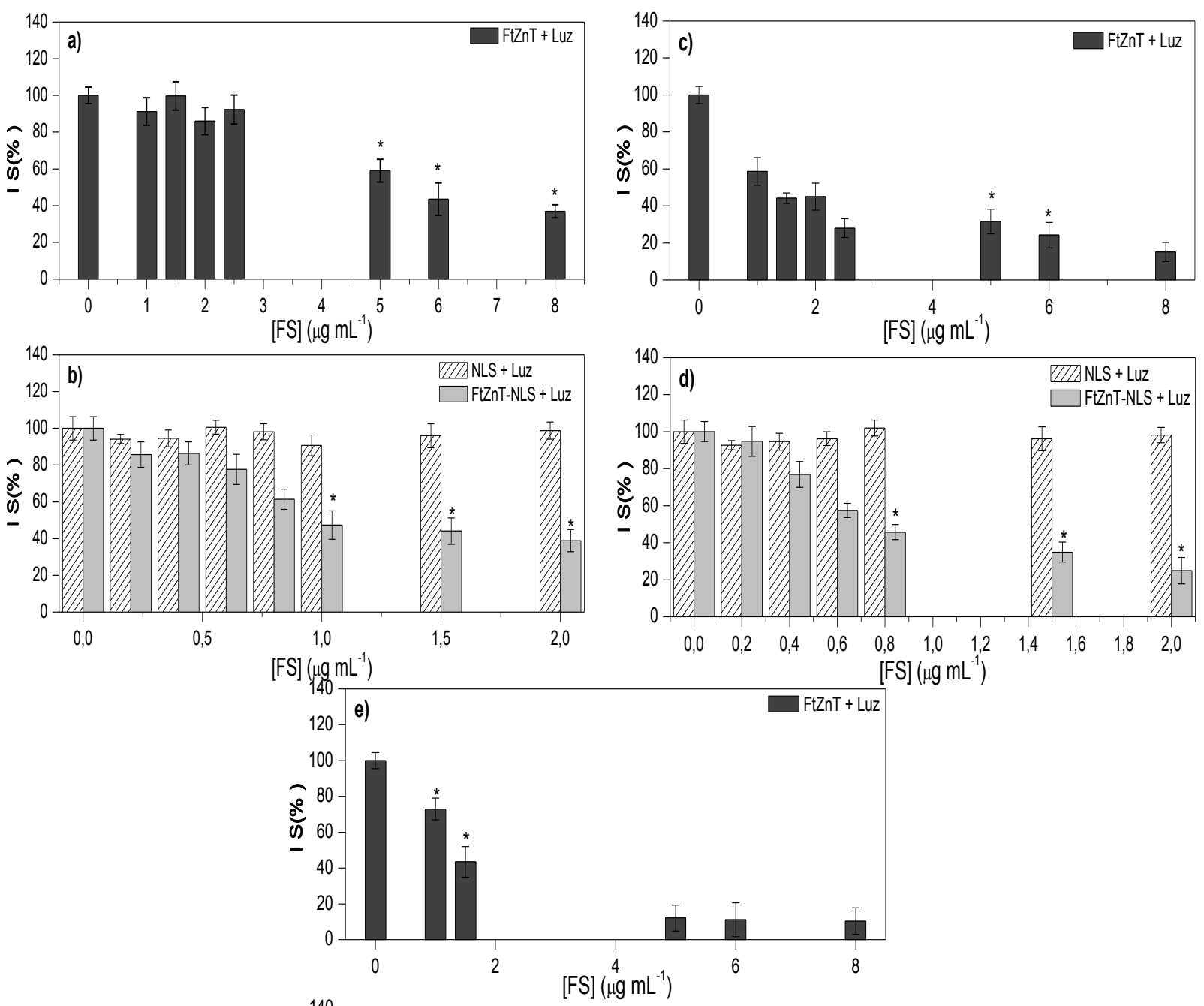

$[\mathrm{FS}]\left(\mu \mathrm{gg} \mathrm{m}^{-1}\right)$
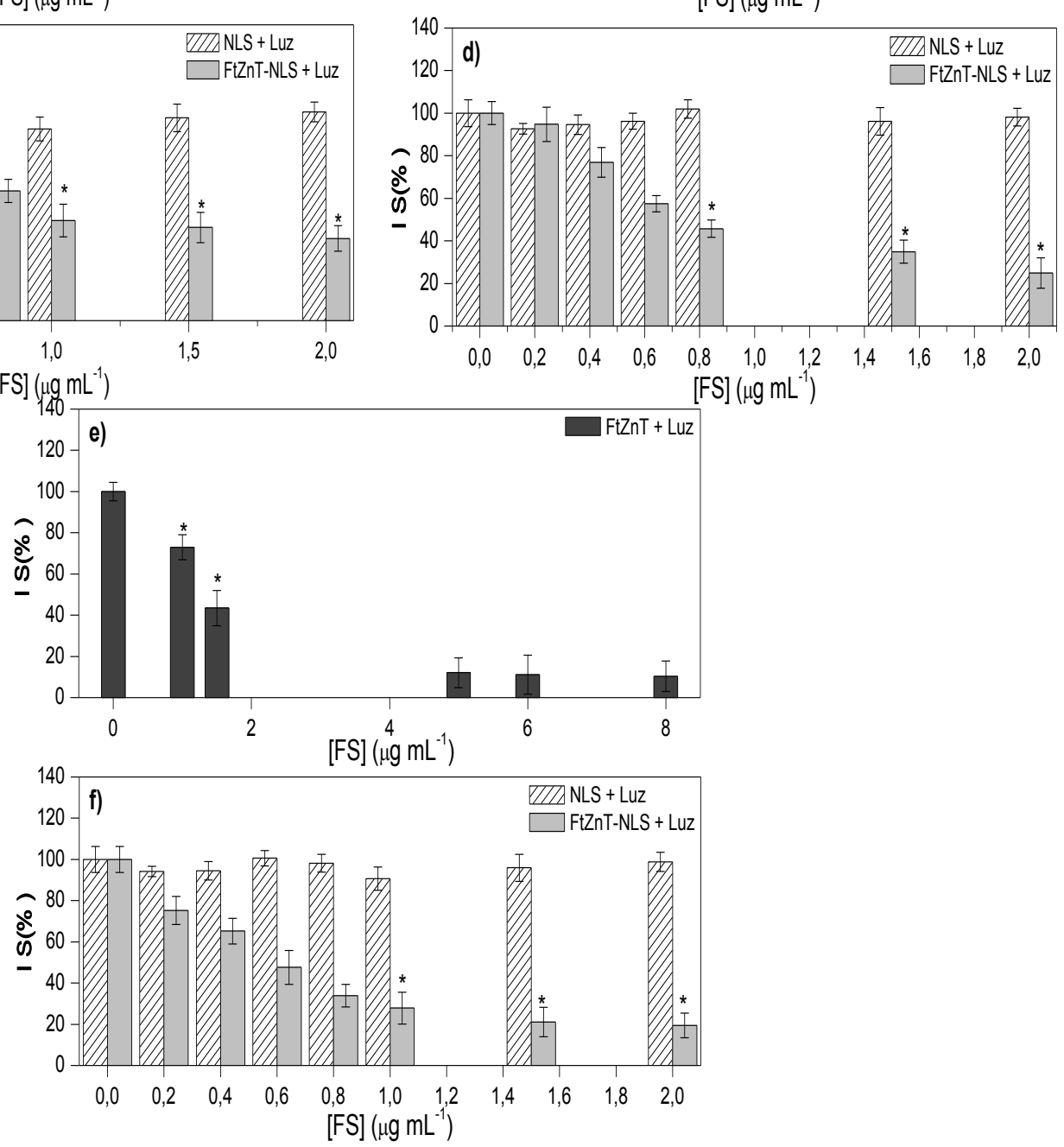

Figura 35: O efeito fototóxico nas células B16-F10 de diferentes concentrações de FtZnT e FtZnTNLS, 18 horas de incubação e utilizando três doses de luz diferentes sob irradiação com LED $630 \pm$ $10 \mathrm{~nm}$ com. Para a FtZnT e doses de luz de a) 50 , c) 100 , e) $150 \mathrm{~J} \mathrm{~cm}^{-2}$ e para FtZnT-NLS b) 50 , d) 100, f) $150 \mathrm{~J} \mathrm{~cm}^{-2}$. Os valores são as médias \pm desvio padrão $(\mathrm{n}=18)$, ${ }^{*}$ resultado foi significativamente diferente (teste t de Student, $p<0,05$ ). 
Tabela 10:A concentração média inibitória $\left(\mathrm{IC}_{50}\right)$ de FtZnT e FtZnT-NLS das células tumorais HEp-2 e B16-F10 na presença de luz LED $630 \pm 10 \mathrm{~nm}$ com três doses de luz diferente e 18 horas de incubação. Os valores são as médias \pm desvio padrão $(n=18)$. As diferenças são consideradas estatisticamente significantes quando $\mathrm{p}<0,05$ (teste $t$ de Student).

\begin{tabular}{c|ccc|ccc}
\hline \multirow{3}{*}{ FS } & \multicolumn{6}{|c}{ IC $_{50}(\boldsymbol{\mu M})$} \\
\cline { 2 - 7 } & \multicolumn{7}{|c}{ Dose de luz $\left(\mathbf{J ~ c m}^{-2}\right)$} \\
\cline { 2 - 7 } & $\mathbf{5 0}$ & $\mathbf{1 0 0}$ & $\mathbf{1 5 0}$ & $\mathbf{5 0}$ & $\mathbf{1 0 0}$ & $\mathbf{1 5 0}$ \\
\hline Hy & $9,32 \pm 0,9$ & $5,97 \pm 0,4$ & $3,63 \pm 0,2$ & $5,21 \pm 0,5$ & $2,16 \pm 0,2$ & $1,60 \pm 0,1$ \\
Hy-NLS & $2,40 \pm 0,02$ & $1,70 \pm 0,06$ & $1,18 \pm 0,09$ & $1,35 \pm 0,1$ & $1,16 \pm 0,01$ & $0,54 \pm 0,05$ \\
Variação (\%) & 388 & 351 & 307 & 19 & 67 & 76 \\
\hline
\end{tabular}

Pode-se constatar que os valores de $\mathrm{IC}_{50}$ diminuíram drasticamente com a dose de luz. Aviabilidade celular também é dependente da concentração do FS o que pode ser observado nas figuras 34 e 35. Esta relação só não foi obedecida nas cinco primeiras concentrações utilizadas para a FtZnT livre e FtZnT-NLS na dose de luz de $50 \mathrm{~J} \mathrm{~cm}^{-2}$, isso ocorreu porque a quantidade de espécies reativas de oxigênio formadas com essa dose de luz não foram suficiente para levar à uma morte celular significativa $(p>0,05)$.

Neste ensaio fototóxico os resultados foram semelhantes aos obtidos com a hipericina livre e incorporada em NLS, ou seja, os valores de $\mathrm{IC}_{50}$ para a FtZnT-NLS foram mais baixos do que para a FtZnT livre. Isso indica que a FtZnT encapsulada com NLS tornou-se significativamente $(p<0,05)$ mais fototóxica do que a FtZnT livre supostamente devido a uma menor formação de agregados, consequentemente um aumento no tempo de vida do estado tripleto, como pode ser visto nos resultados das constantes de velocidade de fotodecomposição do DPBF e ácido úrico (Tabelas 8 e 9). Outro fator importante para o aumento da eficiência fototóxica foi a maior acumulação intracelular dos FSs incorporados em NLS comparados com os FSs livres como pode ser observados na para a Hy livre e Hy-NLS e a Tabela 9para FtZnT livre e FtZnT-NLS. A acumulação intracelular é uma característica muito importante para diminuir a viabilidade celular, pois se analisarmos a figura 34 que corresponde aos ensaios fototóxicos nas células HEp-2 e comparar com a figura 35 que corresponde às células $\mathrm{B} 16-\mathrm{F} 10$, pode-se perceber que a viabilidade nas células B16-F10 foi menor comparando-se com as células HEp-2. Isto pode ser comprovado observando a Tabela 9que mostra uma maior acumulação intracelular 
de FS nas células B16-F10 do que nas células HEp-2, consequentemente levando a uma maior morte celular.

Guo e colaboradores prepararam 2-metoxi-estradiol (2-ME), incorporado em NLS e estudaram a fototoxicidade em três linhagens de células. Eles obtiveram uma porcentagem maior de morte celular para o fármaco em NLS do que para o fármaco livre em solução (Guo, Xing et al., 2012). Zhu et al. obtiveram resultados mais eficientes após a encapsulação de um fármaco hidrofóbico em nanopartículas lipídicas sólidas. Os resultados deste trabalho para os dois tipos de FSs encapsulados em NLS, sendo estes, a hipericina e a tetra-carboxiftalocianinade zinco, estão de acordo com o que está descrito na literatura.

\section{Conclusões}

Neste trabalho foram preparados dois fotossensibilizadores encapsulados em nanopartículas lipídicas sólidas (Hipericina e Tetra-carboxiftalocianina de zinco) para possível aplicação em Terapia Fotodinâmica. As nanopartículas lipídicas sólidas brancas (sem FS) e as NLS com FS foram preparadas usando a técnica de ultrasonicação exibindo tamanhos homogêneos nas nanopartículas e valores altos de eficiência de encapsulação para os dois FSs utilizados neste estudo.

As NLS brancas (sem FS) não apresentaram efeitos citotóxicos e fototóxicos nas condições experimentais utilizadas, uma característica muito importante que deve possuir os sistemas de entrega de qualquer fármaco ou fotossensibilizador. Os FSs incorporados nas nanopartículas lipídicas sólidas também não apresentaram efeito citotóxico no escuro. Após o encapsulamento dos FSs também foi observado um acréscimo na acumulação intracelular e na fototoxicidade nas duas linhagens celulares utilizadas, em três doses de luz e várias concentrações de FS. Além disso, foi observado que a incorporação da hipericina em NLS provocou um aumento na foto-estabilidade da Hy indicando que o FS fica mais protegido da fotodegradação quando está incorporado em matrizes de nanopartículas lipídicas sólidas.

Os dois FSs incorporados em NLS mostraram valores maiores de constantes de velocidade para a foto-decomposição do DPBF e de ácido úrico comparado com os FSs livres o que sugere maior atividade fotodinâmica. Esses resultados podem ser explicados por uma menor agregação causada pelo aumento da solubilidade e 
consequentemente um possível aumento do tempo de vida do estado triplete dos fotossensibilizadores. A intensidade de fluorescência da Hy e Hy-NLS em meio aquoso diminui com o aumento da concentração indicando agregação, pois agregados não fluorescem, porém a diminuição da fluorescência para a Hy-NLS foi menos efetiva comparada com a Hy livre, sugerindo menor agregação da $\mathrm{Hy}$ incorporada em NLS. Esse resultado corrobora com os valores de constantes de velocidade para a foto-decomposição do DPBF e de ácido úrico.

Portanto, este estudo mostra que após a encapsulação destes dois FSs hidrofóbicos (Hipericina e Tetra-carboxiftalocianina de zinco) a foto-estabilidade, a eficiência fotodinâmica, a acumulação intracelular e fototoxicidade in vitro foram melhoradas em comparação com os FSs livres. Assim sendo, pode-se concluir que as nanopartículas lipídicas sólidas constituem um bom sistema para melhorar a entrega de fotossensibilizadores. 


\section{Referências Bibliográficas}

AGOSTINIS, P. et al. Hypericin in cancer treatment: more light on the way. International Journal of Biochemistry \& Cell Biology, v. 34, n. 3, p. 221-241, 2002.

ALLISON, R. R. et al. Photosensitizers in clinical PDT. Photodiagnosis and Photodynamic Therapy, v. 1, n. 1, p. 27-42, 2004.

AMERICAN TYPE CULTURE COLLECTION: Cell lines. Disponivel em: <www.atcc.org> acesso em 05 de Agosto 2011.

ATKINS, P. W. Physical Chemistry. New York: Oxford University Press, 1995, 545 p.

ATTAMA, A. A. et al. Solid lipid nanodispersions containing mixed lipid core and a polar heterolipid: Characterization. European Journal of Pharmaceutics and Biopharmaceutics, v. 67, n. 1, p. 48-57, 2007.

AVERY, H. E. Cinética Química Básica y Mecanismos de Reaccion. Barcelona: Reverte, 1982. $190 \mathrm{p}$.

BARROS NETO, B.; SCARMINIO, I. S.; BRUNS, R. E. Planejamento deotimização de experimentos. Campinas: Editora da Unicamp, 1996. $299 \mathrm{p}$

BEZMAN, S. A. et al. Photodynamic inactivation of escherichia-coli by rose-bengal immobilized on polystyrene beads. Photochemistry and Photobiology, v. 28, n. 3, p. 325329, 1978.

BROWN, J. E.; BROWN, S. B.; VERNON, D. I. Photodynamic therapy - new light on cancer treatment. Journal of the Society of Dyers and Colourists, v. 115, n. 9, p. 249-253, 1999.

BROWN, S. B.; TRUSCOTT, T. G. NEW LIGHT ON CANCER-THERAPY. Chemistry in Britain, v. 29, n. 11, p. 955-958, 1993.

BRYAN, G.T. Histórias Naturais dos Cânceres. Manual de oncologia clínica. Berlin: Springer-Verlag, 1999. P. 28-31.

BUGAJ, A. M. Targeted photodynamic therapy - a promising strategy of tumor treatment. Photochemical \& Photobiological Sciences, v. 10, n. 7, p. 1097-1109, 2011.

BUTLER, M. Mammalian cell biotechnology a practical approach. New York: Oxford University Press, p. 245, 1991.

CARMICHAEL, J. et al. Evaluation of a tetrazolium-based semiautomated colorimetric assay - assessment of chemosensitivity testing. Cancer Research, v. 47, n. 4, p. 936-942, 1987. 
CASTANO, A. P.; DEMIDOVA, T. N.; HAMBLIN, M. R. Mechanisms in photodynamic therapy: part one-photosensitizers, photochemistry and cellular localization. Photodiagnosis and Photodynamic Therapy, v. 1, n. 4, p. 279-293, 2004.

- Mechanisms in photodynamic therapy: Part three-Photosensitizer pharmacokinetics, biodistribution, tumor localization and modes of tumor destruction. Photodiagnosis and Photodynamic Therapy, v. 2, n. 2, p. 91-106, 2005.

CASTANO, A. P.; MROZ, P.; HAMBLIN, M. R. Photodynamic therapy and anti-tumour immunity. Nature Reviews Cancer, v. 6, n. 7, p. 535-545, 2006.

CHANDRASEKHAR, S. Stochastic Problems in Physics and Astronomy. Reviews of Modern Physics, v. 15, n. 1, p. 1-89, 1943.

CHATTERJEE, D. K.; FONG, L. S.; ZHANG, Y. Nanoparticles in photodynamic therapy: An emerging paradigm. Advanced Drug Delivery Reviews, v. 60, n. 15, p. 1627-1637, 2008.

CHOU, T.C.; HAYBALL, M. CalcuSyn: Windows software for dose effect analysis. Cambridge: Biosoft, 1996.

CINCOTTA, L.; FOLEY, J. W.; CINCOTTA, A. H. Novel red absorbing benzo a phenoxazinium and benzo a phenothiazinium photosensitizers - invitro evaluation. Photochemistry and Photobiology, v. 46, n. 5, 1987.

COHEN, E. M. et al. Polymeric micelle nanoparticles for photodynamic treatment of head and neck cancer cells. Otolaryngology-Head and Neck Surgery, v. 143, n. 1, p. 109-115, 2010.

D'HALLEWIN, M. A.; BEZDETNAYA, L.; GUILLEMIN, F. Fluorescence detection of bladder cancer: A review. European Urology, v. 42, n. 5, p. 417-425, 2002.

DA SILVA, A. R. et al. In vitro photodynamic activity of chloro(5,10,15,20tetraphenylporphyrinato) indium(III) loaded-poly(lactide-co-glycolide) nanoparticles in LNCaP prostate tumour cells. Journal of Photochemistry and Photobiology B-Biology, v. 94, n. 2, 2009.

DANIELL, M. D.; HILL, J. S. A HISTORY OF PHOTODYNAMIC THERAPY. Australian and New Zealand Journal of Surgery, v. 61, n. 5, p. 340-348, 1991.

DENIZOT, F.; LANG, R. Rapid colorimetric assay for cell-growth and survival - modifications to the tetrazolium dye procedure giving improved sensitivity and reliability. Journal of Immunological Methods, v. 89, n. 2, p. 271-277, 1986.

DIAMOND, I. et al. Photodynamic therapy of malignant tumours. The Lancet, v. 300, n. 7788, p. 1175-1177, 1972.

DOLMANS, D.; FUKUMURA, D.; JAIN, R. K. Photodynamic therapy for cancer. Nature Reviews Cancer, v. 3, n. 5, p. 380-387, 2003. 
DOUGHERTY, T. J. et al. Photoradiation Therapy for the Treatment of Malignant Tumors. Cancer Research, v. 38, n. 8, p. 2628-2635, 1978.

DOUGHERTY, T. J.; MARCUS, S. L. PHOTODYNAMIC THERAPY. European Journal of Cancer, v. 28A, n. 10, p. 1734-1742, 1992.

DOUGHERTY, T. J., W. R. POTTER and K. R. WEISHAUPT. The structure of the active component of hematoporphyrin derivative.Prog. Clin. Biol. Res.170, 301-314, 1984.

FARAJI, A. H.; WIPF, P. Nanoparticles in cellular drug delivery. Bioorganic \& Medicinal Chemistry, v. 17, n. 8, p. 2950-2962, 2009.

FIGGE, F. H. J.; WEILAND, G. S.; MANGANIELLO, L. O. J. Cancer detection and therapy affinity of neoplastic, embryonic, and traumatized tissues for porphyrins and metalloporphyrins. Proceedings of the Society for Experimental Biology and Medicine, v. 68, n. 3, p. $640-641,1948$.

FISCHER, F. et al. A chemical dosimeter for the determination of the photodynamic activity of photosensitizers. Clinica Chimica Acta, v. 274, n. 1, p. 89-104, 1998.

FORMOSINHO, S. J. Fundamentos de Cinética Química. Lisboa: Fundação Calouste Gulbenkian, 255 p. 1983.

FRANCO, E. L. Cancer epidemiology: substance and methods. Journal of the Brazilian Association for the Advancement of Science, v. 46, n. 1/2, 1994.

FREITAS, C.; MULLER, R. H. Spray-drying of solid lipid nanoparticles (SLN (TM)). European Journal of Pharmaceutics and Biopharmaceutics, v. 46, n. 2, p. 145-151, 1998.

FRESHNEY, R. I. Culture of animal cells. New York: Wiley-Liss Inc., p. 486, 1994.

FUJII, M. et al. Chemical reaction mediated by excited states of Si nanocrystals - Singlet oxygen formation in solution. Journal of Applied Physics, v. 95, n. 7, p. 3689-3693, 2004.

GAD, F. et al. Effects of growth phase and extracellular slime on photodynamic inactivation of gram-positive pathogenic bacteria. Antimicrobial Agents and Chemotherapy, v. 48, n. 6, p. 2173-2178, 2004.

GARCIA VIOR, M. C. et al. A comparative study of a novel lipophilic phthalocyanine incorporated into nanoemulsion formulations: Photophysics, size, solubility and thermodynamic stability. Dyes and Pigments, v. 91, n. 2, p. 208-214, 2011.

GEROLA, A. P. et al. Chemical determination of singlet oxygen from photosensitizers illuminated with LED: New calculation methodology considering the influence of photobleaching. Journal of Photochemistry and Photobiology a-Chemistry, v. 232, 2012. 
GIL-TOMAS, J. et al. Lethal photosensitisation of Staphylococcus aureus using a toluidine blue O-tiopronin-gold nanoparticle conjugate. Journal of Materials Chemistry, v. 17, n. 35, p. 3739-3746, 2007.

GUO, X. et al. Preparation and cytotoxicity of 2-methoxyestradiol-loaded solid lipid nanoparticles. Anti-Cancer Drugs, v. 23, n. 2, 2012.

HARRISON, M. A.; RAE, I. F. General techniques of cell culture. New York: Cambridge University Press, p. 162, 1997.

HOWARD, J. A.; MENDENHALL, G. D. Autoxidation and photooxidation of 1,3diphenylisobenzofuran - kinetic and product study. Canadian Journal of Chemistry-Revue Canadienne De Chimie, v. 53, n. 14, p. 2199-2201, 1975.

HUYGENS, A. et al. Accumulation and photocytotoxicity of hypericin and analogs in twoand three-dimensional cultures of transitional cell carcinoma cells. Photochemistry and Photobiology, v. 78, n. 6, p. 607-614, 2003.

KIESSLICH, T.; KRAMMER, B.; PLAETZER, K. Cellular mechanisms and prospective applications of hypericin in photodynamic therapy. Current Medicinal Chemistry, v. 13, n. 18, 2006.

KONAN, Y. N. et al. Enhanced photodynamic activity of meso-tetra(4hydroxyphenyl)porphyrin by incorporation into sub-200 nm nanoparticles. European Journal of Pharmaceutical Sciences, v. 18, n. 3-4, p. 241-249, 2003.

KONAN, Y. N.; GURNY, R.; ALLEMANN, E. Preparation and characterization of sterile and freeze-dried sub-200 nm nanoparticles. International Journal of Pharmaceutics, v. 233, n. $1-2$, p. 239-252, 2002a.

State of the art in the delivery of photosensitizers for photodynamic therapy. Journal of Photochemistry and Photobiology B-Biology, v. 66, n. 2, p. 89-106, 2002b.

LAKOWICZ, J. R. Principles of fluorescence spectroscopy, Maryland: Springer, 1999. $954 \mathrm{p}$.

LAMBRECHTS, S. A. G.; AALDERS, M. C. G.; VAN MARLE, J. Mechanistic study of the photodynamic inactivation of candida albicans by a cationic porphyrin. Antimicrobial Agents and Chemotherapy, v. 49, n. 5, p. 2026-2034, 2005.

LIPPACHER, A.; MULLER, R. H.; MADER, K. Semisolid SLN (TM) dispersions for topical application: influence of formulation and production parameters on viscoelastic properties. European Journal of Pharmaceutics and Biopharmaceutics, v. 53, n. 2, p. 155-160, 2002.

LIPSON, R. L.; BALDES, E. J. THE PHOTODYNAMIC PROPERTIES OF A PARTICULAR HEMATOPORPHYRIN DERIVATIVE. Archives of Dermatology, v. 82, n. 4, p. 508-516, 1960. 
LOWRY, O. H. et al. PROTEIN MEASUREMENT WITH THE FOLIN PHENOL REAGENT. Journal of Biological Chemistry, v. 193, n. 1, p. 265-275, 1951.

MARCATO, P. D.; DURAN, N. New aspects of nanopharmaceutical delivery systems. Journal of Nanoscience and Nanotechnology, v. 8, n. 5, p. 2216-2229, 2008.

MARGALIT, R.; COHEN, S. Studies of hematoporphyrin and hematoporphyrin derivative equilibria in heterogeneous systems. Porphyrin-liposome binding and porphyrin aqueous dimerization. Biochimica et Biophysica Acta (BBA) - Biomembranes, v. 736, n. 2, p. 163$170,1983$.

MARGALIT, R.; ROTENBERG, M. THERMODYNAMICS OF PORPHYRIN DIMERIZATION IN AQUEOUS-SOLUTIONS. Biochemical Journal, v. 219, n. 2, 1984.

MARGALIT, R.; SHAKLAI, N.; COHEN, S. Fluorimetric studies on the dimerization equilibrium of protoporphyrin-ix and its hemato derivative. Biochemical Journal, v. 209, n. 2, 1983.

MARTINS, S. et al. Solid lipid nanoparticles as intracellular drug transporters: An investigation of the uptake mechanism and pathway. International Journal of Pharmaceutics, v. 430, n. 1-2, Jul 12012.

MATHESON, I. B. C. The absolute value of the reaction rate constant of bilirubin with singlet oxygen in $\mathrm{D}_{2} \mathrm{O}$. Photochemistry and Photobiology, v. 29, n. 5, p. 875-878, 1979.

MEHNERT, W.; MADER, K. Solid lipid nanoparticles - Production, characterization and applications. Advanced Drug Delivery Reviews, v. 47, n. 2-3, p. 165-196, 2001.

MOREIRA, L. M., et al. Influência de diferentes sistemas de solvente água-etanol sobre as propriedades físico-químicas e espectroscópicas dos compostos macrocíclicos feofitina e clorina a. Química Nova, v. 33, n. 2, p. 258-262, 2010.

MOSER, J. G. In Photodynamic Tumor Therapy: 2nd and 3rd Generation Photosensitizers, Harwood Academic Publishers,Amsterdam. p. 256. 1998.

MOSQUEIRA, V. C. F. et al. Poly(D,L-lactide) nanocapsules prepared by a solvent displacement process: Influence of the composition on physicochemical and structural properties. Journal of Pharmaceutical Sciences, v. 89, n. 5, p. 614-626, 2000.

MULLER, R. H. et al. Phagocytic uptake and cytotoxicity of solid lipid nanoparticles (SLN) sterically stabilized with poloxamine 908 and poloxamer 407. Journal of Drug Targeting, $v$. 4, n. 3, p. 161-170, 1996.

MULLER, R. H.; MADER, K.; GOHLA, S. Solid lipid nanoparticles (SLN) for controlled drug delivery - a review of the state of the art. European Journal of Pharmaceutics and Biopharmaceutics, v. 50, n. 1, p. 161-177, 2000. 
MULLER, R. H.; RADTKE, M.; WISSING, S. A. Solid lipid nanoparticles (SLN) and nanostructured lipid carriers (NLC) in cosmetic and dermatological preparations. Advanced Drug Delivery Reviews, v. 54, p. S131-S155, 2002.

MUROV, S. L.; et al. Handbook of photochemistry, New York: Marcel Dekker, Inc., p. 420, 1993.

NAKAMURA, E.; ISOBE, H. Functionalized fullerenes in water. The first 10 years of their chemistry, biology, and nanoscience. Accounts of Chemical Research, v. 36, n. 11, p. 807815, 2003.

NUNES, S. M. T.; SGUILLA, F. S.; TEDESCO, A. C. Photophysical studies of zinc phthalocyanine and chloroaluminum phthalocyanine incorporated into liposomes in the presence of additives. Brazilian Journal of Medical and Biological Research, v. 37, n. 2, 2004.

O'CONNOR, A. E.; GALLAGHER, W. M.; BYRNE, A. T. Porphyrin and Nonporphyrin Photosensitizers in Oncology: Preclinical and Clinical Advances in Photodynamic Therapy. Photochemistry and Photobiology, v. 85, n. 5, p. 1053-1074, 2009.

OLBRICH, C. et al. Cationic solid-lipid nanoparticles can efficiently bind and transfect plasmid DNA. Journal of Controlled Release, v. 77, n. 3, p. 345-355, 2001.

PARDEIKE, J.; HOMMOSS, A.; MUELLER, R. H. Lipid nanoparticles (SLN, NLC) in cosmetic and pharmaceutical dermal products. International Journal of Pharmaceutics, v. 366, n. 12, p. 170-184, 2009.

PATIL, M. N.; PANDIT, A. B. Cavitation - A novel technique for making stable nanosuspensions. Ultrasonics Sonochemistry, v. 14, n. 5, 2007.

PELCZAR, JR., et al. Microbiologia conceitos e aplicações. São Paulo: Person Education do Brasil, p. 524, 2005.

PERNI, S. et al. Toluidine blue-containing polymers exhibit potent bactericidal activity when irradiated with red laser light. Journal of Materials Chemistry, v. 19, n. 18, p. 2715-2723, 2009.

. Nanoparticles: their potential use in antibacterial photodynamic therapy. Photochemical \& Photobiological Sciences, v. 10, n. 5, p. 712-720, 2011.

PERUSSI, J. R. Inativação Fotodinâmica de Microrganismos. Química Nova, Vol. 30, No. 4, 988-994, 2007.

RABELLO, B. R. et al. Singlet oxygen dosimetry using uric acid as a chemical probe: Systematic evaluation. Journal of Photochemistry and Photobiology a-Chemistry, v. 238, 2012.

RANG, H.P.; DALE, M.M.; RITTER, J.M.; MOORE,P.K. Quimioterapia do Câncer. In: Farmacologia. 5a Edição, Rio de Janeiro: Elsevier cap. 50, p. 789 - 809, 2004. 
REDMOND, R. W.; GAMLIN, J. N. A compilation of singlet oxygen yields from biologically relevant molecules. Photochemistry and Photobiology, v. 70, n. 4, p. 391-475, 1999.

RENGIFO-HERRERA, J. A. et al. A comparison of solar photocatalytic inactivation of waterborne E-coli using tris (2,2 '-bipyridineftuthenium(II), rose bengal, and TiO2. Journal of Solar Energy Engineering-Transactions of the Asme, v. 129, n. 1, p. 135-140, 2007.

RESNICK, R.; HALLIDAY, D. Física. São Paulo: Livros Técnicos e Científicos, 396 p. 1979.

RICCI-JUNIOR, E.; MARCHETTI, J. M. Zinc(II) phthalocyanine loaded PLGA nanoparticles for photodynamic therapy use. International Journal of Pharmaceutics, v. 310, n. 1-2, 2006.

ROSSI, L. M. et al. Protoporphyrin IX Nanoparticle Carrier: Preparation, Optical Properties, and Singlet Oxygen Generation. Langmuir, v. 24, n. 21, p. 12534-12538, 2008.

SANTOS-MAGALHAES, N. S. et al. Colloidal carriers for benzathine penicillin G: Nanoemulsions and nanocapsules. International Journal of Pharmaceutics, v. 208, n. 1-2, p. $71-80,2000$.

SAHOO, S. K.; LABHASETWAR, V. Nanotech approaches to delivery and imaging drug. Drug Discovery Today. V. 8, p. 1112-1120, 2003.

SCHAFFAZICK, S. R. et al. Freeze-drying polymeric colloidal suspensions: nanocapsules, nanospheres and nanodispersion. A comparative study. European Journal of Pharmaceutics and Biopharmaceutics, v. 56, n. 3, p. 501-505, 2003.

SCHAFFAZICK, S. R.; GUTERRES, S. S.; FREITAS, L. L.; POHLMANN, A. R. Caracterização e Estabilidade Físico-Química de Sistemas Poliméricos Nanoparticulados para Administração de Fármacos. Química Nova, vl. 26, No. 5, p. 726-737, 2003.

SCHWARTZ, S. K., K. ABSOLON and H. VERMUND Some relationships of porphyrins, $x-$ rays and tumours. Univ. Minn. Med. Bull.27, 7-8, 1955.

SCHUITMAKER, J. J. et al. Photodynamic therapy: A promising new modality for the treatment of cancer. Journal of Photochemistry and Photobiology B-Biology, v. 34, n. 1, p. 3-12, 1996.

SHAH, K. A. et al. Solid lipid nanoparticles (SLN) of tretinoin: Potential in topical delivery. International Journal of Pharmaceutics, v. 345, n. 1-2, 2007.

SHARMAN, W. M.; ALLEN, C. M.; VAN LIER, J. E. Photodynamic therapeutics: basic principles and clinical applications. Drug Discovery Today, v. 4, n. 11, 1999.

SIBATA, C. H. et al. Photodynamic therapy: a new concept in medical treatment. Brazilian Journal of Medical and Biological Research, v. 33, n. 8, 2000. 
SIMPLICIO, F. I.; MAIONCHI, F.; HIOKA, N. Terapia Fotodinâmica: Aspectos farmacológicos, aplicações e avanços recentes no desenvolvimento de medicamentos. Química Nova, v. 25, n. 5, p. 801-807, 2002.

SONCIN, M. et al. Approaches to selectivity in the $\mathrm{Zn}(\mathrm{II})$-phthalocyanine-photosensitized inactivation of wild-type and antibiotic-resistant Staphylococcus aureus. Photochemical \& Photobiological Sciences, v. 1, n. 10, p. 815-819, 2002.

Effect of the delivery system on the biodistribution of ge(iv) octabutoxyphthalocyanines in tumor-bearing mice. Cancer Letters, v. 89, n. 1, 1995.

SOUTO, E. B.; MÜLLER, R. H. Cosmetic features and applications of lipid nanoparticles (SLN®, NLC®). International Journal of Cosmetic Science, v. 30, n. 3, p. 157-165, 2008.

SPILLER, W. et al. Singlet oxygen quantum yields of different photosensitizers in polar solvents and micellar solutions. Journal of Porphyrins and Phthalocyanines, v. 2, n. 2, p. 145-158, 1998.

STABLES, G. I.; ASH, D. V. PHOTODYNAMIC THERAPY. Cancer Treatment Reviews, v. 21, n. 4, p. 311-323, 1995.

THUDICHUM, J. L.; COUNCIL.H.M. Tenth Report of the Medical Officer of the Privy. Stationary Office, London, 1867.

TIYABOONCHAI, W.; WOISZWILLO, J.; MIDDAUGH, C. R. Formulation and characterization of amphotericin B-polyethylenimine-dextran sulfate nanoparticles. Journal of Pharmaceutical Sciences, v. 90, n. 7, p. 902-914, 2001.

TSAI, T. et al. Improved Photodynamic Inactivation of Gram-Positive Bacteria Using Hematoporphyrin Encapsulated in Liposomes and Micelles. Lasers in Surgery and Medicine, v. 41, n. 4, p. 316-322, 2009.

TYRRELL, J.; CAMPBELL, S. M.; CURNOW, A. The effect of air cooling pain relief on protoporphyrin IX photobleaching and clinical efficacy during dermatological photodynamic therapy. Journal of Photochemistry and Photobiology B-Biology, v. 103, n. 1, p. 1-7, 2011.

UNER, M. Preparation, characterization and physico-chemical properties of Solid Lipid Nanoparticles (SLN) and Nanostructured Lipid Carriers (NLC): Their benefits as colloidal drug carrier systems. Pharmazie, v. 61, n. 5, p. 375-386, 2006.

VERMEULEN, K.; VAN BOCKSTAELE, D. R.; BERNEMAN, Z. N. The cell cycle: a review of regulation, deregulation and therapeutic targets in cancer. Cell Proliferation, v. 36, n. 3, p. 131-149, 2003.

WANG, W. et al. A Novel Near-Infrared Antibacterial Material Depending on the Upconverting Property of $\mathrm{Er}(3+)-\mathrm{Yb}(3+)-\mathrm{Fe}(3+)$ Tridoped $\mathrm{TiO}(2)$ Nanopowder. Journal of Physical Chemistry C, v. 114, n. 32, p. 13663-13669, 2010. 
WISSING, S. A.; KAYSER, O.; MULLER, R. H. Solid lipid nanoparticles for parenteral drug delivery. Advanced Drug Delivery Reviews, v. 56, n. 9, p. 1257-1272, 2004.

XIAO, L. et al. Porous Silicon Nanoparticle Photosensitizers for Singlet Oxygen and Their Phototoxicity against Cancer Cells. Acs Nano, v. 5, n. 5, p. 3651-3659, 2011.

YANO, S. et al. Current states and future views in photodynamic therapy. Journal of Photochemistry and Photobiology C-Photochemistry Reviews, v. 12, n. 1, p. 46-67, 2011.

YOUSSEF, T. et al. Evaluation of hypericin-loaded solid lipid nanoparticles: Physicochemical properties, photostability and phototoxicity. Pharmaceutical Development and Technology, v. 17, n. 2, 2012.

ZEISSER-LABOUEBE, M. et al. Benefits of nanoencapsulation for the hypercin-mediated photodetection of ovarian micrometastases. European Journal of Pharmaceutics and Biopharmaceutics, v. 71, n. 2, p. 207-213, 2009.

Hypericin-loaded nanoparticles for the photodynamic treatment of ovarian cancer. International Journal of Pharmaceutics, v. 326, n. 1-2, p. 174-181, 2006.

ZHU, R. et al. Phospho-Sulindac (OXT-328) Inhibits the Growth of Human Lung Cancer Xenografts in Mice: Enhanced Efficacy and Mitochondria Targeting by its Formulation in Solid Lipid Nanoparticles. Pharmaceutical Research, v. 29, n. 11, 2012.

ČUNDERLÍKOVÁ, B.; GANGESKAR, L.; MOAN, J. Acid-base properties of chlorin e6: relation to cellular uptake. Journal of Photochemistry and Photobiology B: Biology, v. 53, n. 1-3, p. 81-90, 1999. 